SVERIGES RIKSBANK

WORKING PAPER SERIES

203

요 요

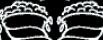

구을

SVERIGES

Evaluating An Estimated

New Keynesian Small Open Economy Model

Malin Adolfson, Stefan Laséen, Jesper Lindé and Mattias Villani

FEBRUARY 2007 
WORKING PAPERS ARE OBTAINABLE FROM

Sveriges Riksbank •Information Riksbank • SE-103 37 Stockholm Fax international: +4687870526

Telephone international: +4687870100

E-mail: info@riksbank.se

The Working Paper series presents reports on matters in the sphere of activities of the Riksbank that are considered to be of interest to a wider public.

The papers are to be regarded as reports on ongoing studies and the authors will be pleased to receive comments.

The views expressed in Working Papers are solely the responsibility of the authors and should not to be interpreted as reflecting the views of the Executive Board of Sveriges Riksbank. 


\title{
Evaluating An Estimated New Keynesian Small Open Economy Model
}

\author{
Malin Adolfson \\ Stefan Laséen \\ Jesper Lindé \\ Sveriges Riksbank \\ Sveriges Riksbank \\ Sveriges Riksbank and CEPR \\ Mattias Villani* \\ Sveriges Riksbank and Stockholm University \\ Sveriges Riksbank Working Paper Series \\ No. 203 \\ February 2007
}

\begin{abstract}
This paper estimates and tests a new Keynesian small open economy model in the tradition of Christiano, Eichenbaum, and Evans (2005) and Smets and Wouters (2003) using Bayesian estimation techniques on Swedish data. To account for the switch to an inflation targeting regime in 1993 we allow for a discrete break in the central bank's instrument rule. A key equation in the model - the uncovered interest rate parity (UIP) condition - is well known to be rejected empirically. Therefore we explore the consequences of modifying the UIP condition to allow for a negative correlation between the risk premium and the expected change in the nominal exchange rate. The results show that the modification increases the persistence and volatility in the real exchange rate and that this model has an empirical advantage compared with the standard UIP specification.
\end{abstract}

Keywords: DSGE; VAR; VECM; Open economy; Bayesian inference.

JEL Classification Numbers: E17; C11; C53.

${ }^{*}$ Address: Sveriges Riksbank, SE-103 37 Stockholm, Sweden. E-mails: malin.adolfson@riksbank.se, stefan.laseen@riksbank.se, jesper.linde@riksbank.se and mattias.villani@riksbank.se.

We would like to thank Marco Del Negro, Lars Svensson, Edward Nelson, and in particular our discussant John C. Williams for useful comments and helpful discussions. We also thank participants at the conference "DSGE Modeling at Policymaking Institutions: Progress \& Prospects", Washington D.C., December 2005. The views expressed in this paper are solely the responsibility of the authors and should not be interpreted as reflecting the views of the Executive Board of Sveriges Riksbank. 


\section{Introduction}

During the last years there has been a growing interest from academia and especially central banks in using dynamic stochastic general equilibrium (DSGE) models for analyzing macroeconomic fluctuations and to use these models for quantitative policy analysis. Smets and Wouters $(2003,2004)$ have in a series of influential papers shown that the forecasting performance of the new generation of (closed economy) DSGE models in the tradition of Christiano, Eichenbaum and Evans (2005) compare very well with both standard and Bayesian vector autoregressive (VAR) models. Adolfson et al. (2005a) report similar results for an open economy DSGE model. However, even if these models appear to be able to capture the development of some key macroeconomic time series, there are still challenges to make them fulfill the observed properties in the data. Often the cross-equation restrictions implied by the DSGE model are simply too strict when taken to the data. One example is the inability of open economy models to account for the persistence and volatility in the real exchange rate, another is the failure of accounting for the international transmission of business cycles (see, e.g., Chari, Kehoe and McGrattan (2002); Lubik and Schorfheide, 2005; Justiniano and Preston (2005); de Walque, Smets and Wouters, 2005).

A key equation in open economy DSGE models is the uncovered interest rate parity (UIP) condition, which in its simplest formulation suggests that the difference between domestic and foreign nominal interest rates equals the expected future change in the nominal exchange rate. The UIP condition is a key equation in open economy models not only for the exchange rate but also for many macroeconomic variables, since there is a lot of internal propagation of exchange rate movements working through fluctuating relative prices. There is, however, strong empirical evidence against the standard UIP condition. VAR evidence suggest that the impulse response function for the real exchange rate after a shock to monetary policy is hump-shaped with a peak effect after about 1 year (see, e.g., Eichenbaum and Evans, 1995; Faust and Rogers, 2003), whereas the standard UIP condition imply a peak effect within the quarter followed by a relatively quick mean reversion. Moreover, a DSGE model with a standard UIP condition cannot account for the so-called "forward premium puzzle" recorded in the data, i.e. that a currency whose interest rate is high tends to appreciate which implies that the risk premium must be negatively correlated with the expected exchange rate depreciation (see, e.g., Fama, 1984; Froot and Frankel, 1989).

In an attempt to account for these empirical shortcomings, we alter the structural open economy DSGE model developed in Adolfson et al. (2005b) and modify the uncovered interest rate parity (UIP) condition to allow for a negative correlation between the risk premium and the expected change in the exchange rate, following the vast empirical evidence reported in for example Engel (1996). In the log-linearized version of the model, our suggested modification of the risk premium introduces a lagged dependence between the exchange rate and the domestic interest rate (which is absent using a standard UIP condition), and this may help the model to account for the hump-shaped impulse response functions to a policy shock found in VARs. To explore the quantitative role of the UIP condition in the model we make a thorough analysis of the empirical performance of the model with the standard and modified UIP condition for a set of key aggregate quantities and prices along a number of dimensions.

The model used in the analysis is a small open economy version of the closed economy DSGE model of Christiano, Eichenbaum and Evans (2005) with both nominal and real frictions. As in Altig et al. (2003), we introduce a stochastic unit root technology shock, which enables us to work with trending data. The model is estimated with Bayesian techniques on Swedish data from 1980 to 2004, following Schorfheide (2000), Otrok (2001) and Smets and Wouters (2003). 
Sweden went from a fixed to a floating exchange rate and adopted an inflation targeting regime in the mid 90's. We therefore believe that there are good reasons to allow for a change in the conduct of monetary policy before and after this event when estimating the model. The Riksbank abandoned the fixed exchange rate regime in November 1992 after the turmoil in the foreign exchange markets, and adopted a 2 percent inflation target in January 1993. The direction of monetary policy did consequently change in the first half of the 1990s and to formally take this into account in the model we allow the central bank to behave differently before and after the regime shift. ${ }^{1}$

By comparing impulse response functions and Bayesian posterior model probabilities we show that our specification allowing for a modified UIP condition better matches the observed properties of Swedish data relative to the model using a standard UIP condition. In addition, we examine the forecasting accuracy of the two DSGE specifications using a traditional out-ofsample rolling forecast evaluation for the period 1999Q1 to 2004Q4. We contrast the forecasts from the alternative DSGE models to forecasts from both standard and Bayesian VAR models as well as traditional benchmark models such as the random walk, to get a better sense of the (relative) precision in the DSGE. Again we conclude that our DSGE specification with a regime shift and the modified UIP condition compares relatively well to more traditional forecasting tools. Lastly, we also use the approach in Del Negro and Schorfheide (2004) and Del Negro, Schorfheide, Smets and Wouters (2006) to learn more about the misspecification in each particular DSGE model, by exploiting the DSGE as a prior for a VAR model. If a particular DSGE prior is overruled by the data when estimating the VAR this questions the theoretical restrictions included in the DSGE model and indicates misspecification. Our results indicate that our open economy DSGE model's theoretical restrictions are in fact useful for structuring reduced form VARs. However, even our relatively large model appears to be misspecified in the sense that a prior which is more loosely centered around the DSGE model is preferred in terms of the marginal likelihood. This is in line with the findings of Del Negro, Schorfheide, Smets and Wouters (2006).

The remainder of the paper is organized as follows. In Section 2, we briefly describe the theoretical open economy DSGE model. In Section 3 we discuss the data and the prior distributions used in the estimation. We also describe how to form a prior on the VAR from the DSGE model, and discuss how the (optimal) sharpness in this prior can help us characterize the degree of misspecification in our structural model. Section 4 contains the empirical results. We present the parameter estimates in the different DSGE specifications and compare the Bayesian posterior model probabilities. In addition, we report the forecasting accuracy of the two DSGE models and relate this to the forecasts from a Bayesian and a standard VAR. Subsequently we present the empirical results from the hybrid DSGE-VAR models, evaluating the degree of misspecification. Lastly, Section 6 provides some conclusions.

\footnotetext{
${ }^{1}$ The behavior of monetary policy in the inflation targeting period (1993Q1-) is approximated with a Taylortype instrument rule. For the "fixed exchange rate" period (1980Q1-1992Q4), we conduct and present estimation results for a number of different specifications, ranging from a purely fixed exchange rate rule to a rule of the same form as for the inflation targeting period (but allow for different parameter values). To support the notion of a break in the monetary policy behaviour, we also provide results under the assumption that no break has occurred. The reason to perform estimations with different versions of the policy rule is that it is hard a priori to have a clear cut view on private sector perceptions about the conduct of monetary policy during this period. We elaborate more on this when presenting the alternative policy formulations in Section 2.1.
} 


\section{The DSGE model}

\subsection{Model overview}

This section gives an overview of the model economy and presents the key equations in the theoretical model.

The model is an open economy DSGE model very similar to the one developed in Adolfson et al. (2005b) and shares its basic closed economy features with many recent new Keynesian models, including the benchmark models of Christiano, Eichenbaum and Evans (2005), Altig, Christiano, Eichenbaum and Lindé (2003), and Smets and Wouters (2003).

The model economy consist of households, domestic goods firms, importing consumption and investment firms, exporting firms, a government, a central bank, and an exogenous foreign economy. The households consume a basket consisting of domestically produced goods and imported goods, which are supplied by domestic and importing firms, respectively. We allow the imported goods to enter both aggregate consumption as well as aggregate investment. This is needed when matching the joint dynamics in both imports and consumption since imports (and investment) are much more volatile than consumption.

Households can invest in their stock of capital, save in domestic bonds and/or foreign bonds and hold cash. The choice between domestic and foreign bonds balances into an arbitrage condition pinning down expected exchange rate changes (i.e., an uncovered interest rate parity condition). Compared to a standard setting the risk premium is allowed to be negatively correlated with the expected change in the exchange rate, following the evidence discussed in for example Duarte and Stockman (2005). As in the closed economy model households rent capital to the domestic firms and decide how much to invest in the capital stock given costs of adjusting the investment rate. Wage stickiness is introduced through an indexation variant of the Calvo (1983) model.

Domestic production is exposed to stochastic unit root technology growth as in Altig et al. (2003). The firms (domestic, importing and exporting) all produce differentiated goods and set prices according to an indexation variant of the Calvo model. By including nominal rigidities in the importing and exporting sectors we allow for short-run incomplete exchange rate pass-through to both import and export prices.

Monetary policy is approximated with both a fixed exchange rate rule and a Taylor-type interest rate rule in which we allow for different monetary policy conduct before and after the adoption of an inflation targeting regime.

The model adopts a small open economy perspective where we assume that the foreign economy is exogenous. The foreign inflation, output and interest rate are therefore given by an exogenous VAR. In what follows we provide the optimization problems of the different firms and the households, and describe the behavior of the central bank.

\subsection{Model}

The model economy includes four different categories of operating firms. These are domestic goods firms, importing consumption, importing investment, and exporting firms, respectively. Within each category there is a continuum of firms that each produces a differentiated good. The domestic goods firms produce their goods using capital and labor inputs, and sell them to a retailer which transforms the intermediate products into a homogenous final good that in turn is sold to the households.

The final domestic good is a composite of a continuum of $i$ differentiated goods, each supplied 
by a different firm, which follows the constant elasticity of substitution (CES) function

$$
Y_{t}=\left[\int_{0}^{1}\left(Y_{i, t}\right)^{\frac{1}{\lambda_{t}^{d}}} d i\right]^{\lambda_{t}^{d}}, 1 \leq \lambda_{t}^{d}<\infty
$$

where $\lambda_{t}^{d}$ is a stochastic process that determines the time-varying flexible-price markup in the domestic goods market. The demand for firm $i$ 's differentiated product, $Y_{i, t}$, follows

$$
Y_{i, t}=\left(\frac{P_{i, t}^{d}}{P_{t}^{d}}\right)^{-\frac{\lambda_{t}^{d}}{\lambda_{t}^{d}-1}} Y_{t}
$$

The production function for intermediate good $i$ is given by

$$
Y_{i, t}=z_{t}^{1-\alpha} \epsilon_{t} K_{i, t}^{\alpha} H_{i, t}^{1-\alpha}-z_{t} \phi
$$

where $z_{t}$ is a unit-root technology shock common to the domestic and foreign economies, $\epsilon_{t}$ is a domestic covariance stationary technology shock, $K_{i, t}$ the capital stock and $H_{i, t}$ denotes homogeneous labor hired by the $i^{\text {th }}$ firm. A fixed cost $z_{t} \phi$ is included in the production function. We set this parameter so that profits are zero in steady state, following Christiano et al. (2005).

We allow for working capital by assuming that a fraction $\nu$ of the intermediate firms' wage bill has to be financed in advance through loans from a financial intermediary. Cost minimization yields the following nominal marginal cost for intermediate firm $i$ :

$$
M C_{t}^{d}=\frac{1}{(1-\alpha)^{1-\alpha}} \frac{1}{\alpha^{\alpha}}\left(R_{t}^{k}\right)^{\alpha}\left[W_{t}\left(1+\nu\left(R_{t-1}-1\right)\right)\right]^{1-\alpha} \frac{1}{\left(z_{t}\right)^{1-\alpha}} \frac{1}{\epsilon_{t}},
$$

where $R_{t}^{k}$ is the gross nominal rental rate per unit of capital, $R_{t-1}$ the gross nominal (economy wide) interest rate, and $W_{t}$ the nominal wage rate per unit of aggregate, homogeneous, labor $H_{i, t}$.

Each of the domestic goods firms is subject to price stickiness through an indexation variant of the Calvo (1983) model. Since we have a time-varying inflation target in the model we allow for partial indexation to the current inflation target, but also to last period's inflation rate in order to allow for a lagged pricing term in the Phillips curve. Each intermediate firm faces in any period a probability $\left(1-\xi_{d}\right)$ that it can reoptimize its price. The reoptimized price is denoted $P_{t}^{d, n e w}{ }^{2}$ The different firms maximize profits taking into account that there might not be a chance to optimally change the price in the future. Firm $i$ therefore faces the following optimization problem when setting its price

$$
\begin{gathered}
\max _{P_{t}^{d, n e w}} \mathrm{E}_{t} \sum_{s=0}^{\infty}\left(\beta \xi_{d}\right)^{s} v_{t+s}\left[\left(\left(\pi_{t}^{d} \pi_{t+1}^{d} \ldots \pi_{t+s-1}^{d}\right)^{\kappa_{d}}\left(\bar{\pi}_{t+1}^{c} \bar{\pi}_{t+2}^{c} \ldots \bar{\pi}_{t+s}^{c}\right)^{1-\kappa_{d}} P_{t}^{d, \text { new }}\right) Y_{i, t+s}\right. \\
\left.-M C_{i, t+s}^{d}\left(Y_{i, t+s}+z_{t+s} \phi^{j}\right)\right],
\end{gathered}
$$

where the firm is using the stochastic household discount factor $\left(\beta \xi_{d}\right)^{s} v_{t+s}$ to make profits conditional upon utility. $\beta$ is the discount factor, and $v_{t+s}$ the marginal utility of the households' nominal income in period $t+s$, which is exogenous to the intermediate firms. $\pi_{t}^{d}$ denotes inflation

\footnotetext{
${ }^{2}$ For the firms that are not allowed to reoptimize their price, we adopt the indexation scheme $P_{t+1}^{d}=$ $\left(\pi_{t}^{d}\right)^{\kappa_{d}}\left(\bar{\pi}_{t+1}^{c}\right)^{1-\kappa_{d}} P_{t}^{d}$ where $\kappa_{d}$ is an indexation parameter.
} 
in the domestic sector, $\bar{\pi}_{t}^{c}$ a time-varying inflation target of the central bank and $M C_{i, t}^{d}$ the nominal marginal cost.

The first order condition of the profit maximization problem in equation (5) yields the following log-linearized Phillips curve:

$$
\begin{aligned}
\left(\widehat{\pi}_{t}^{d}-\widehat{\bar{\pi}}_{t}^{c}\right)= & \frac{\beta}{1+\kappa_{d} \beta}\left(\mathrm{E}_{t} \widehat{\pi}_{t+1}^{d}-\rho_{\pi} \widehat{\bar{\pi}}_{t}^{c}\right)+\frac{\kappa_{d}}{1+\kappa_{d} \beta}\left(\widehat{\pi}_{t-1}^{d}-\widehat{\bar{\pi}}_{t}^{c}\right) \\
& -\frac{\kappa_{d} \beta\left(1-\rho_{\pi}\right)}{1+\kappa_{d} \beta} \widehat{\bar{\pi}}_{t}^{c}+\frac{\left(1-\xi_{d}\right)\left(1-\beta \xi_{d}\right)}{\xi_{d}\left(1+\kappa_{d} \beta\right)}\left(\widehat{m c}_{t}^{d}+\widehat{\lambda}_{t}^{d}\right),
\end{aligned}
$$

where a hat denotes log-deviation from steady state (i.e., $\hat{X}_{t}=\ln X_{t}-\ln X$ ).

We now turn to the import and export sectors. There is a continuum of importing consumption and investment firms that each buys a homogenous good at price $P_{t}^{*}$ in the world market, and converts it into a differentiated good through a brand naming technology. The exporting firms buy the (homogenous) domestic final good at price $P_{t}^{d}$ and turn this into a differentiated export good through the same type of brand naming. The nominal marginal cost of the importing and exporting firms are thus $S_{t} P_{t}^{*}$ and $P_{t}^{d} / S_{t}$, respectively, where $S_{t}$ is the nominal exchange rate (domestic currency per unit of foreign currency). The differentiated import and export goods are subsequently aggregated by an import consumption, import investment and export packer, respectively, so that the final import consumption, import investment, and export good is each a CES composite according to the following:

$$
C_{t}^{m}=\left[\int_{0}^{1}\left(C_{i, t}^{m}\right)^{\frac{1}{\lambda_{t}^{m c}}} d i\right]^{\lambda_{t}^{m c}}, \quad I_{t}^{m}=\left[\int_{0}^{1}\left(I_{i, t}^{m}\right)^{\frac{1}{\lambda_{t}^{m i}}} d i\right]^{\lambda_{t}^{m i}}, \quad X_{t}=\left[\int_{0}^{1}\left(X_{i, t}\right)^{\frac{1}{\lambda_{t}^{x}}} d i\right]^{\lambda_{t}^{x}},
$$

where $1 \leq \lambda_{t}^{j}<\infty$ for $j=\{m c, m i, x\}$ is the time-varying flexible-price markup in the import consumption $(m c)$, import investment $(m i)$ and export $(x)$ sector. By assumption the continuum of consumption and investment importers invoice in the domestic currency and exporters in the foreign currency. In order to allow for short-run incomplete exchange rate pass-through to import as well as export prices we therefore introduce nominal rigidities in the local currency price, following for example Smets and Wouters (2002). ${ }^{3}$ This is modeled through the same type of Calvo setup as above. The price setting problems of the importing and exporting firms are completely analogous to that of the domestic firms in equation (5), and the demand for the differentiated import and export goods follow similar expressions as to equation (2). In total there are thus four specific Phillips curve relations determining inflation in the domestic, import consumption, import investment and export sectors.

In the model economy there is also a continuum of households which attain utility from consumption, leisure and real cash balances. The preferences of household $j$ are given by

$$
\mathrm{E}_{0}^{j} \sum_{t=0}^{\infty} \beta^{t}\left[\zeta_{t}^{c} \ln \left(C_{j, t}-b C_{j, t-1}\right)-\zeta_{t}^{h} A_{L} \frac{\left(h_{j, t}\right)^{1+\sigma_{L}}}{1+\sigma_{L}}+A_{q} \frac{\left(\frac{Q_{j, t}}{z_{t} P_{t}^{d}}\right)^{1-\sigma_{q}}}{1-\sigma_{q}}\right]
$$

where $C_{j, t}, h_{j, t}$ and $Q_{j, t} / P_{t}^{d}$ denote the $j^{t h}$ household's levels of aggregate consumption, labor supply and real cash holdings, respectively. Consumption is subject to habit formation through

\footnotetext{
${ }^{3}$ There would be complete pass-through in the absence of nominal rigidities, since there are neither distribution costs in the import and export sectors nor an endogenous pricing to market behavior among the firms in the model.
} 
$b C_{j, t-1}$, such that the household's marginal utility of consumption is increasing in the quantity of goods consumed last period. $\zeta_{t}^{c}$ and $\zeta_{t}^{h}$ are persistent preference shocks to consumption and labor supply, respectively. To make cash balances in equation (8) stationary when the economy is growing they are scaled by the unit root technology shock $z_{t}$. Households consume a basket of domestically produced goods and imported products which are supplied by the domestic and importing consumption firms, respectively. Aggregate consumption is assumed to be given by the following constant elasticity of substitution (CES) function:

$$
C_{t}=\left[\left(1-\omega_{c}\right)^{1 / \eta_{c}}\left(C_{t}^{d}\right)^{\left(\eta_{c}-1\right) / \eta_{c}}+\omega_{c}^{1 / \eta_{c}}\left(C_{t}^{m}\right)^{\left(\eta_{c}-1\right) / \eta_{c}}\right]^{\eta_{c} /\left(\eta_{c}-1\right)},
$$

where $C_{t}^{d}$ and $C_{t}^{m}$ are consumption of the domestic and imported good, respectively. $\omega_{c}$ is the share of imports in consumption, and $\eta_{c}$ is the elasticity of substitution across consumption goods.

The households invest in a basket of domestic and imported investment goods to form the capital stock, and decide how much capital to rent to the domestic firms given costs of adjusting the investment rate. The households can increase their capital stock by investing in additional physical capital $\left(I_{t}\right)$, taking one period to come in action. The capital accumulation equation is given by

$$
K_{t+1}=(1-\delta) K_{t}+\Upsilon_{t}\left(1-\tilde{S}\left(I_{t} / I_{t-1}\right)\right) I_{t},
$$

where $\tilde{S}\left(I_{t} / I_{t-1}\right)$ determines the investment adjustment costs through the estimated parameter $\tilde{S}^{\prime \prime}$, and $\Upsilon_{t}$ is a stationary investment-specific technology shock. Total investment is assumed to be given by a CES aggregate of domestic and imported investment goods ( $I_{t}^{d}$ and $I_{t}^{m}$, respectively) according to

$$
I_{t}=\left[\left(1-\omega_{i}\right)^{1 / \eta_{i}}\left(I_{t}^{d}\right)^{\left(\eta_{i}-1\right) / \eta_{i}}+\omega_{i}^{1 / \eta_{i}}\left(I_{t}^{m}\right)^{\left(\eta_{i}-1\right) / \eta_{i}}\right]^{\eta_{i} /\left(\eta_{i}-1\right)},
$$

where $\omega_{i}$ is the share of imports in investment, and $\eta_{i}$ is the elasticity of substitution across investment goods.

Further, along the lines of Erceg, Henderson and Levin (2000), each household is a monopoly supplier of a differentiated labor service which implies that they can set their own wage. After having set their wage, households supply the firms' demand for labor at the going wage rate. Each household sells its labor to a firm which transforms household labor into a homogenous good that is demanded by each of the domestic goods producing firms. Wage stickiness is introduced through the Calvo (1983) setup, where household $j$ reoptimizes its nominal wage rate $W_{j, t}^{n e w}$ according to the following

$$
\begin{gathered}
\max _{W_{j, t}^{\text {new }}} \mathrm{E}_{t} \sum_{s=0}^{\infty}\left(\beta \xi_{w}\right)^{s}\left[-\zeta_{t+s}^{h} A_{L} \frac{\left(h_{j, t+s}\right)^{1+\sigma_{L}}}{1+\sigma_{L}}+\right. \\
\left.v_{t+s} \frac{\left(1-\tau_{t+s}^{y}\right)}{\left(1+\tau_{t+s}^{w}\right)}\left(\left(\pi_{t}^{c} \ldots \pi_{t+s-1}^{c}\right)^{\kappa_{w}}\left(\bar{\pi}_{t+1}^{c} \ldots \bar{\pi}_{t+s}^{c}\right)^{\left(1-\kappa_{w}\right)}\left(\mu_{z, t+1} \ldots \mu_{z, t+s}\right) W_{j, t}^{n e w}\right) h_{j, t+s}\right],
\end{gathered}
$$

where $\xi_{w}$ is the probability that a household is not allowed to reoptimize its wage, $\tau_{t}^{y}$ a labor income tax, $\tau_{t}^{w}$ a pay-roll tax (paid for simplicity by the households), and $\mu_{z, t}=z_{t} / z_{t-1}$ is the growth rate of the permanent technology level. ${ }^{4}$

\footnotetext{
${ }^{4}$ For the households that are not allowed to reoptimize, the indexation scheme is $W_{j, t+1}=$ $\left(\pi_{t}^{c}\right)^{\kappa_{w}}\left(\bar{\pi}_{t+1}^{c}\right)^{\left(1-\kappa_{w}\right)} \mu_{z, t+1} W_{j, t}^{n e w}$, where $\kappa_{w}$ is an indexation parameter.
} 
The choice between domestic and foreign bond holdings balances into an arbitrage condition pinning down expected exchange rate changes (i.e., an uncovered interest rate parity condition). To ensure a well-defined steady-state in the model, we assume that there is premium on the foreign bond holdings which depends on the aggregate net foreign asset position of the domestic households, following, e.g., Lundvik (1992), and Schmitt-Grohé and Uribe (2001). A common problem with open economy DSGE models is that they typically do not provide enough persistence to generate a hump-shaped response of the real exchange rate after a shock to monetary policy, which is commonly found in estimated VARs (see, e.g., Eichenbaum and Evans, 1995; Faust and Rogers, 2003). A novel feature with our specification of the risk premium is the inclusion of the expected change in the exchange rate $E_{t} S_{t+1} / S_{t-1}$. This is based on the observation that risk premia are strongly negatively correlated with the expected change in the exchange rate (i.e., the expected depreciation), see e.g. Duarte and Stockman (2005) and Fama (1984). This pattern is often referred to as the "forward premium puzzle". The risk premium is given by:

$$
\Phi\left(a_{t}, S_{t}, \tilde{\phi}_{t}\right)=\exp \left(-\tilde{\phi}_{a}\left(a_{t}-\bar{a}\right)-\tilde{\phi}_{s}\left(\frac{E_{t} S_{t+1}}{S_{t}} \frac{S_{t}}{S_{t-1}}-1\right)+\tilde{\phi}_{t}\right),
$$

where $a_{t} \equiv\left(S_{t} B_{t}^{*}\right) /\left(P_{t} z_{t}\right)$ is the net foreign asset position, and $\tilde{\phi}_{t}$ is a shock to the risk premium. Consistent with the empirical evidence the idea here is that the domestic investors will require a lower expected return on their foreign bond holdings relative to their domestic deposits if the future exchange rate is easier to predict (that is, if the exchange rate is expected to depreciate consecutively). However, this formulation is not structural in the sense that such a risk premium can be associated with the utility function in (8) or any standard utility function for a representative agent (see Backus, Foresi and Telmer, 2001, for a discussion). The UIP condition in its log-linearized form is given by:

$$
\widehat{R}_{t}-\widehat{R}_{t}^{*}=\left(1-\widetilde{\phi}_{s}\right) \mathrm{E}_{t} \Delta \widehat{S}_{t+1}-\widetilde{\phi}_{s} \Delta \widehat{S}_{t}-\widetilde{\phi}_{a} \widehat{a}_{t}+\widehat{\widetilde{\phi}}_{t}
$$

where $\Delta$ is the first difference operator. By setting $\tilde{\phi}_{s}=0$ we obtain the UIP condition typically used in small open economy models (see, e.g., Adolfson et al., 2005b). In the empirical analysis we formally test which specification is supported by the data.

Following Smets and Wouters (2003), monetary policy is approximated with a generalized Taylor (1993) rule. The central bank is assumed to adjust the short term interest rate in response to deviations of CPI inflation from the time-varying inflation target, the output gap (measured as actual minus trend output), the real exchange rate $\left(\hat{x}_{t} \equiv \hat{S}_{t}+\hat{P}_{t}^{*}-\hat{P}_{t}^{c}\right)$ and the interest rate set in the previous period. The instrument rule (expressed in log-linearized terms) follows:

$$
\begin{aligned}
\widehat{R}_{t}= & \rho_{R, t} \widehat{R}_{t-1}+\left(1-\rho_{R, t}\right)\left[\widehat{\bar{\pi}}_{t}^{c}+r_{\pi, t}\left(\hat{\pi}_{t-1}^{c}-\widehat{\bar{\pi}}_{t}^{c}\right)+r_{y, t} \hat{y}_{t-1}+r_{x, t} \hat{x}_{t-1}\right] \\
& +r_{\Delta \pi, t} \Delta \hat{\pi}_{t}^{c}+r_{\Delta y, t} \Delta \hat{y}_{t}+\varepsilon_{R, t},
\end{aligned}
$$

where $\varepsilon_{R, t}$ is an uncorrelated monetary policy shock. The output target used by the central bank is here defined to be the trend level of output. An alternative specification is to define the output target in terms of the level output that would have prevailed in the absence of nominal rigidities. This model consistent output gap would probably come closer to optimal monetary policy (see Woodford, 2003, for further discussion). However, the marginal likelihoods speak clearly against such a specification for Sweden. The log marginal likelihoods differ by almost 20 units between these two specifications, indicating that the trend output gap appear to better capture the actual policy behavior of Sveriges Riksbank than the model consistent output gap 
during this sample period. Del Negro et al. (2006) find a similar result when estimating a closed economy DSGE model on US data.

Since Sweden went from a "fixed" to a floating exchange rate/inflation targeting regime in December 1992, we want to allow for a discrete break in the parameters to account for a policy regime shift. It is not obvious, however, how one should model policy prior to $1993 Q 1$. Therefore, we study the empirical performance of three variants of the policy rule. In addition, results are also reported in the case where no break is allowed for, to see if the data support our prior that the policy rule has changed. ${ }^{5}$

The first specification is what will be referred to as a fixed exchange rate rule. It has the following structural form

$$
\widehat{R}_{t}=r_{s} \Delta \hat{S}_{t}
$$

where $r_{s}=1,000,000$, i.e. the interest rate will respond sharply to nominal exchange rate movements so as to keep it constant. Note that the reduced form associated with this formulation implies that the the interest rate will, for instance, respond one to one to foreign interest rate movements. ${ }^{6}$

The second specification is what will be referred to as a semi-fixed, or "target zone" rule following the ideas in Svensson (1994). This rule has essentially the same structure as (15) above but instead of responding to the real exchange rate, $r_{s} \Delta \hat{S}_{t}$ is added to the rule with a high prior on $r_{s}$. The prior value of $r_{s}$ is set so that the volatility of the nominal exchange rate in the model matches the exchange rate volatility in the data during the target-zone period (using the prior mode for the other parameters in the model). ${ }^{7}$

The third specification uses exactly the same formulation of the policy as in the inflation targeting period. Let $\theta_{R, t}$ collect the parameters of the monetary policy rule. We assume that

$$
\theta_{R, t}= \begin{cases}\theta_{R, 1}, & \text { if } t<1993 Q 1 \\ \theta_{R, 2}, & \text { if } t \geq 1993 Q 1\end{cases}
$$

where $\theta_{R, 1}$ captures the behavior of the central bank pre inflation targeting and $\theta_{R, 2}$ captures the behavior during the inflation targeting regime. There are mainly three reasons why we believe that a Taylor type rule may provide a good approximation of the conduct of monetary policy also before the adoption of an inflation target, when Sweden had a fixed exchange rate. First, it should be recognized that the regime in practice was more of a managed float since the exchange rate was allowed to fluctuate within certain bands with recurring devaluations of the Krona. ${ }^{8}$ Second, there are writings published by the Riksbank which suggest that price stability was the overall objective even prior to the abandoning of the fixed exchange rate (Sveriges Riksbank Press

\footnotetext{
${ }^{5}$ From 1977 to 1991, the Krona was pegged to a trade-weighted basket of 15 currencies of Sweden's most important trading partners. The exchange rate was managed so as to allow limited fluctuations around the benchmark rate. However, the Krona was devalued 10\% and 16\% in 1981 and 1982, respectively. From mid-1991 the peg of the Swedish Krona was changed to a basket based on the European Currency Unit (ECU), with a fluctuation range of plus or minus $1.5 \%$ of a central rate of SEK7.40054=ECU1.00.

${ }^{6}$ This rule abstracts from the two devaluations in 1981 and 1982 in the sense that the regime shift to the Taylor-type inflation targeting rule in (15) only captures the adoption of a floating exchange rate in 1993 and the associated depreciation of the Krona. However, we only use the period 1980Q1-1985Q4 to form a prior on the unobserved state and not for inference.

${ }^{7}$ Curdia and Finocchario (2005) use a similar rule, but assume that the Riksbank responded to exchange rate deviations from central parity instead.

${ }^{8}$ It could also be argued that the inflation and output response in the instrument rule captures the information required to stabilize the exchange rate. See Monacelli (2004) for a discussion of how a rule of this kind can describe how monetary policy is formulated in small open economies, and/or economies whose monetary policy setting is constrained by the participation to a managed/ fixed exchange rate regime.
} 
release 5/1993). However, third and finally, the Riksbank was not an independent institution during this period, and the interest rate setting were most likely influenced by policy makers, with a clear preference for output (employment) stabilization. For these reasons, the private sector's perception of the actual policy rule in place - on which they base their decision rules could have been very different to that of the simple fixed exchange rate rule given by (16). We nevertheless let the data determine which one of these policy specifications are most preferred. When modelling the break in policy conduct, there is a need to take a stance on whether it was unanticipated or not. To simplify the analysis, we assume (i) that the break is completely unexpected and that (ii) once it had occurred, the new policy rule is assumed to be fully credible. ${ }^{9}$

The structural shock processes in the model is given in log-linearized form by the univariate representation

$$
\hat{\varsigma}_{t}=\rho_{\varsigma} \hat{\varsigma}_{t-1}+\varepsilon_{\varsigma, t}, \quad \varepsilon_{\varsigma, t} \stackrel{i i d}{\sim} N\left(0, \sigma_{\varsigma}^{2}\right)
$$

where $\varsigma_{t}=\left\{\mu_{z, t}, \epsilon_{t}, \lambda_{t}^{j}, \zeta_{t}^{c}, \zeta_{t}^{h}, \Upsilon_{t}, \tilde{\phi}_{t}, \varepsilon_{R, t}, \bar{\pi}_{t}^{c}, \tilde{z}_{t}^{*}\right\}$ and $j=\{d, m c, m i, x\}$.

The government spends resources on consuming part of the domestic good, and collects taxes from the households. The resulting fiscal surplus/deficit plus the seigniorage are assumed to be transferred back to the households in a lump sum fashion. Consequently, there is no government debt. The fiscal policy variables - taxes on labor income, consumption, and the pay-roll, together with (HP-detrended) government expenditures - are assumed to follow an identified VAR model with two lags.

To simplify the analysis we adopt the assumption that the foreign prices, output (HPdetrended) and interest rate are exogenously given by an identified VAR model with four lags. Both the foreign and the fiscal VAR models are being estimated, using uninformative priors, ahead of estimating the structural parameters in the DSGE model. ${ }^{10}$

To clear the final goods market, the foreign bond market, and the loan market for working capital, the following three constraints must hold in equilibrium:

$$
\begin{gathered}
C_{t}^{d}+I_{t}^{d}+G_{t}+C_{t}^{x}+I_{t}^{x} \leq z_{t}^{1-\alpha} \epsilon_{t} K_{t}^{\alpha} H_{t}^{1-\alpha}-z_{t} \phi, \\
S_{t} B_{t+1}^{*}=S_{t} P_{t}^{x}\left(C_{t}^{x}+I_{t}^{x}\right)-S_{t} P_{t}^{*}\left(C_{t}^{m}+I_{t}^{m}\right)+R_{t-1}^{*} \Phi\left(a_{t-1}, \widetilde{\phi}_{t-1}\right) S_{t} B_{t}^{*}, \\
\nu W_{t} H_{t}=\mu_{t} M_{t}-Q_{t},
\end{gathered}
$$

where $G_{t}$ is government expenditures, $C_{t}^{x}$ and $I_{t}^{x}$ are the foreign demand for export goods which follow CES aggregates with elasticity $\eta_{f}$, and $\mu_{t}=M_{t+1} / M_{t}$ is the monetary injection by the central bank. When defining the demand for export goods, we introduce a stationary asymmetric (or foreign) technology shock $\tilde{z}_{t}^{*}=z_{t}^{*} / z_{t}$, where $z_{t}^{*}$ is the permanent technology level abroad, to allow for temporary differences in permanent technological progress domestically and abroad.

\footnotetext{
${ }^{9}$ For the first and second formulation of the policy rule, we allow the agents to change their state variables according to the decision rules pertaining to the inflation targeting regime already from $1992 Q 3$ (i.e. two quarters prior to the regime shift) in an attempt to improve the empirical performance of those two rules. The reason is that there were considerable financial turmoil in the Swedish exchange rate markets during this quarter. Among other things, the Riksbank raised the over-night interest rate to 500 percent (annualized rate) during this quarter in order to defend the Swedish Krona.

${ }^{10}$ The reason why we include foreign output HP-detrended and not in growth rates in the VAR is that the level of foreign output enters the DSGE model (e.g., in the aggregate resource constraint). In the state-space representation of the model, which links the theoretical model to the observed data, we subsequently add the unit-root world productivity shock and the stationary asymmetric (or foreign) technology shock to the business cycle component of foreign output in order to obtain the observed level of foreign GDP. This enables us to identify the stationary asymmetric technology shock, since the process for detrended foreign output is identified from the VAR and the process for the (unit root) world productivity is identified from this and the domestic quantities.
} 
To compute the equilibrium decision rules, we proceed as follows. First, we stationarize all quantities determined in period $t$ by scaling with the unit root technology shock $z_{t}$. Then, we log-linearize the model around the constant steady state and calculate a numerical (reduced form) solution with the AIM algorithm developed by Anderson and Moore (1985).

\section{Estimation}

\subsection{Estimating the DSGE model}

We start the empirical analysis by estimating the DSGE model, using a Bayesian approach and placing a prior distribution on the structural parameters. To estimate the model we use quarterly Swedish data for the period 1980Q1 - 2004Q4. All data were taken from Statistics Sweden, except the repo rate which were taken from Sveriges Riksbank. The nominal wage is taken from Statistics Sweden's short term wage and salary statistics ${ }^{11}$ and is deflated by the GDP deflator. The foreign variables on output, the interest rate and inflation are weighted together across Sweden's 20 largest trading partners in 1991 using weights from the IMF. ${ }^{12}$

We include a large set of variables in the observed data vector, and match the following 15 variables: the GDP deflator, the real wage, consumption, investment, the real exchange rate, the short-run interest rate, hours worked, GDP, exports, imports, the consumer price index (CPI), the investment deflator, foreign output, foreign inflation and the foreign interest rate. As in Altig et al. (2003), the unit root technology shock induces a common stochastic trend in the real variables of the model. To make these variables stationary we use first differences and derive the state space representation for the following vector of observed variables

$$
\tilde{Y}_{t}=\left[\begin{array}{cccccccc}
\pi_{t}^{d} & \Delta \ln \left(W_{t} / P_{t}\right) & \Delta \ln C_{t} & \Delta \ln I_{t} & \hat{x}_{t} & R_{t} & \hat{H}_{t} & \Delta \ln Y_{t} \ldots \\
\Delta \ln \tilde{X}_{t} & \Delta \ln \tilde{M}_{t} & \pi_{t}^{c p i} & \pi_{t}^{d e f, i} & \Delta \ln Y_{t}^{*} & \pi_{t}^{*} & R_{t}^{*}
\end{array}\right]^{\prime} .
$$

The growth rates are computed as quarter to quarter log-differences, while the inflation and interest rate series are measured as annualized quarterly rates. It should be noted that the stationary variables $\hat{x}_{t}$ and $\hat{H}_{t}$ are measured as deviations around the mean, i.e. $\hat{x}_{t}=\left(x_{t}-x\right) / x$ and $\hat{H}_{t}=\left(H_{t}-H\right) / H$, respectively. We choose to work with per capita hours worked, rather than total hours worked, because this is the object that appears in most general equilibrium business cycle models. ${ }^{13}$

In comparison with prior literature, such as for example Justiniano and Preston (2004) and Lubik and Schorfheide (2005), we have chosen to work with a large number of variables in order to facilitate identification of the parameters and shocks we estimate. For instance, despite the fact that the foreign variables are exogenous, we include them as observable variables as they enable identification of the asymmetric technology shock and are informative about the parameters governing the transmission of foreign impulses to the domestic economy. We estimate 13 structural shocks (see equation (17)) where 5 are assumed to be identically independently

\footnotetext{
${ }^{11}$ The wage series for the first part of our sample is compiled by Friberg (2006).

${ }^{12}$ The shares of import and export to output are increasing from about 0.25 to 0.40 and from 0.21 to 0.50 respectively during the sample period. In the model, import and export are however assumed to grow at the same rate as output. Hence, we decided to remove the excess trend in import and export in the data, to make the export and import shares stationary. For all other variables we use the actual series (seasonally adjusted with the X12-method except the variables in the GDP identity which were seasonally adjusted by Statistics Sweden).

${ }^{13}$ We used working age population to generate hours per capita. See Christiano, Eichenbaum and Vigfusson (2003) for a discussion on using per capita adjusted hours versus non-adjusted hours.
} 
distributed. ${ }^{14}$ In addition to these there are eight shocks provided by the exogenous (preestimated) fiscal and foreign VARs, whose parameters are kept fixed at their posterior mean estimates throughout the estimation of the DSGE model parameters. The shocks enter in such a way that there is no stochastic singularity in the likelihood function. ${ }^{15}$ To compute the likelihood function, the reduced form solution of the model is transformed into a state-space representation mapping the unobserved state variables into the observed data. We apply the Kalman filter to calculate the likelihood function of the observed variables, where the period $1980 Q 1-1985 Q 4$ is used to form a prior on the unobserved state variables in $1985 Q 4$ and the period 1986Q1-2004Q4 for inference.

The joint posterior distribution of all estimated parameters is obtained in two steps. First, the posterior mode and Hessian matrix evaluated at the mode is computed by standard numerical optimization routines. Second, the Hessian matrix is used in the Metropolis-Hastings algorithm to generate a sample from the posterior distribution (see Smets and Wouters (2003), and the references therein, for details). The results reported are based on a sample of 500,000 post burn-in draws from the posterior distribution.

We choose to calibrate those parameters which we think are weakly identified by the variables that we include in the vector of observed data. These parameters are mostly related to the steady-state values of the observed variables (i.e., the great ratios: $C / Y, I / Y$ and $G / Y) .{ }^{16}$ An alternative approach could be to include these parameters in the estimation. However, such a strategy would require a different set of variables to ensure proper identification, or conditioning the likelihood on the initial levels of the ratios, but would not yield different results since these parameters would simply capture the sample mean of the great ratios.

The parameters we choose to estimate pertain mostly to the nominal and real frictions in the model as well as the exogenous shock processes. Table 1 shows the assumptions for the prior distribution of the estimated parameters. The location of the prior distribution of the 43(51) estimated parameters with no break (break) in the monetary policy rule corresponds to a large extent to those in Adolfson et al. (2005b) on Euro area data. There are, however, some important differences in the choice of prior distribution to take notice of. First, the priors on the price stickiness parameters are chosen based on survey evidence on the frequency of price changes from a large number of Swedish firms. Apel, Friberg and Hallsten (2005) report that prices in Swedish firms adjust only infrequently; the median firm adjusts the price once a year. Hence, the price and wage stickiness parameters are set so that the average length between price

\footnotetext{
${ }^{14}$ The shocks that are assumed to be iid are the monetary policy shock, the markup shock in the domestic goods market, as well as the markup shocks the importing consumption, importing investment and exporting goods markets.

${ }^{15}$ Even if there is no stochastic singularity in the model we include measurement errrors in the 12 domestic variables, since we know that the data series used are not perfectly measured and at best only approximations of the 'true' series. In particular it was hard to remove the seasonal variation in the series, and there are still spikes in for example the inflation series, perhaps due to changes in the collection of the data. The variance of the uncorrelated measurement errors is set to 0 for the foreign variables and the domestic interest rate, 0.1 percent for the real wage, consumption and output, and 0.2 percent for all the other variables. This implies that the fundamental shocks explain about $90-95 \%$ of the variation in most of the variables. The measurement errors capture some of the high frequency movements in the data but not fluctuations related to the business cycle. Note also that our estimation results are robust to changning the size of the measurement errors (see the Appendix).

${ }^{16}$ The calibrated parameters are set to the following: the money growth $\mu=1.010445$; the discount factor $\beta=0.999$; the depreciation rate $\delta=0.01$; the capital share in production $\alpha=0.25$; the share of imports in consumption and investment $\omega_{c}=0.40$ and $\omega_{i}=0.70$, respectively; the share of wage bill financed by loans $\nu=1$; the labour supply elasticity $\sigma_{L}=1$; the wage markup $\lambda_{w}=1.05$; inflation target persistence $\rho_{\pi}=0.975$; the steady-state tax rates on labour income and consumption $\tau^{y}=0.30$ and $\tau^{c}=0.24$, respectively; government expenditures-output ratio 0.30 ; the subsitution elasticity between consumption goods $\eta_{c}=5$; and the capital utilization parameter $\sigma_{a}=10^{6}$ so that there is no variable capital utilization.
} 
and wage adjustments is 4 quarters. Second, the prior mean for the standard error of the markup shocks are all set to 1. This is about three times the prior mean in Adolfson et al. (2005b). The choice is based on the fact that Sweden is a much smaller economy than the Euro area and is therefore presumably expected to be subject to larger markup shocks. This is consistent with the observation that not only domestic, but also import prices are substantially more volatile than what is observed for the Euro area.

We choose identical priors for the parameters in the monetary policy rule before and after the adoption of an inflation target in 1993Q1. This is a useful benchmark prior for communicating the results, and allows us to assess how parameters change between the regimes due to information in the data and not due to different priors.

\subsection{Detecting model misspecification using a VAR with a DSGE prior}

The main Bayesian tool for contrasting the empirical coherence of different DSGE models is the posterior distribution over the set of compared models, wherein the marginal likelihood enters as the most essential ingredient. Such a model comparison is of course only a relative one, however. It may very well be the case that all of the models under comparison are severely misspecified. One way to investigate this is to compare their marginal likelihoods to those of more flexible empirically oriented models, such as VARs (see e.g. Smets and Wouters, 2003). Bayesian model probabilities have great appeal, but there is no escaping from the fact that they are sensitive to the choice of prior. This sensitivity may not have dramatic effects when the models under consideration are similar, and the prior is elicited in essentially the same way. This is not the case in the DSGE versus VAR comparison, however, as the statistically oriented priors traditionally used for reduced form VARs (e.g. Litterman, 1986) are radically different from the micro-based economic priors in DSGE models.

Del Negro and Schorfheide (2004) introduce an interesting alternative way to assess the degree of misspecification in DSGE models using Bayesian techniques. Del Negro, Schorfheide, Smets and Wouters (2006) extends the Del Negro-Schorfheide approach and re-interpret it from a different view-point. The idea is to compare the marginal likelihood of the possibly misspecified DSGE model to that of a VAR with a prior centered on the same DSGE model with the tightness of the prior determined by a single scalar-valued parameter $\lambda$ (for details see Appendix 2). The DSGE-based prior has the effect of pulling the unrestricted VAR estimates toward the subspace where the DSGE restrictions are satisfied. In the limit $\lambda=\infty$, the prior imposes the DSGE restrictions with probability one, and the VAR thus collapses to the (VAR approximation of the) DSGE model. As $\lambda$ gets smaller the prior becomes increasingly less informative and the Bayesian estimates of the VAR coefficients approach the OLS estimates. Del Negro and Schorfheide (2004) suggest computing the marginal likelihood of the VAR with a DSGE-based prior for different choices of $\lambda$ and subsequently find the optimal $\lambda$, which we denote by $\hat{\lambda}$. A large $\hat{\lambda}$ then means that the implied cross-equation restrictions from the DSGE model are highly compatible with the observed data. A $\hat{\lambda}$ on the lower end of the scale suggests a preference for a prior on the VAR with a minimal use of the DSGE restrictions, which therefore cast doubt on the empirical coherence of the DSGE model.

Even if the DSGE model do not possess a finite order VAR representation, the auxiliary VAR model mainly works as a tool to relax the restrictions in the DSGE model in our analysis, and obtain a specification with superior empirical fitness. The VAR is not required to nest the underlying structural model for this analysis to remain sensible since the moments of the DSGE model that are used to form the prior on the VAR are exact regardless of the quality of the approximation (see also Del Negro et al., 2006). This means that a large $\hat{\lambda}$ still indicates that it 
is a good idea to use the cross moments from the DSGE model in the formation of a prior, in the sense that such a prior agrees well with the likelihood function.

The estimated VAR model contains the 15 observed variables that are used in the DSGE estimation (see equation (21)), where non-stationary variables enter in first differences. However, the unit root technology shock in the theoretical DSGE model induces a common stochastic trend in the levels of all real variables, which implies that the levels of the variables may contain information about the current state of the economy. We therefore also estimate a vector error correction model (VECM) with a DSGE-based prior, following Del Negro et al. (2006), by just adding the cointegrating relations of the DSGE model to the VAR.

Given that the DSGE model allows all the reduced form parameters to change as a result of the regime shift, even if only a subset of the structural parameters change (i.e., the conduct of monetary policy), the same must be true in the VAR/VECM model. We therefore allow for a potential break in all the VAR/VECM parameters (lag-polynominal and covariance matrix) in $t=1993 Q 1$. However, the VAR parameters in the two regimes coincide in all dimensions except those related to the monetary policy change, which an unrestricted estimation of the VAR parameters would ignore. Here we center the prior on the DSGE model with a break in the monetary rule which takes this fact into account. It should also be noted that although it is straightforward to use different prior tightness on the DSGE cross restrictions in these two subperiods, we restrict $\lambda$ to be the same for all $t$.

\section{Results}

\subsection{Parameter estimates and marginal likelihood comparison}

In Table 1 we report the priors along with the posterior median and standard deviation for the parameters in the various model specifications with different policy rules. The first four posterior results pertain to the model with a "standard" UIP condition while the last column relate to the model with the modified UIP condition.

A clear message from Table 1 is that a fixed exchange rate rule during the first part of the sample 1986Q1-1992Q4 is not preferred by the data. The log marginal likelihoods clearly favor any of the other policy rules. Even a specification of the model without allowing for a break in the policy rule is preferable to the fixed exchange rate version. The no-break policy rule is also preferred to the the target zone specification which has a high prior value on the parameter multiplying the change in the nominal exchange rate $\left(r_{s}\right)$. For the target zone rule, we also notice that the obtained posterior value for $r_{s}$ is substantially lower than the prior value, so the data do not seem to be supportive of a strong exchange rate response in the policy rule. ${ }^{17}$ Moving to the third formulation of the policy rule using a Taylor type instrument rule with a discrete break, we see, however, that this more flexible specification of the rule during the first part of the sample induces a strong improvement in the log marginal likelihood compared to the no-break case. Our interpretation of these results is that there is clear evidence in favor of a break in the monetary policy conduct, but that the fixed-exchange rate/target zone versions of the policy rule are not empirically successful. Perhaps due to lack of credibility since the more flexible rule with a larger role for output stabilization appears to be more empirically coherent.

Turning to the "deep" parameters, we find that they are similar in the different specifications of the model, the main exception being the degree of wage stickiness which is found to be sub-

\footnotetext{
${ }^{17}$ It should, however, be noted that the estimated target zone rule still keeps the nominal exchange rate within a band of $\pm 2 \%$. This is actually similar to what is obtained under the Taylor type rule with a break, and the exchange rate volatility under the first part of the sample is consequently about the same under the two rules.
} 
stantially lower using the fixed-exchange rate or target-zone rules. For the other specifications, the posterior of the wage stickiness parameter essentially equals the prior. ${ }^{18}$ For the two model specifications using Taylor-type instrument rules, we see that the policy rule parameters are similar in the two regimes, with the exception of the estimated standard deviations of the inflation target shock and the monetary policy shock which are considerably lower after the adoption of an inflation target. Consequently, monetary policy in Sweden seems to have become more predictable after the adoption of an inflation target in 1993. Notably, the posterior distribution for the coefficient on lagged inflation $\left(r_{\pi}\right)$ in equation (15) is essentially identical to the prior distribution, suggesting weak identification of this parameter (see also Appendix 1) . However, by lowering and raising the prior mode and the standard deviation, we found that high values on this parameter is not favored by the Bayesian model probabilities but that values between 1.1-2 appear to be about equally plausible (given the other priors). ${ }^{19}$

We then go on to test the specification with the modified UIP condition. The idea is that the negative correlation between the risk premium and the expected change in the exchange rate via the UIP condition will affect the persistence in the real exchange rate after a contractionary monetary policy shock. Looking at the parameter estimates in Table 1 we see that the persistence in the risk premium shock decreases in the specification with the modified UIP condition compared to the specification with a standard UIP condition. A lower persistence in the shock to the risk premium is now needed to capture the observed autocorrelation in the real exchange rate since the modified UIP condition induces endogenous inertia in the risk premium through the negative correlation between the risk premium and the expected exchange rate change. While there is negative correlation between these parameters locally, it is very important to understand that the empirical relevance of these parameters for the entire model is identified by the fact that we evaluate the model's empirical coherence on a number of variables in addition to the real exchange rate. Consequently the risk premium parameter $\tilde{\phi}_{s}$ is identified separately from the risk-premium process parameters because the former parameter changes all shocks' propagation to the other variables in the model via the exchange rate. To understand this mechanism we have conducted the following experiments.

First, we reestimated the model using uniform priors on both $\tilde{\phi}_{s}$ and $\rho_{\tilde{\phi}}$ and computed the posterior median of $\tilde{\phi}_{s}$ and $\rho_{\tilde{\phi}}$ to be 0.67 and 0.48 , respectively, which are in line with the results in Table 1. The associated log marginal likelihood is -2249.8 , which is a slight improvement compared to the benchmark in Table $1(-2252.5)$. Second, we calibrated $\tilde{\phi}_{s}\left(\rho_{\tilde{\phi}}\right)$ to zero, and reestimated the model using a uniform prior on $\rho_{\tilde{\phi}}\left(\tilde{\phi}_{s}\right)$. The estimation outcome was $\rho_{\tilde{\phi}}=0.94\left(\tilde{\phi}_{s}=0.79\right)$ and the log marginal likelihood $-2269.9(-2256.8)$. While the $\tilde{\phi}_{s}$ and $\rho_{\tilde{\phi}}$ parameters move somewhat in relation to the benchmark result to compensate for the missing source of exchange rate persistence in these cases, it is clear from the associated log marginal likelihood values that the data support the existence of exchange rate persistence both through the modified UIP condition and through autocorrelated risk premium shocks. In particular, the drop in log marginal likelihood when omitting the modified risk premium is substantial, a finding in line with the key message of the paper. Third, we constructed contour plots of

\footnotetext{
${ }^{18}$ We have experimented with both a higher and a lower prior mode, as well as a uniform prior, on the wage stickiness parameter, where the results indicate that the data is only weakly informative on this parameter (i.e., the posterior moves less than one-to-one with the prior). Since our prior belief is that wage stickiness is an important fricition we want to allow for uncertainty in the wage setting behavior, why we use an informative prior rather than calibrating this parameter.

${ }^{19}$ Lowering the prior mode to 1.1 results in a posterior mode of 1.15 and a log marginal likelihood of about -2253. On the other hand, if the prior mode is increased to 5 with a prior standard deviation of 1.5 , the posterior mode is 2.1 with a log marginal likelihood of -2258 .
} 
the likelihood function in the $\left\{\tilde{\phi}_{s}, \rho_{\tilde{\phi}}\right\}$-space conditional on the posterior median of the other parameters (see Appendix 1). While we found some degree of substitutability between $\tilde{\phi}_{s}$ and $\rho_{\tilde{\phi}}$ locally around the posterior mode (i.e., the likelihood is nearly constant in a neighborhood of the posterior mode), the likelihood is well shaped globally. However, dropping all observed variables except the real exchange rate in the measurement equation and drawing the same contour plots resulted in an ill-behaved corner solution $\left(\tilde{\phi}_{s}=1, \rho_{\tilde{\phi}}=0\right)$. In conclusion, it is our belief that the parameters in the modified version are well identified. This is also manifested by the difference in log marginal likelihoods, where the model with the modified UIP condition obtains a posterior probability of 1.0. The data thus indicate that there is in fact a negative correlation between the risk premium on foreign bonds and the expected exchange rate development in Sweden.

Figure 1 shows the impulse response functions after a one standard deviation shock to monetary policy with and without the modified UIP condition. The solid lines depict the median and $95 \%$ interval posterior responses in the specification with a modified UIP condition, and the dashed lines show the responses in the specification with a standard UIP condition. In either specification the contractionary shock has a gradual effect on both output and inflation, with a maximum impact in about 1 to $1 \frac{1}{2}$ years which is in line with the 'conventional wisdom' on the transmission of monetary policy originally stemming from VARs. The interest rate increase also makes the exchange rate appreciate directly, via the UIP condition. This in turn feeds into the import prices but not fully since prices are sticky which forces the exchange rate pass-through to be incomplete. Also domestic and export prices are affected to some extent through the marginal cost of imported inputs. In the specification including a standard UIP condition, the appreciation is immediate before the exchange rate gradually returns to its equilibrium value (dashed lines). However, in the model with the modified UIP condition the real exchange rate appreciates only slowly and gradually (solid lines), in contrast. The larger persistence in the modified UIP condition, through the lagged dependence between the exchange rate and the risk premium, turns the real exchange rate from a spiked to a hump-shaped response. The reason is that the new specification of the UIP condition, with a negative correlation between the risk premium and the expected exchange rate change, induces the households to require a lower risk adjusted expected return on their foreign investments relative to the remuneration on domestic bonds since the exchange rate is expected to depreciate in the future. But to then equalize the returns on the different bonds in the next period, the exchange rate necessarily has to appreciate even more in the forthcoming periods. Consequently, compared to the standard UIP specification the DSGE model with a modified UIP condition produces impulse response functions after an unexpected monetary policy shock that appear to come qualitatively closer what is observed in estimated VARs regarding the real exchange rate (see Adolfson et al., 2006 for evidence on Swedish data).

\subsection{Forecasting performance}

Even if there is a close connection between the out-of-sample predictive performance and Bayesian model posterior probabilities, there are reasons to also carry out a traditional out-of sample prediction exercise (see Adolfson et al., 2005a, for such arguments). We therefore go on to analyzing the out-of-sample precision of the forecasts from the different DSGE specifications in detail. For comparison we also include the forecasts from a VAR model including the 15 variables we match the DSGE models against, using both maximum likelihood estimates of the parameters and Bayesian posterior distributions. We also contrast the alternative DSGE forecasts to naïve forecasts such as univariate random walks and the means of the most recent data observations. This is especially interesting for the exchange rate since it has proven to be difficult to beat 
the random walk for the nominal exchange rate in terms of the forecasting precision (see, e.g., Meese and Rogoff, 1983).

The forecast accuracy are assessed using a standard rolling forecast procedure where the models' parameters are estimated up to a specified time period where the forecast distribution for the next 8 quarters subsequently is computed. The estimation sample is then extended to include one more (observed) data point, and the dynamic forecast distribution is computed for another 8 quarters. The forecasts are evaluated between 1999Q1 and 2004Q4 which gives 24 observations for the 1-step ahead forecast and 16 observations for the 2-year ahead forecast. It should be noted that the VARs are re-estimated at this quarterly frequency while the DSGE models are re-estimated only yearly.

Figure 2a shows the root mean squared forecast errors in percentage terms for the 12 domestic variables at 1 to 8 quarters horizon from the two alternative DSGE models with a standard UIP condition or the modified UIP condition, allowing for a policy regime shift in the Taylor type instrument rule. The forecast errors are calculated based on year-to-year forecasts for all variables except for the real exchange rate and hours worked which are measured as quarterly deviations from the steady-state.

By comparing the specifications with and without the modified UIP condition (solid and dashed lines, respectively) we see that the forecast accuracy in particular for the real exchange rate and the interest rate improves when the modified UIP condition is included in the model. The reason is that the low persistence in the standard UIP condition makes the real exchange return too rapidly to the steady state. Also the precision of the CPI inflation forecast increases at the medium to long-term horizons. On the other hand, the forecast accuracy of hours worked, output and investment are worse than in the specification with a standard UIP condition. Taken together, the joint forecasting precision (not shown) indicates that the two models perform equally well when accounting for all variables, while the model with the modified UIP condition has somewhat better accuracy when taking the forecasts of the subset of key macroeconomic variables, CPI inflation, output, interest rate, real exchange rate, exports and imports, into account.

To get a sense for the precision of the forecasts we examine the actual forecasts from the two models using the standard UIP and the modified UIP conditions. Figure 3 shows the rolling forecasts for CPI inflation, the real exchange rate and the interest rate between 1999Q1 and $2004 Q 4$ from the standard and modified UIP specifications together with the actual outcomes. It is clear that the modified UIP enables the model to produce more persistent real exchange rate forecasts, while the mean reversion of the real exchange rate is a lot faster when using the standard UIP condition. It is also clear from Figure 3 that the shape of the forecasts for the CPI inflation and the interest rate are affected to a smaller extent. From a policy making perspective we believe that the model with the modified UIP is clearly preferable because it is unlikely that a central banker would like to use a model which always implies that the forecast path of the real exchange rate is quickly mean reverting no matter what.

In Figure $2 \mathrm{~b}$ we compare the DSGE model including the modified UIP condition with two VAR models (Bayesian and maximum likelihood estimates) and two naïve setups (random walks and the means of the eight most recent data observations). ${ }^{20}$ The DSGE model compares very well to both the VAR and the BVAR for almost all variables. The exception is hours worked. The precision in both the output and the CPI inflation forecasts from the DSGE is line with the more empirically oriented VAR models, and at the two-year horizon they are in fact better. Especially interesting are the real exchange rate and interest rate forecasts where the DSGE

\footnotetext{
${ }^{20}$ It should be noted that the we are using an informative prior on the long-run mean in the BVAR such that the forecasts converge asymptotically to the steady state in the DSGE model (see Adolfson et al., 2005a, for details).
} 
model outperforms the two VARs at just about all horizons. In particular the real exchange rate forecasts from the DSGE does remarkably well and beats also the random walk as well as the means of the latest eight observations. More problematic is perhaps that the interest rate forecasts in the structural model is not able to surpass the random walk at any horizon. Nevertheless, taking the joint forecast precision of all variables into account, the DSGE model performs better than both the VAR and the BVAR at all horizons (not shown). The joint forecasts from the DSGE are more precise than joint forecasts from the VAR or the BVAR. Consequently, the DSGE model with a modified UIP condition appear to be the best forecasting tool out of the different models we compare.

\subsection{Model misspecification}

According to the Bayesian model posterior probabilities and the shape of the impulse response functions after a monetary policy shock we know that the DSGE specification including the modified UIP condition and allowing for changes in the policy rule is preferred by the data. However, as argued in Section 3.2, we still only know that this specification is preferred over the competing variants of the DSGE model; it may very well be the case that all of these models, including the winning specification, suffer from misspecification. Here we use the tools developed by Del Negro and Schorfheide (2004) and extended by Del Negro, Schorfheide, Smets and Wouters (2006) to gauge the degree of misspecification in a DSGE model by comparing its marginal likelihood to the marginal likelihood of a VAR with a prior centered on that particular DSGE model (see the Appendix for details).

Table 2 reports the log marginal likelihoods when varying the tightness in the prior on the VAR/VECM model $(\lambda)$ from very diffuse to more and more informative. Or in other words, when letting the cross-equation DSGE restrictions become more and more enforced in the VAR/VECM estimation. The table shows estimation results from the VAR and the VECM with a break in the parameters using the DSGE model with a Taylor-type instrument rule including a shift in the policy parameters as the prior. The VAR and the VECM are estimated using two different DSGE priors; the DSGE specification with a standard UIP condition and the DSGE specification including the modified UIP condition. By comparing the hybrid models' marginal likelihoods when using these two DSGE priors we can examine the importance of the implied DSGE restrictions when taking possible misspecification of the DSGEs into account.

The results can be summarized as follows. First, according to the difference in marginal likelihoods between the structural DSGE model and the VAR/VECM approximations of the DSGE (i.e., $\lambda=\infty$ ), the VECM provides a better approximation of the DSGE than the VAR. The reason is that the unit root technology shock in the theoretical DSGE model induces a common stochastic trend in the levels of all real variables, which makes the DSGE contain six cointegrating relations. Allowing the approximation to also hold cointegration vectors (which is done in the VECM but not in the VAR) therefore improves the marginal likelihood difference between the resulting hybrid model and the DSGE. ${ }^{21}$ Taken together we believe that the VECM approximation of the DSGE is satisfactory. As explained in Section 3.2 the analysis correctly identifies whether the DSGE is a useful prior also in the case with a less accurate approximation (which holds true for the VAR). However, as the approximation error increases it becomes more difficult to measure in which dimensions the cross-equation restrictions need to be relaxed since the DSGE model does not map well into the VAR in this case. For this reason we only use the

\footnotetext{
${ }^{21}$ Also a comparison of the autocovariance function of the DSGE-VAR and DSGE-VECM with $\lambda=\infty$ to the autocovariance function of the DSGE model indicates that the addition of cointegration relations to the VAR helps to improve the approximation of the DSGE model (see the Appendix).
} 
VECM setup below when trying to assess in which dimensions the DSGE is misspecified.

The optimal value of $\lambda$ is around 5 in the VAR model and 7 in the VECM model. These numbers are much larger than those reported in Del Negro and Schorfheide $(2004)(\hat{\lambda}=0.6)$ and Del Negro et al. (2006) ( $\hat{\lambda}=0.75$ for the VAR and $\hat{\lambda}=1$ for the VECM). It may seem as if the restrictions in our DSGE model compares favorably to previously studied models since the prior tightness $\lambda$ is a measure of prior concentration of the VAR prior around the DSGE cross moments. However, it should be noted that the optimal lambdas are not comparable across studies. The interpretation of the prior tightness $\lambda$ is directly dependent on the model size and the size of the data set. One complicating circumstance is that we need $\lambda$ large enough for the prior to be proper, which is a necessary condition for computing meaningful marginal likelihoods. Part of the artificial DSGE observations that forms the prior (usually referred to as a training sample) is consumed in the process of turning the initially improper prior into a proper density $\left(\lambda_{\min }\right)$, and is therefore not used in the actual model evaluation. ${ }^{22}$ One way to control for the fact that $\lambda_{\min }$ is dependent on the model and sample size is to report the marginal likelihood as a function of the ratio of the number of post-training artificial observation to the number of actual observations, $\lambda-\lambda_{\min }$, or perhaps even better, the number of post-training artificial observations and the size of the actual data. ${ }^{23}$

Table 2 also shows that the VECMs always have smaller marginal likelihood compared to the corresponding VARs. Irrespective of the choice of model and the size of $\lambda$, there is essentially zero posterior probability placed on the VECM compared to the VAR. This suggests that there is weak support in the data for the cointegration restrictions in the DSGE model. This result is more or less expected as graphs on the supposedly stationary cointegration relations reveal that at least some of them are on the borderline to non-stationarity (not shown here). Complementary evidence on this issue is given in Adolfson et al. (2005a) where it is reported that imposing cointegration restrictions in the estimation of a DSGE on Euro area data produces forecasts that are less accurate compared to when the model consistent cointegrating vectors are not imposed.

Turning to the comparison of the specifications with and without the modified UIP condition, we see in the VECM that the difference in marginal likelihood between the two UIP specifications is increasing when $\lambda$ is increasing from its minimum value up to the (almost) DSGE approximating value of $\infty$. For the VAR models the results are less clear. Given that the restrictions in the DSGE have more impact on the estimated VAR/VECM when $\lambda$ is large, it is expected that the marginal likelihood difference will approach that of the two structural DSGEs as $\lambda$ increases. In the DSGE approximating VECMs the difference between the standard and modified UIP specifications is $6 \mathrm{log}$ units in favour of the modified condition. This should be compared with $15 \log$ unit differences that are obtained for the structural DSGE. However, the Bayesian posterior model probabilities at the optimal $\lambda$ (where the degree of sharpness in the DSGE prior maximizes the marginal likelihood) indicate that the difference in marginal likelihoods between the VAR/VECM specifications using the DSGE with or without the modified UIP condition is in fact relatively small.

One way to assess how much and in what dimensions the cross equation restrictions has

\footnotetext{
${ }^{22}$ The prior is proper if $\lambda \geq \lambda_{\min }=[n(p+1)+q] / T$, where $n$ is the number of endogenous variables in the VAR with $p$ lags, $q$ the number of exogenous variables and $T$ the number of actual data observations (see the Appendix for details). This is further complicated by the fact that we have a break in our model, which requires two training samples, one before and one after the regime shift. In our application we have $n=15$ endogenous variables in the VAR, $p=4$ lags and $T=48$ observations after the regime shift, so that $\lambda_{\min }$ is close to 2.7 , which clearly shows that this aspect is quite important for the interpretation of the results.

${ }^{23}$ For instance, the optimal number of post-training artificial observations in the DSGE-VECM is 195 to be compared with the 28 and 48 actual data observations in the two regimes, respectively.
} 
been relaxed is to compare the cross correlation functions for $\lambda=\infty$ and $\lambda=\widehat{\lambda}$ along with the standard deviations of the variables taken from the VECM covariance matrix. This is done in Figure 4. From the figure we see that the differences in both autocorrelations and standard deviations are generally large both contemporaneously and over time, suggesting that $\widehat{\lambda}=7$ implies a substantial relaxation of the DSGE's cross equation restrictions on both the VAR polynomial and the covariance matrix. In particular the differences are large for real exchange rate's autocorrelations and standard deviation, indicating that the model is still misspecified in this dimension even when including our modified UIP condition. ${ }^{24}$ It should, however, be acknowledged that there is a great amount of uncertainty regarding the univariate point estimates of the correlations, but the improvement in log marginal likelihood for the hybrid model compared to the structural DSGE suggest that these differences are important when taken together.

\section{Conclusions}

In this paper we have tried to improve on a small open economy dynamic model in the new Keynesian tradition to make it comply better with the empirical evidence on the transmission mechanism of monetary policy and the forward discount puzzle. The former is especially important for a policy making institution such as a central bank. Even if a DSGE model is able to capture the main development of the key macroeconomic time series and can forecast these well, one may also want to use the structural model for carrying out policy experiments such as evaluating alternative interest rate paths. It is then of crucial importance that the mechanisms in the model conform to the central bank's view of the workings in the economy.

We have therefore addressed the common problem that open economy sticky price models where agents are allowed to freely trade in foreign and domestic bonds are typically not able to reproduce the observed persistence and volatility of the real exchange rate. This is troublesome when analyzing the effects of changes in monetary policy because the UIP condition is an integral part of determining how interest rate adjustments affect nominal and real exchange rates. The way the exchange rate responds to various shocks through the UIP condition is also important for many macroeconomic variables because of the nominal frictions in the model. Sticky prices increase the exchange rate's effect on relative prices which in turn have an impact on most aggregate quantities and prices. To be able to generate intrinsic persistence of the exchange rate in the model, we introduced a negative correlation between the risk premium on foreign investments and the expected change in the exchange rate, following the empirical evidence in for example Engel (1996). Our tools to evaluate the modification empirically were Bayesian posterior model probabilities, impulse response functions, out-of-sample forecasts, and an analysis of the different DSGE restrictions' empirical coherence by examining the suitability of the DSGEs as a prior for a VAR model.

We find that the modified UIP condition is strongly preferable to a standard specification according to the Bayesian posterior odds, and that it has a significant effect on the impulse response functions of a monetary policy shock. The transmission mechanism of monetary policy in the modified model is more in line with the results obtained from the identified VAR literature, in the sense that the effects on the real exchange rate becomes hump-shaped with a peak effect after year. The modified DSGE model also produces more accurate forecasts on the real exchange rate and the interest rate compared with a standard UIP specification. We therefore think it

\footnotetext{
${ }^{24}$ Regarding the quantitative role of the modified UIP condition, there are in fact some differences between the cross correlation functions of the real exchange rate in the two specifications also under the optimal lambda (see the Appendix). However, judging from the difference in marginal likelihoods between the two models these discrepancies do not seem to be jointly important.
} 
is worthwhile exploring alternative structural models of the interest rate parity condition. This remains an important challenge to academics as well as model builders at central banks. 


\section{References}

Adolfson, Malin, Mikael K. Andersson, Jesper Lindé, Mattias Villani and Anders Vredin (2006), "Modern Forecasting Models in Action: Improving Macroeconomic Analyses at Central Banks", Working Paper No. 188, Sveriges Riksbank.

Adolfson, Malin, Jesper Lindé and Mattias Villani (2005a), "Forecasting Performance of an Open Economy Dynamic Stochastic General Equilibrium Model", Working Paper No. 190, Sveriges Riksbank.

Adolfson, Malin, Stefan Laséen, Jesper Lindé and Mattias Villani (2005b), "Bayesian Estimation of an Open Economy DSGE Model with Incomplete Pass-Through", Working Paper No. 179, Sveriges Riksbank.

Altig, David, Lawrence Christiano, Martin Eichenbaum and Jesper Lindé (2003), "The Role of Monetary Policy in the Propagation of Technology Shocks", manuscript, Northwestern University.

Anderson, Gary and George Moore (1985), "A Linear Algebraic Procedure for Solving Linear Perfect Foresight Models", Economics Letters 17(3), 247-252.

Apel, Mikael, Richard Friberg and Kerstin Hallsten (2005), "Microfoundations of Macroeconomic Price Adjustment: Survey Evidence from Swedish Firms", Journal of Money Credit and Banking 37, 313-338.

Backus, David, Silverio Foresi and Chris Telmer (2001), "Affine Term Structure Models and the Forward Premium Anomaly", Journal of Finance 56 (1), 279-304.

Calvo, Guillermo (1983), "Staggered Prices in a Utility Maximizing Framework", Journal of Monetary Economics 12, 383-398.

Chari, , Patrick Kehoe and Ellen McGrattan (2002), "Can Sticky Price Models Generate Volatile and Persistent Real Exchange Rates?", Review of Economic Studies 69, 533-563.

Christiano, Lawrence, Martin Eichenbaum and Charles Evans (2005), "Nominal Rigidities and the Dynamic Effects of a Shock to Monetary Policy", Journal of Political Economy 113(1), $1-45$.

Christiano, Lawrence, Martin Eichenbaum and Robert Vigfusson (2003), "What Happens After a Technology Shock?", NBER Working Paper, No. 9819.

Curdia, Vasco and Daria Finocchiaro (2005), "An Estimated DSGE for Sweden with a Monetary Regime Change", Seminar Paper No. 740, Institute for Intenational Economic Studies, Stockholm University.

Del Negro, Marco, Frank Schorfheide (2004), "Priors from General Equilibrium Models for VARS", International Economic Review 45(2), 643-673.

Del Negro, Marco, Frank Schorfheide, Frank Smets and Raf Wouters (2006), "On the Fit and Forecasting Performance of New Keynesian Models", Journal of Business and Economic Statistics, forthcoming.

Duarte, Margarida and Alan Stockman (2005), "Rational Speculation and Exchange Rates", Journal of Monetary Economics, 52, 3-29. 
Eichenbaum, Martin and Charles Evans (1995), "Some Empirical Evidence on the Effects of Shocks to Monetary Policy on Exchange Rates", Quarterly Journal of Economics 110, 975-1010.

Engel, Charles (1996), "The Forward Discount Anomaly and the Risk Premium: A Survey of Recent Evidence", Journal of Empirical Finance 3, 123-192.

Erceg, Christopher, Dale Henderson and Andrew Levin (2000), "Optimal Monetary Policy with Staggered Wage and Price Contracts", Journal of Monetary Economics 46(2), 281-313.

Fama, Eugene (1984), "Forward and Spot Exchange Rates", Journal of Monetary Economics, $14,319-338$.

Faust, Jon and John Rogers (2003), "Monetary Policy's Role in Exchange Rate Behavior", Journal of Monetary Economics 50, 1403-1424.

Friberg, Kent (2006), "Intersectoral Wage Linkages: The Case of Sweden", Empirical Economics, forthcoming.

Froot, Kenneth. and Jeffery Frankel (1989), "Forward Discount Bias: Is It an Exchange Risk Premium", Quarterly Journal of Economics 104(1), 139-61.

Gelman, Alexander, John Carlin, Hal Stern and Donald Rubin (1995), Bayesian Data Analysis, Chapman \& Hall, New York.

Geweke, John (1999), "Using Simulation Methods for Bayesian Econometrics Models: Inference, Development and Communication", Econometric Reviews 18(1), 1-73.

Hansen, Peter (2005), "Granger's Representation Theorem: A Closed-Form Expression for I(1) Processes", Econometrics Journal 8, 23-38.

Justiniano, Alejandro and Bruce Preston (2004), "Small Open Economy DSGE Models: Specification, Estimation and Model Fit", Manuscript, Columbia University.

Justiniano, Alejandro and Bruce Preston (2005), "Can Structural Small Open Economy Models Account for the Influence of Foreign Shocks?", Manuscript, Columbia University.

Litterman, Robert (1986), "Forecasting with Bayesian Vector Autoregressions - Five Years of Experience", Journal of Business and Economic Statistics 4, 25-37.

Lubik, Thomas and Frank Schorfheide (2005), "A Bayesian Look at New Open Economy Macroeconomics", in eds. Gertler, Mark. and Kenneth Rogoff, NBER Macroeconomics Annual, 313-336.

Lundvik, Petter (1992), "Foreign Demand and Domestic Business Cycles: Sweden 1891-1987", Chapter 3 in Business Cycles and Growth, Monograph Series No. 22, Institute for International Economic Studies, Stockholm University.

Meese, Richard and Kenneth Rogoff (1983), "Empirical Exchange Rate Models of the Seventies: Do They Fit Out of Sample?", Journal of International Economics, 14, 3-24.

Monacelli, Tommaso (2004), "Into the Mussa Puzzle: Monetary Policy Regimes and the Real Exchange Rate in a Small Open Economy", Journal of International Economics, 62, 191217. 
Otrok, Christopher, "On Measuring the Welfare Cost of Business Cycles", Journal of Monetary Economics 47(1), 61-92.

Schmitt-Grohé Stephanie and Martín Uribe (2001), "Stabilization Policy and the Costs of Dollarization", Journal of Money, Credit, and Banking 33(2), 482-509.

Schorfheide, Frank (2000), "Loss Function-based Evaluation of DSGE Models", Journal of Applied Econometrics, 15(6), 645-670.

Smets, Frank and Raf Wouters (2002), "Openness, Imperfect Exchange Rate Pass-Through and Monetary Policy", Journal of Monetary Economics 49(5), 913-940.

Smets, Frank and Raf Wouters (2003), "An Estimated Stochastic Dynamic General Equilibrium Model of the Euro Area", Journal of the European Economic Association, 1(5), 1123-1175.

Smets, Frank and Raf Wouters (2004), "Forecasting with a Bayesian DSGE Model. An Application to the Euro Area", Working Paper No. 389, European Central Bank.

Svensson, Lars E.O. (1994), "Why Exchange Rate Bands? Monetary Independence In Spite of Fixed Exchange Rates", Journal of Monetary Economics 33(1), 157-199.

Sveriges Riksbank (1993), Press Release 5/1993, Stockholm, Sweden.

Taylor, John (1993), "Discretion Versus Policy Rules in Practice" Carnegie-Rochester Series on Public Policy, North-Holland, 39, 195-214.

de Walque, Grégory, Frank Smets and Raf Wouters (2005), "An Open Economy DSGE Model Linking the Euro Area and the US Economy", manuscript, National Bank of Belgium.

Woodford, Michael (2003), Interest and Prices: Foundations of a Theory of Monetary Policy, Princeton University Press, Princeton. 
Table 1: Prior and posterior distributions

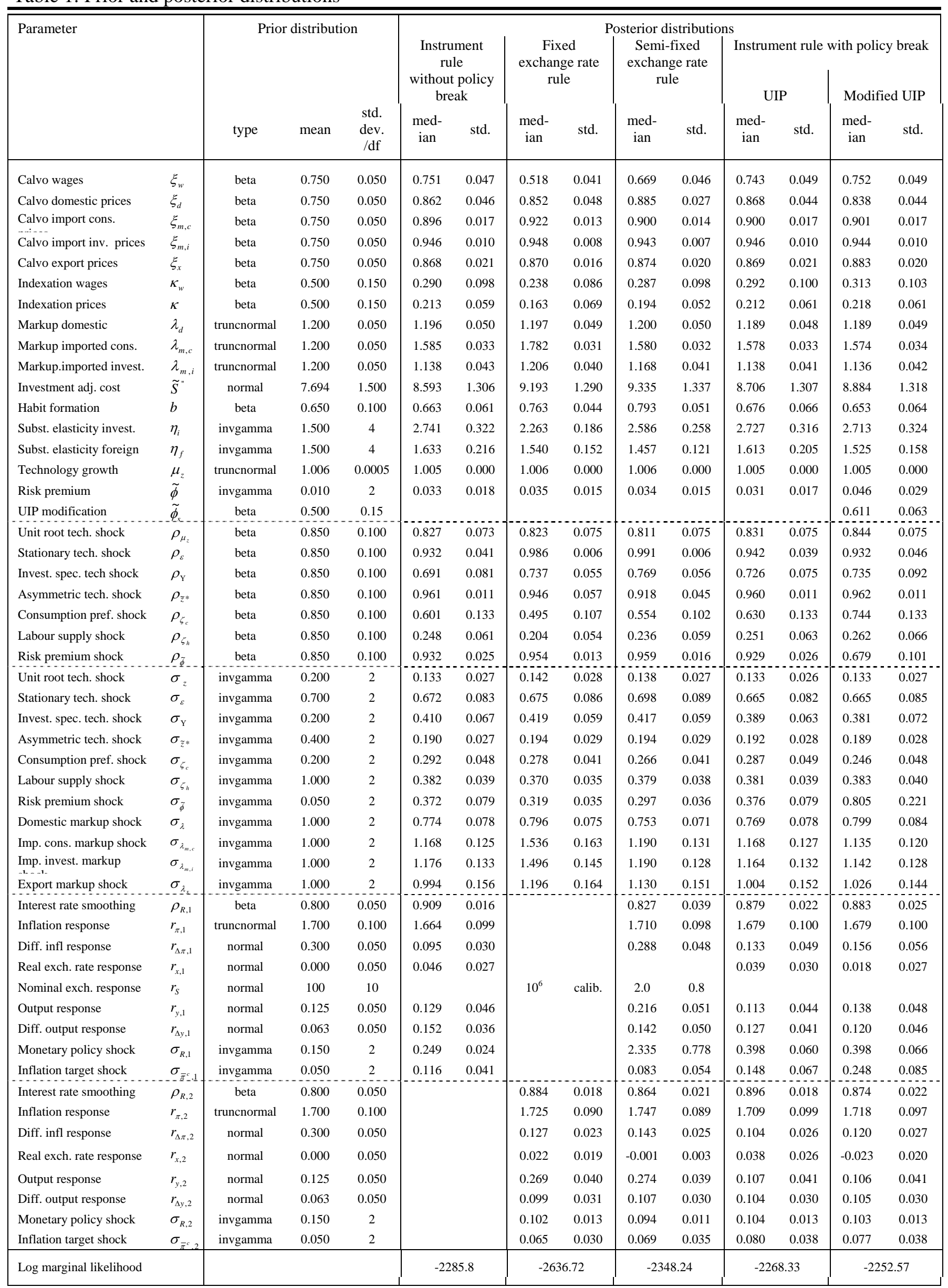


Table 2: Log marginal likelihood of VAR/VECM with DSGE prior (Taylor-type instrument rule with break)

\begin{tabular}{|c|cc|cc|}
\hline \hline & \multicolumn{2}{|c|}{ DSGE-VAR } & \multicolumn{2}{c|}{ DSGE-VECM } \\
\hline 2.714 & UIP & Modified UIP & UIP & -2187.77 \\
2.929 & -2164.78 & -2163.19 & -2190.79 & -2025.89 \\
4 & & & -2028.20 & -2000.46 \\
4.5 & -1998.27 & -1996.23 & -2002.60 & -1985.78 \\
5 & -1980.51 & -1979.88 & -1987.80 & -1977.53 \\
5.5 & -1964.96 & -1970.43 & -1979.47 & -1973.91 \\
7 & -1970.78 & -1965.86 & -1974.12 & -1976.39 \\
7.5 & -1965.98 & -1966.72 & -1975.74 & -1990.83 \\
8 & -1968.72 & -1969.46 & -1978.24 & -2091.13 \\
10 & -1972.05 & -1972.79 & -1992.72 & -2160.00 \\
25 & -1988.94 & -1987.02 & -2093.68 & -2265.08 \\
\hline 50 & -2083.09 & -2081.13 & -2164.52 & -2252.57 \\
\hline$\infty$ & -2143.73 & -2140.50 & -2270.78 & -2268.33 \\
\hline
\end{tabular}

Note: The table displays laplace approximations of the log marginal likelihood. $\lambda=2.714$ and $\lambda=2.929$ are the minimal tightnesses for the VAR and VECM, respectively. Bold numbers indicate the $\lambda$ with the maximal log marginal likelihood. 
Figure 1: Impulse response functions (posterior median and $95 \%$ uncertainty intervals) to a one standard deviation monetary policy shock, with standard (dahsed lines) and modified UIP condition (solid lines).
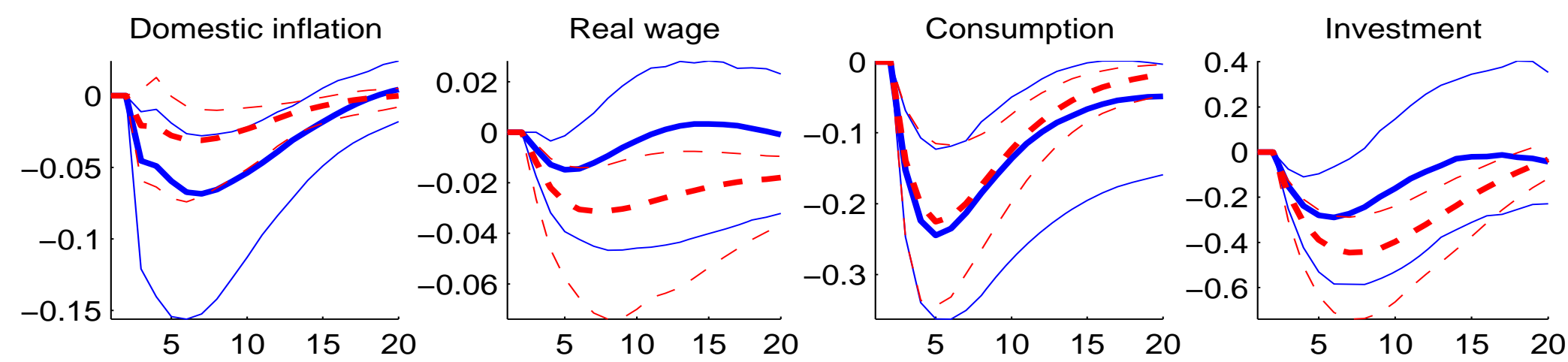

Real exchange rate

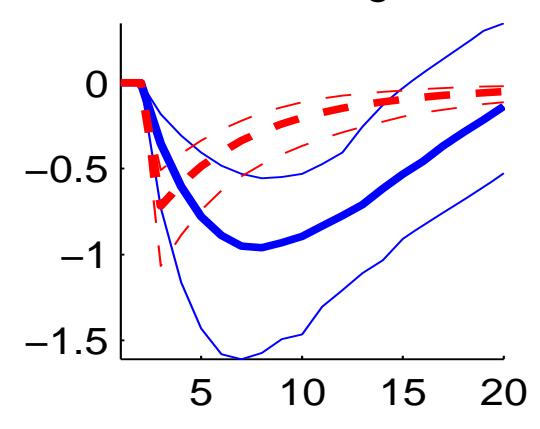

Interest rate
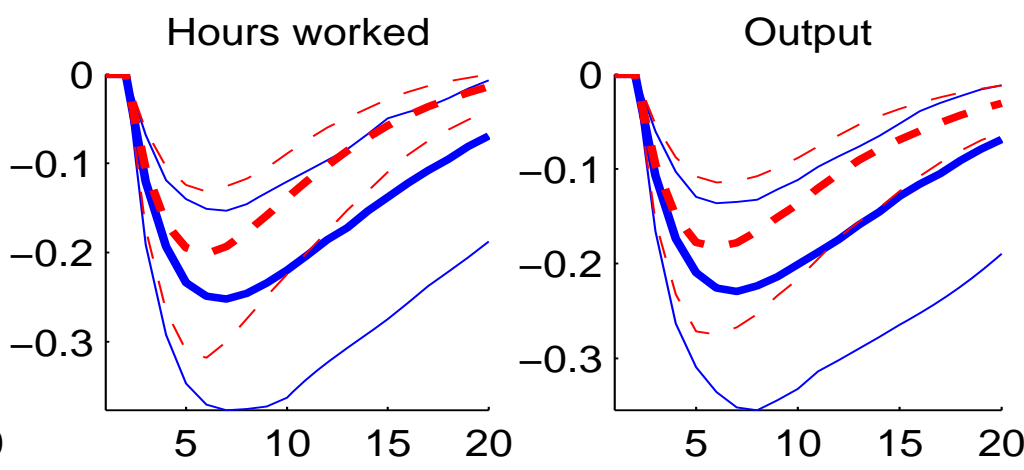

Export
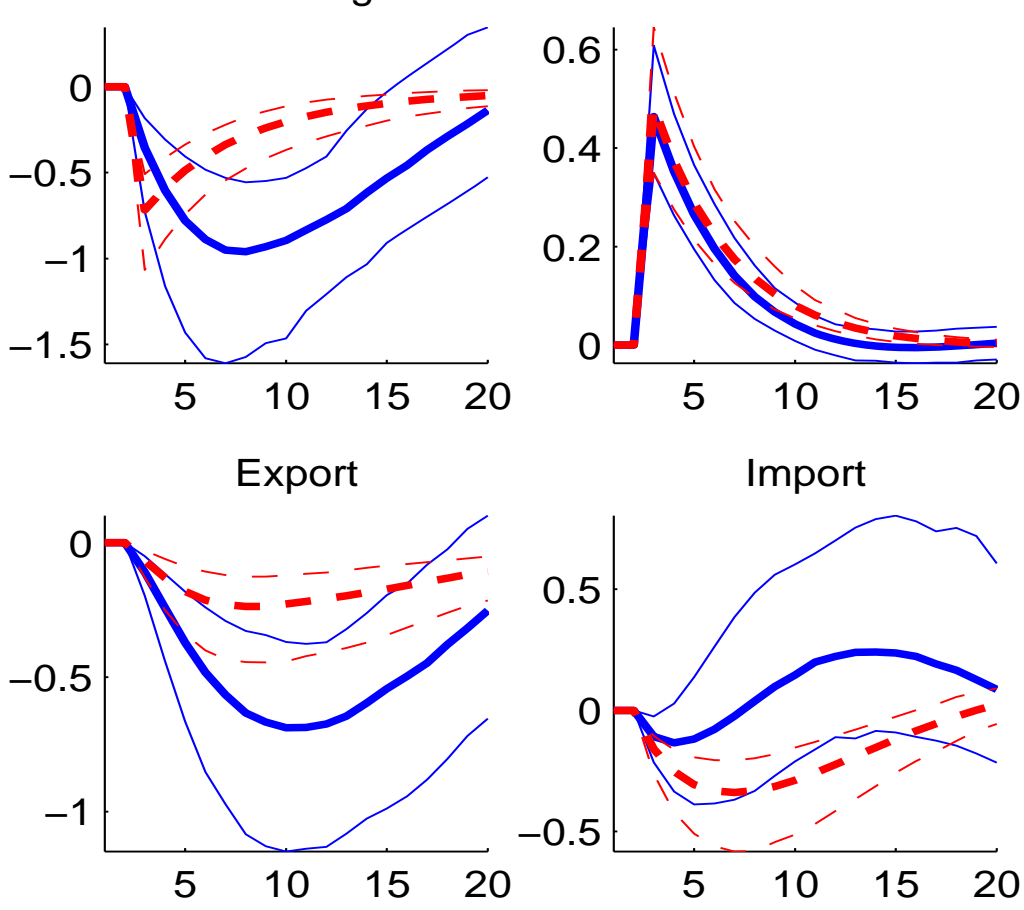

Import
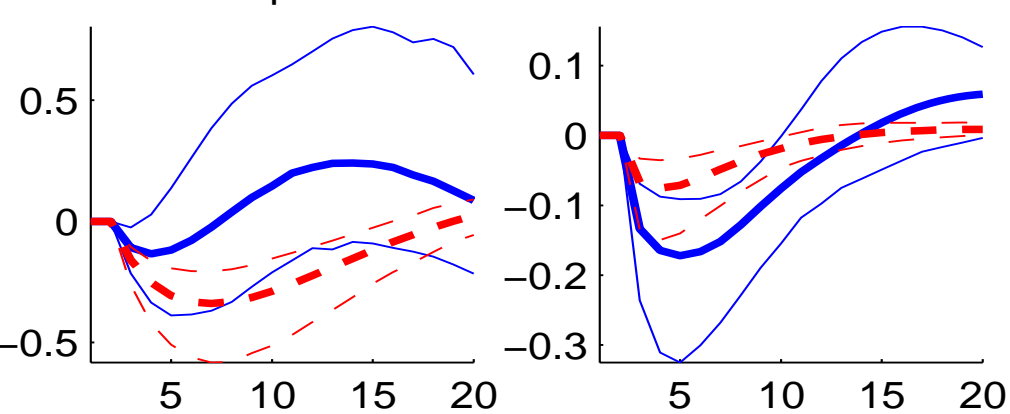

Invest. defl. inflation

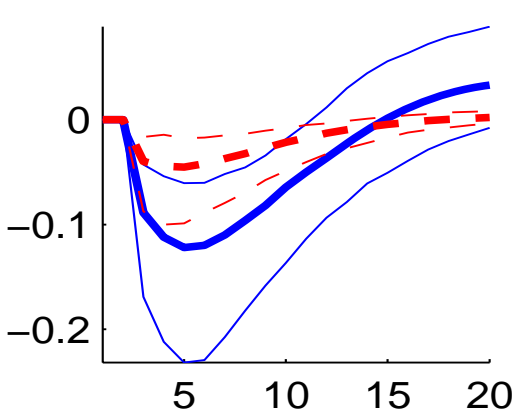

Note: Inflation and interest rates are reported as annualized quarterly rates while quantities as log-deviations from steady state. 
Figure 2a: Root mean squared forecast errors for DSGEs with standard and modified UIP
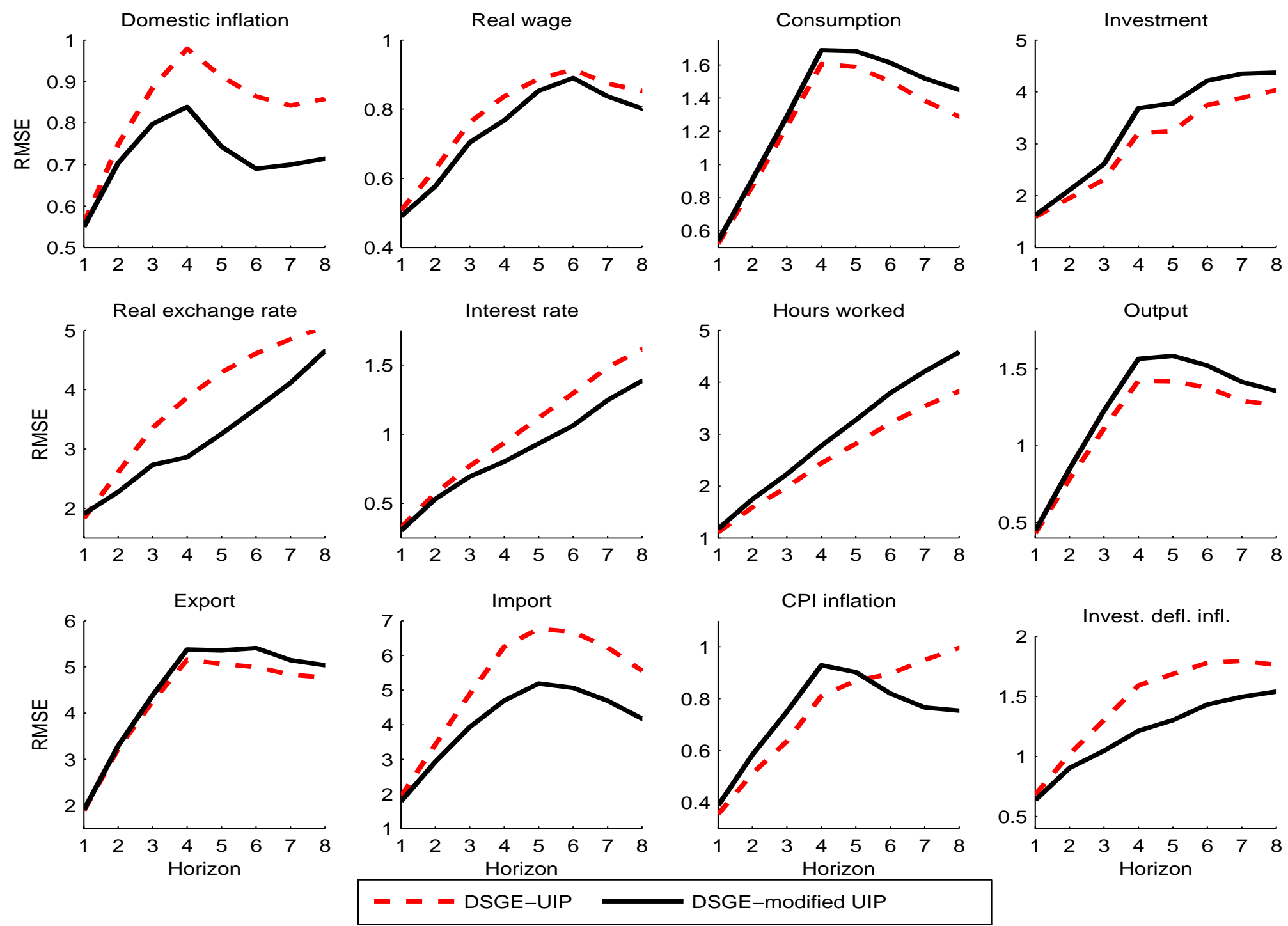
Figure 2b: Root mean squared forecast errors for DSGE, BVAR, VAR and naïve
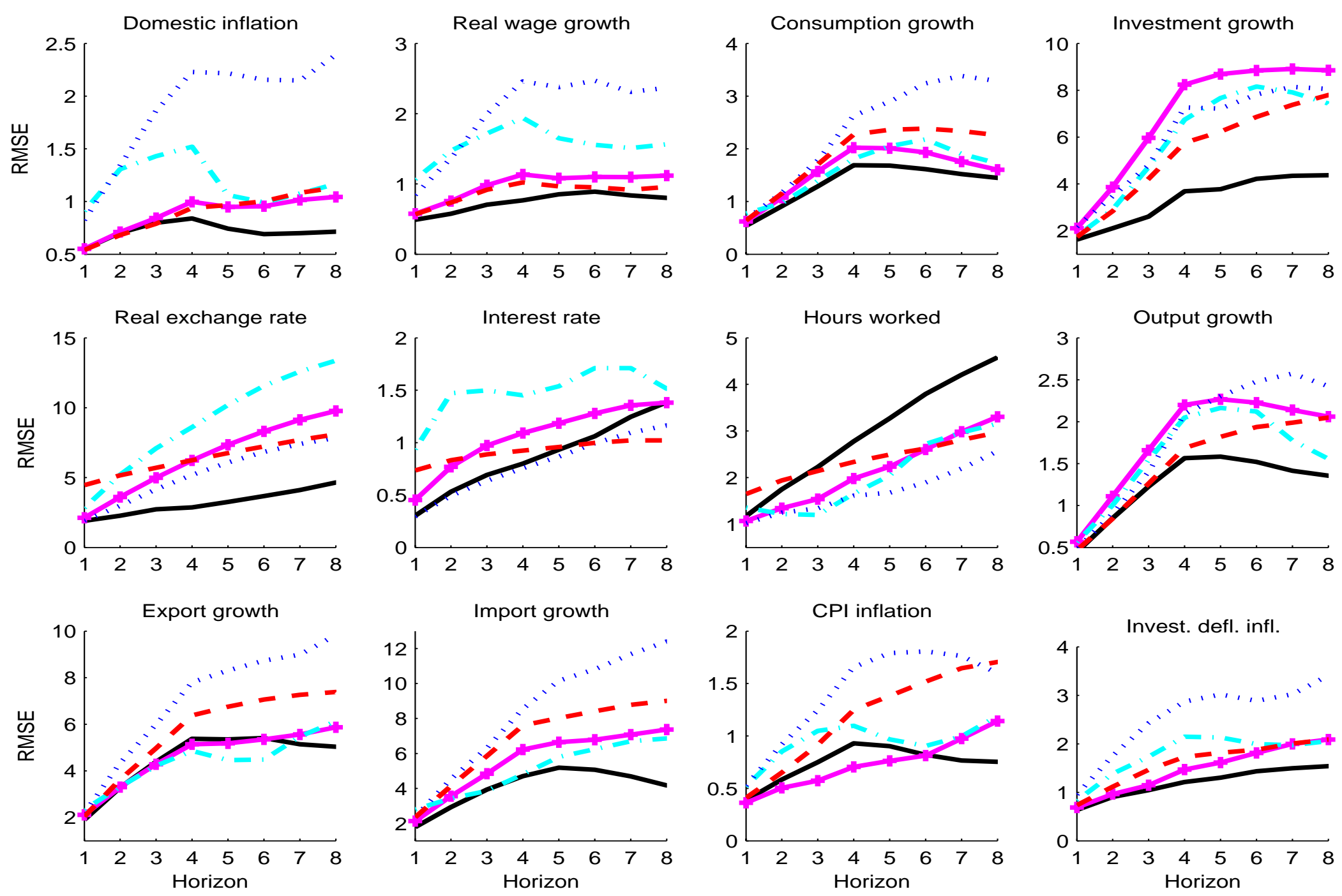

DSGE - modified UIP $\longleftarrow$ Bayesian VAR

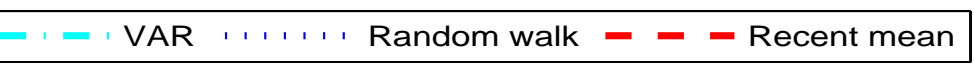


Figure 3: Actual data (thick line) and forecasts (thin lines) 1999Q1 - 2004Q4 from the DSGE using different UIP specifications
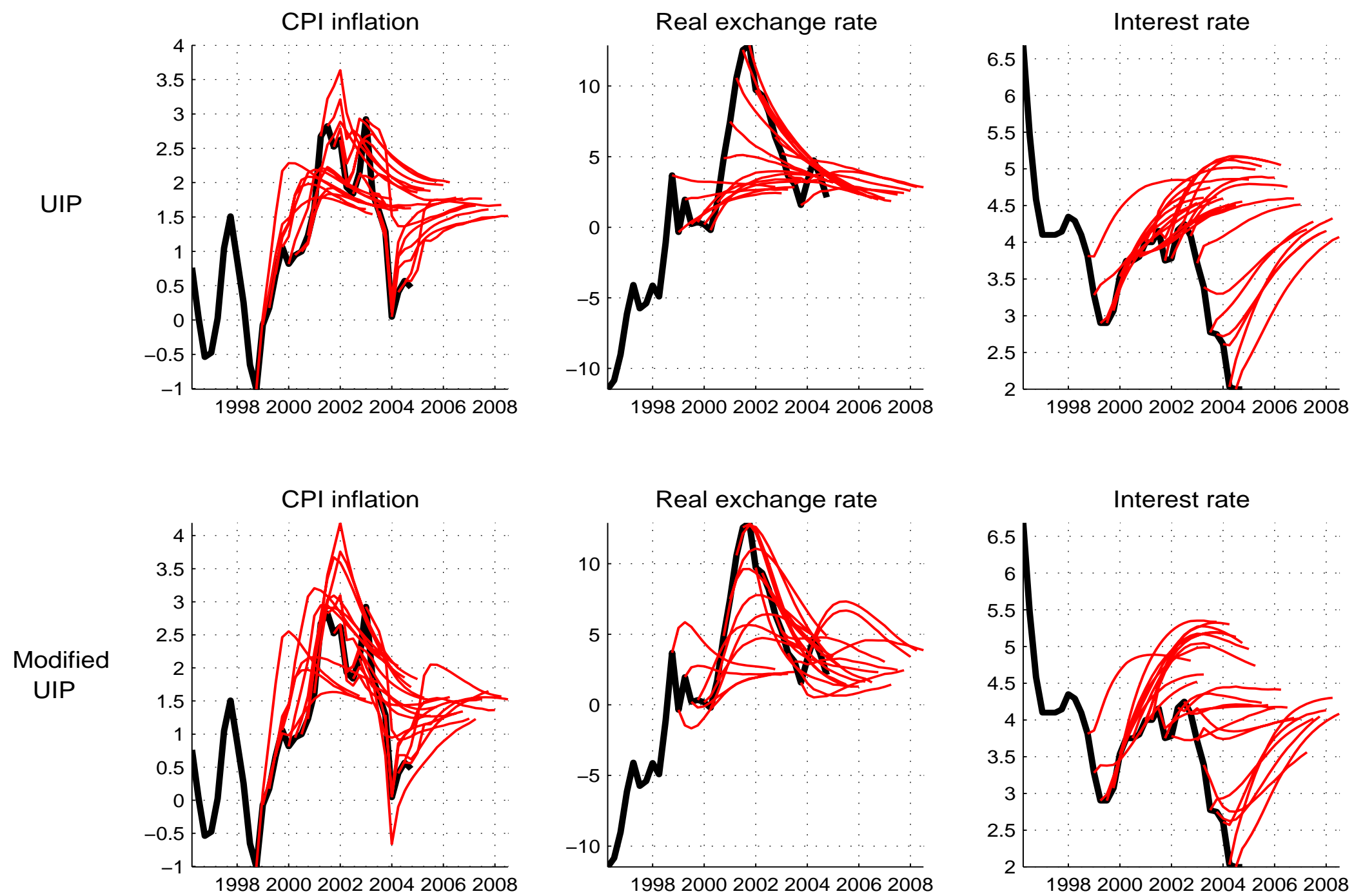
Figure 4: Comparing cross-correlation functions (CCF) from the DSGE-VECM with the modified UIP condition for $\lambda=\widehat{\lambda}$ (solid lines) and $\lambda=\infty$ (dashed lines). The subgraphs below the diagonal display the cross-correlation between the column variable and the lag of the row variable. The opposite order applies to the upper diagonal graphs. The CCFs are computed at the posterior mode estimates of the parameters within each model. The numbers in the bottom of the graphs are the standard deviations of the respective variable in the $\lambda=\hat{\lambda}$ case. The corresponding standard deviations for the case $\lambda=\infty$ are displayed to the right of the subgraphs.
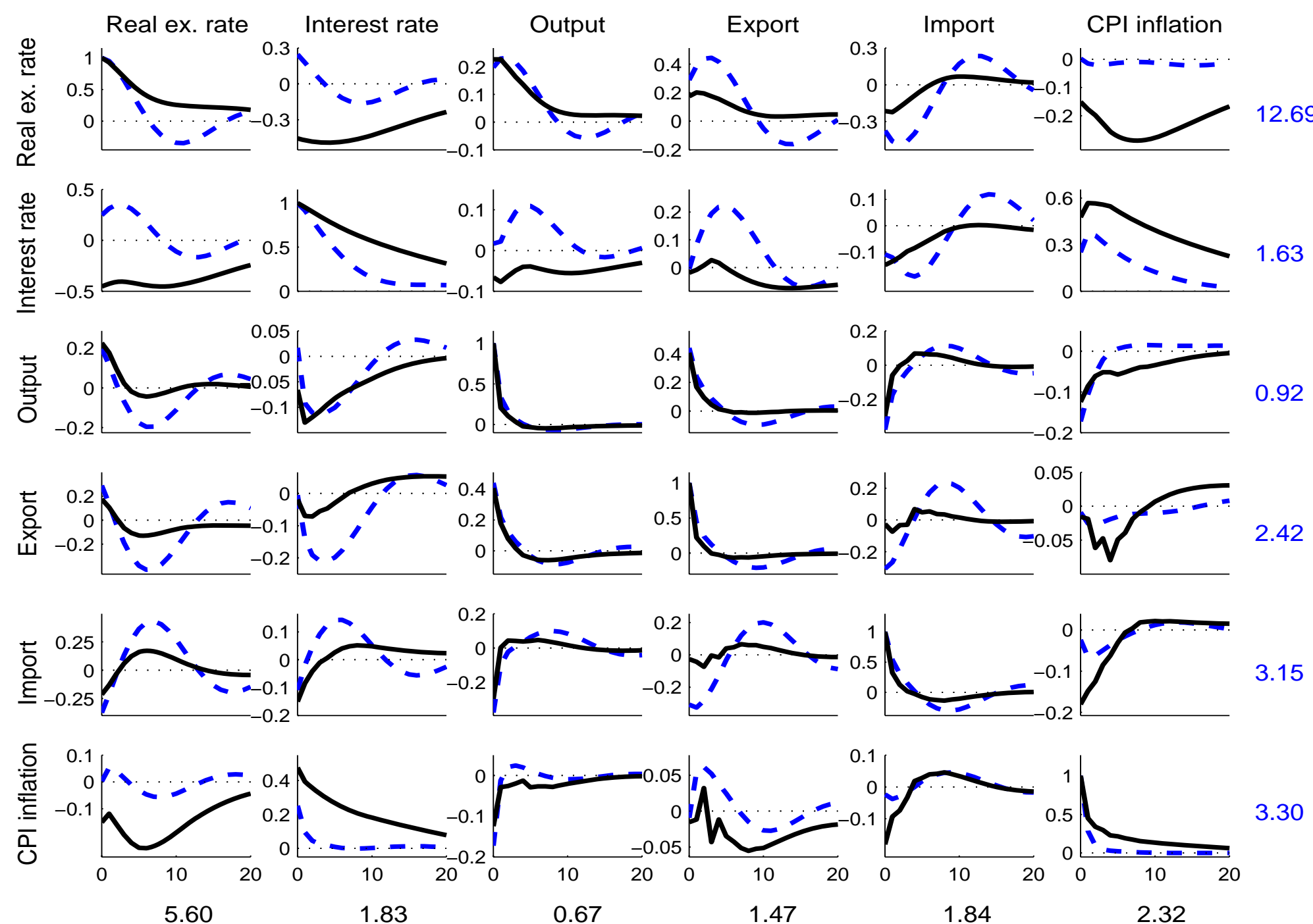


\section{Appendix A. Estimation results}

\section{A.1. Prior vs. posterior plots}

Figures A.1a to A.1c report the prior and posterior distributions for all estimated parameters in the model including the modified UIP condition and using a flexible Taylor-type instrument rule to model the pre-inflation targeting regime (i.e., the last model in Table 1). In accordance with the results in Table 1, the figures show that the data is generally informative about the parameters, as the posterior distributions differ from the priors, with a few exceptions (i.e., $\xi_{w}$ and $r_{\pi}$ ). The results for these parameters are discussed in greater detail in the main text.

\section{A.2. Raw Metropolis chains}

In Figures A.2a to A.2c we report the 500,000 post burn-in Metropolis draws for each parameter. The Markov chain in Figure A.2 show that there are no clear trends or correlations between the parameters in the model.

The CUSUM plots of the Metropolis draws are depicted in Figures A.3a to A.3c. The solid line (labeled posterior) is the accumulated mean of the draws, while the dashed line (labeled average) is a window average of the last 50,000 draws. As expected from the raw Metropolis draws, the CUSUM plots show no sign of a trending mean in the parameters throughout the whole chain. Even if the window averages are varying slightly, there do not appear to be any high correlation between the different parameters. In particular, we notice from Figures A.2 and A.3 that the risk premium parameters $\tilde{\phi}_{s}, \rho_{\tilde{\phi}}$ and $\sigma_{\tilde{\phi}}$ do not show any clear sign of cross-correlation or time-varying means, supporting the discussion in the main text that these parameters are well identified.

\section{A.3. Sequential log marginal likelihoods}

In Figure A.4, we plot the log marginal likelihood sequentially for each 50,000th draw, using all the preceding iterations in the computation of the marginal likelihood with the modified harmonic estimator in Geweke (1999). ${ }^{25}$ The lines pertain to eight different probabilities of the truncated elipsodes of the joint posterior distribution. As can be seen from Figure A.4, the spread between the largest and smallest elipsodes is not very large after a couple of 100,000 draws. It is also clear from the figure that the marginal likelihood converges after about 200,000 draws. To obtain convergence, we found it to be of critical importance to obtain a good estimate of the Hessian matrix. We start by maximizing the posterior density and evaluating the Hessian matrix at the posterior mode using standard numerical optimization routines. Prior to the optimization we transform all the parameters to the unconstrained domain (we use logit transformations on parameters restricted to the unit interval, and a log transformation for strictly positive parameters). Second, draws from the posterior distribution are generated using the MetropolisHastings algorithm.

\footnotetext{
${ }^{25}$ The marginal likelihood of a model $i$ is defined as $m_{i}=\int L_{i}\left(\theta_{i} ; x\right) p_{i}\left(\theta_{i}\right) d \theta_{i}$, where $L_{i}\left(\theta_{i} ; x\right)$ is the usual likelihood function of the model's parameter vector conditional on the observed data $x . p_{i}\left(\theta_{i}\right)$ is the prior distribution of the model's parameters. $m_{i}$ is the unconditional probability of the observed data, under the assumed prior distribution, and is therefore a measure of model fit. The marginal likelihood is a relative measure and should be compared across competing models. The Bayes factor comparing two models $i$ and $j$ is defined as $B_{i j}=m_{i} / m_{j}$.
} 


\section{A.4. Multivariate ANOVA}

In Figure A.5, we report the multivariate potential scale reduction factor (MPSRF) based on four independent Metropolis chains with different starting values consisting of 500,000 draws each. The analysis is based on subsampling every 5th draw for computational reasons. Gelman et al. (1995) argue that by rule-of-thumb, the MPSRF should be less than 1.1 to have a satisfactory convergence. As is evident from Figure A.5, this requirement is fulfilled in our chains after about 100, 000 draws (i.e, after 20,000 iterations in the plot), and after about 250,000 draws it is down to less than 1.05. Figure A.5 also depicts the total variance in all the four Markov chains together with the variance within each parallel chain. As the number of draws increases we see that the difference between the total and within variation in the parallel chains decreases.

\section{A.5. Contour plots}

In the main text, we argue from using uniform priors and comparing Bayesian model probabilities that the parameters associated with the UIP condition, $\tilde{\phi}_{s}$ and $\rho_{\tilde{\phi}}$, are well identified given our set of observable variables in the measurement equation. In Figure A.6 we show contour plots of the likelihood function in the $\left\{\tilde{\phi}_{s}, \rho_{\tilde{\phi}}\right\}$-space conditional on the posterior median of the other parameters. Figure A.6a shows the likelihood for different values of $\tilde{\phi}_{s}$ and $\rho_{\tilde{\phi}}$ using the entire set of 15 observables. The data is relatively informative about the intrinsic persistence $\tilde{\phi}_{s}$ but has less to say about the exogenous autocorrelation $\rho_{\tilde{\phi}}$. Even if the likelihood in Figure A.6a is nearly constant in the neighborhood of the posterior mode, the likelihood function appear to be well shaped when all the other parameters are not kept fixed. When plotting the likelihood contours using only the real exchange rate in the measurement equation, we see that the data is even less informative about $\rho_{\tilde{\phi}}$ (see Figure A.6b). $\rho_{\tilde{\phi}}$ can take on almost any value for small values of $\tilde{\phi}_{s}$, and the likelihood function in this case suggest a corner solution of $\left(\tilde{\phi}_{s}=1, \rho_{\tilde{\phi}}=0\right)$.

\section{A.6. Measurement errors}

In order to examine the sensitivity of our results to the choice of including measurement errors in the estimation, we provide in Table A.1 the posterior mode estimates when varying the size of the measurement errors. For ease of comparison we also include the baseline case. As a first sensitivity check we set the variance of the measurement errors to 0.05 percent for all the domestic variables and 0 for the foreign variables (i.e., less than half of what we are using in the baseline case in the main text). From the table we see that this does not change the parameter estimates by much. However, when treating the data as being measured almost perfectly (setting the variance of the measurement errors to 0.01 percent for the domestic variables, see the last column) certain parameters shift, sometimes substantially from an economic viewpoint. For example, the price stickiness parameter increases from 0.82 to 0.92 and the substitution elasticity between investment goods drops from 2.67 to 1.28. However, given that we know there are measurement problems in the Swedish data we are using, it is not surprising that the estimates change somewhat when no measurement errors are included in the estimation. Statistics Sweden has made several alterations in how they collect their price statistics and we were for example not able to remove all the seasonal variation in the GDP deflator. We therefore believe that a small amount of measurement errors is reasonable to include in the estimation. It should also be noted that it is the fundamental shocks in the model that explain the major part of the variability in the data. In Figure A.7 we plot the actual data against the fluctuations generated by the model without any measurement errors. As can be seen from the figure the two series 
are very similar, so the measurement errors account only for a small fraction of the variability in the data.

\section{A.7. Unconditional moments}

To get a better sense for the modified UIP condition's compliance to the data we provide in Table A.2 a posterior predictive analysis for the real exchange rate. The table shows the unconditional moments for the real exchange rate in the data and in the two DSGE models (the latter computed from simulated data in the model with the standard UIP condition and in the model with the modified UIP condition, respectively). The table indicates that the specification with the modified UIP condition captures the autocorrelation of the real exchange rate in the actual data but overpredicts the volatility somewhat, while the specification with a standard UIP underpredicts both the persistence and the volatility in the real exchange rate. However, it should be noted that we are probably considering a too short sample period for making the second moments a sufficiently informative statistic to truly evaluate the empirical coherence of the models. This is particular the case if the transition from the fixed exchange rate regime to the inflation targeting regime should be taken into account.

\section{Appendix B. Misspecification analysis}

\section{B.1. Using a VAR with a DSGE prior}

To describe the DSGE-VAR approach in some detail, let the VAR model with $p$ lags be denoted

$$
y_{t}=\Phi_{0}+\Phi_{w} w_{t}+\Phi_{1} y_{t-1}+\ldots+\Phi_{p} y_{t-p}+u_{t}=\Phi^{\prime} x_{t}+u_{t}, \quad t=1, \ldots, T,
$$

where $y_{t}$ contains the $n$ stationary endogenous variables $(\mathrm{I}(1)$ variables enter in first differences), $w_{t}$ is a $q$-dimensional vector of exogenous variables, $x_{t}^{\prime}=\left(1, w_{t}^{\prime}, y_{t-1}^{\prime}, \ldots, y_{t-p}^{\prime}\right), \Phi^{\prime}=$ $\left(\Phi_{0}, \Phi_{w}, \Phi_{1}, \ldots, \Phi_{p}\right)$ and $u_{t} \sim N\left(0, \Sigma_{u}\right)$ are independent across time. Del Negro and Schorfheide (2004) propose a prior for $\Phi$ and $\Sigma_{u}$ that one may think of as centered around OLS estimates based on a simulated data set of $T^{*}$ observations from a DSGE model with parameter vector $\theta$. The posterior of the VAR coefficients may similarly be thought of as the result of applying a Bayesian VAR to the combined data set of actual and artificial data. Del Negro and Schorfheide (2004) avoid the simulation variability in the above mental sketch by replacing the simulated cross moment matrices $\sum y_{t} y_{t}^{\prime}, \sum x_{t} x_{t}^{\prime}$ and $\sum x_{t} y_{t}^{\prime}$ (which are the building blocks in the OLS estimates) with their population counterparts $T^{*} E_{\theta}\left(y_{t} y_{t}^{\prime}\right), T^{*} E_{\theta}\left(x_{t} x_{t}^{\prime}\right)$ and $T^{*} E_{\theta}\left(x_{t} y_{t}^{\prime}\right)$, respectively. $E_{\theta}$ here denotes the expectation with respect to the DSGE model with parameter vector $\theta$. Formally, Del Negro and Schorfheide (2004) propose the following Normal-Inverted Wishart prior for $\Phi$ and $\Sigma_{u}$, conditional on $\theta$,

$$
\begin{aligned}
\Sigma_{u} \mid \theta & \sim I W\left[\lambda T \Sigma_{u}^{*}(\theta), \lambda T-k\right] \\
\operatorname{vec} \Phi \mid \Sigma_{u}, \theta & \sim N\left\{\operatorname{vec} \Phi^{*}(\theta), \Sigma_{u} \otimes\left[\lambda T E_{\theta}\left(x_{t} x_{t}^{\prime}\right)\right]^{-1}\right\}
\end{aligned}
$$

where the prior means of $\Phi$ and $\Sigma_{u}$ are computed from the DSGE moments:

$$
\begin{aligned}
\Phi^{*}(\theta) & =E_{\theta}^{-1}\left(x_{t} x_{t}^{\prime}\right) E_{\theta}\left(x_{t} y_{t}^{\prime}\right) \\
\Sigma_{u}^{*}(\theta) & =E_{\theta}\left(y_{t}^{\prime} y_{t}\right)-E_{\theta}\left(y_{t} x_{t}^{\prime}\right) E_{\theta}^{-1}\left(x_{t} x_{t}^{\prime}\right) E_{\theta}\left(x_{t} y_{t}^{\prime}\right),
\end{aligned}
$$


$k=n p+q+1$ and $\lambda=T^{*} / T$ is the ratio of the number of artificial DSGE observations to the number of observations in the actual data. This prior is proper if $\lambda \geq \lambda_{\min }=(k+n) / T{ }^{26}$

As $\lambda$ decreases, the posterior estimates of the VAR coefficients approach the unrestricted OLS estimates. It is important to understand that this does not mean that the corresponding limiting marginal likelihood can be interpreted as some kind of measure of fit for an unrestricted VAR. A marginal likelihood is always associated with a prior, which when $\lambda=\lambda_{\min }$ is the prior which uses just enough DSGE observations to make it proper. As the marginal likelihood is the prior expectation of the likelihood function, it is clear that such a vague prior may be only weakly connected to more traditional measures of fit based on OLS estimates.

The regime shift in the DSGE model's monetary policy rule requires special attention in the DSGE-VAR analysis. Given that the DSGE model allows all the reduced form parameters to change as result of the regime shift, even if only a subset of the structural parameters change (i.e., the conduct of monetary policy), the same must be true in the VAR model. We therefore consider the following $n$-dimensional VAR with a potential break in all parameters at a known time point $t=T_{1}$

$$
y_{t}=\left\{\begin{array}{lll}
\Phi_{1}^{\prime} x_{t}+\varepsilon_{t}, & \operatorname{Cov}\left(\varepsilon_{t}\right)=\Sigma_{1} & \text { for } t \leq T_{1} \\
\Phi_{2}^{\prime} x_{t}+\varepsilon_{t}, & \operatorname{Cov}\left(\varepsilon_{t}\right)=\Sigma_{2} & \text { for } t>T_{1}
\end{array} .\right.
$$

A completely unrestricted estimation this model ignores that $\left(\Phi_{1}, \Sigma_{1}\right)$ and $\left(\Phi_{2}, \Sigma_{2}\right)$ coincide in all dimensions except those related to the monetary policy rule, and is therefore a nearly impossible task, given the limited data available in the two subperiods. An elegant solution is to use a Del Negro-Schorheide type of prior centered on the DSGE model with a regime change in the monetary policy rule. If we assume that the two sets of parameters $\left(\Phi_{1}, \Sigma_{1}\right)$ and $\left(\Phi_{2}, \Sigma_{2}\right)$ are a priori independent conditional on the parameters of the DSGE model, then the results in Del Negro and Schorfheide (2004) are easily generalized to the extended model in (B.2). Although it is straightforward to use different prior tightness in the two subperiods, we restrict $\lambda$ to be the same for all $t$. Note also that $\lambda_{\min }=(k+n) / \min \left(T_{1}, T_{2}\right)$, which may be rather large when at least one of $T_{1}$ or $T_{2}$ are small.

\section{B.2. VAR approximation error}

The first step in the analysis is to determine how well a VAR/VECM with finite lag length can approximate the DSGE model. To investigate this we compare the autocovariance function of the DSGE-VAR and DSGE-VECM with $\lambda=\infty$ (i.e. where $\Phi=\Phi^{*}(\theta)$ and $\Sigma_{u}=\Sigma_{u}^{*}(\theta)$ ) to the autocovariance function of the DSGE model with the modified UIP. ${ }^{27}$ We use the posterior mode of the DSGE model as an estimate of $\theta$. The results for a VAR/VECM with four lags are displayed in Figure $8 .^{28}$ The general impression from Figure A.8 is that the VAR(4) is rather successful in approximating the autocovariances of the individual variables (diagonal subgraphs), but is not able to capture several of the cross-covariances between the variables.

\footnotetext{
${ }^{26}$ This is a conjugate prior, so that the posterior of $\Phi$ and $\Sigma_{u}$ also belongs to the Normal-Inverted Wishart family, again conditional on $\theta$. This makes it possible to obtain a closed form expression for the marginal posterior of $\theta$ (see Del Negro and Schorfheide, 2004). Posterior sampling from the marginal posterior of $\theta$ may then be performed in exactly the same way as in the pure DSGE model. The main difference being that the time-consuming Kalman filtering of the state variables in the DSGE model are replaced by the less demanding computation of the DSGE cross-moments (see Del Negro and Schorfheide, 2004 for details on how these moments are computed by solving Lyapunov equations).

${ }^{27}$ The autocovariance function for the VECMs were computed from the MA representation of $\mathrm{I}(1)$ processes (the so called Granger representation) using the explicit expressions in Hansen (2005). The MA coefficients were truncated after 500 lags.

${ }^{28}$ In order to make the subplots visible we report results for a subset of variables included in the estimation but it is important to note that all variables are included in the VARs when computing the vector autocovariances.
} 
Note that the VAR by construction gives identical autocovariances as the DSGE model up to lag $p$, the lag length in the VAR. Experiments with a longer lag length in the VAR/VECM showed an increasing accuracy in the approximation, but we continue to use $p=4$ in the ensuing analysis as a longer lag length is unsuitable for estimation given the relatively short data set. Turning to the VECM(4) approximation in Figure A.8, it seems that the addition of cointegrating relations to the VAR helps to improve the approximation to the DSGE model.

\section{B.3. Assessing the role of the UIP condition}

In order to examine the quantitative role of the modified UIP condition when the cross equation restrictions have been optimally relaxed, we compare in Figure A.9 the cross correlation functions in the DSGE-VECM model with the standard (solid) and modified UIP (dashed) condition for the optimal lambda $(\widehat{\lambda}=7)$. The figure also reports the standard deviation of the variables in the model with the standard UIP condition (in the bottom of the subgraphs) and in the model with the modified UIP condition (to the right of the subgraphs). From the figure we see that there are some differences remaining between the two specifications also in the hybrid model. In particular there are still differences between the cross correlations pertaining to the real exchange rate, although the induced volatility in the real exchange rate is a lot more similar between the two specifications of the VECM relative to the recorded difference between the structural DSGE models (cf. Figure A.9 and Table A.2 in this Appendix). However, the marginal likelihood comparison in Table 2 in the main paper suggest that the discrepancies in Figure A.9 are not jointly very important. 
Table A.1: Posterior mode estimates under different sizes of measurement errors

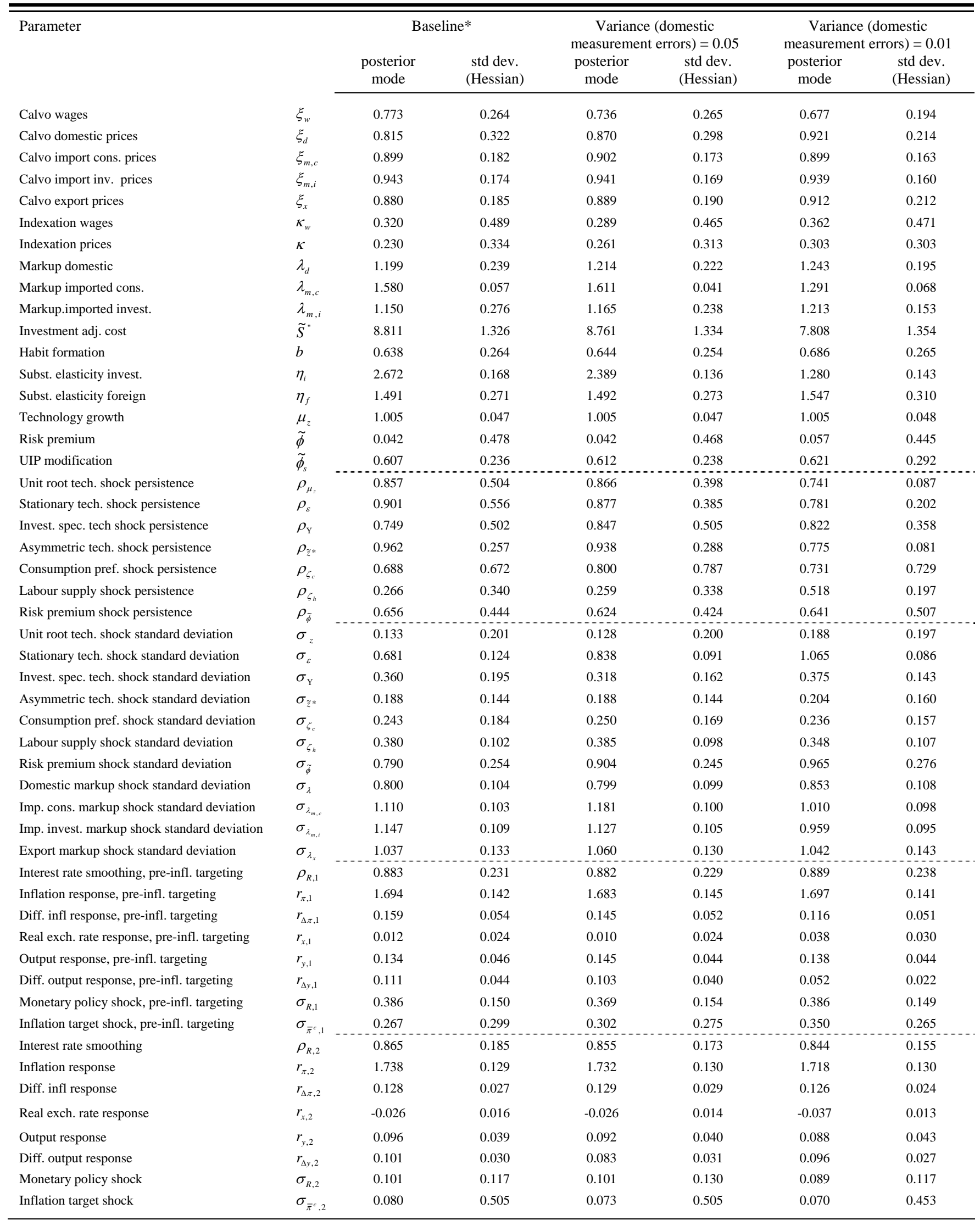

*Note: The variance of the measurement errors in the baseline estimation is set to 0 for the foreign variables and the domestic interest rate, 0.1 percent for the real wage, consumption and output, and 0.2 percent for all the other variables. 
Table A.2: Second moments for the real exchange rate, data and model

\begin{tabular}{lccc}
\hline \hline & Data (86Q1-04Q4) & Model standard UIP & Model modified UIP \\
\cline { 2 - 4 } & 9.28 & $5.92(3.79-9.52)$ & $14.54(7.34-27.79)$ \\
Standard deviation & 0.97 & $0.85(0.67-0.94)$ & $0.97(0.93-0.99)$ \\
Autocorrelation & &
\end{tabular}

Note: For the model the median and 95 percent uncertainty intervals (in parenthesis) are reported from simulating the two model specifications 10.000 times with 76 periods each using different draws from the posterior distribution every time. 
Figure A.1a: Prior and posterior distributions, friction parameters
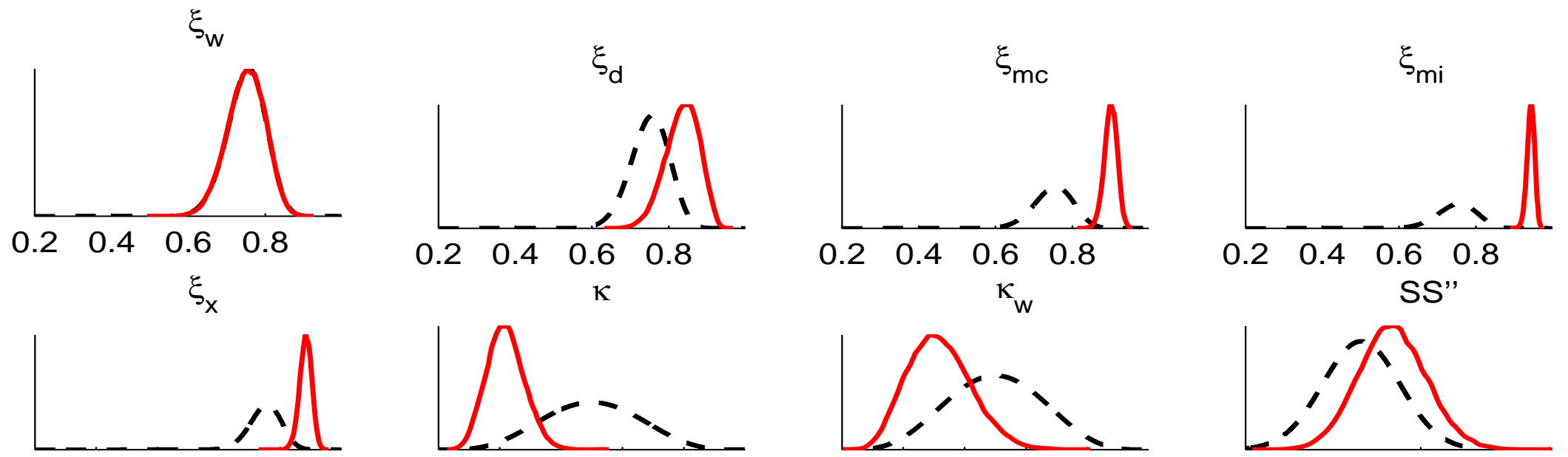

$\begin{array}{llll}0.2 & 0.4 & 0.6 & 0.8\end{array}$
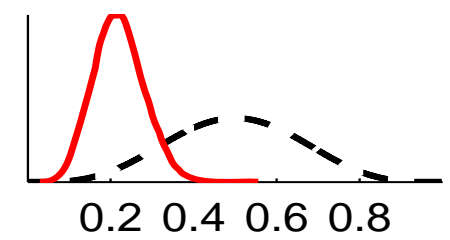

b
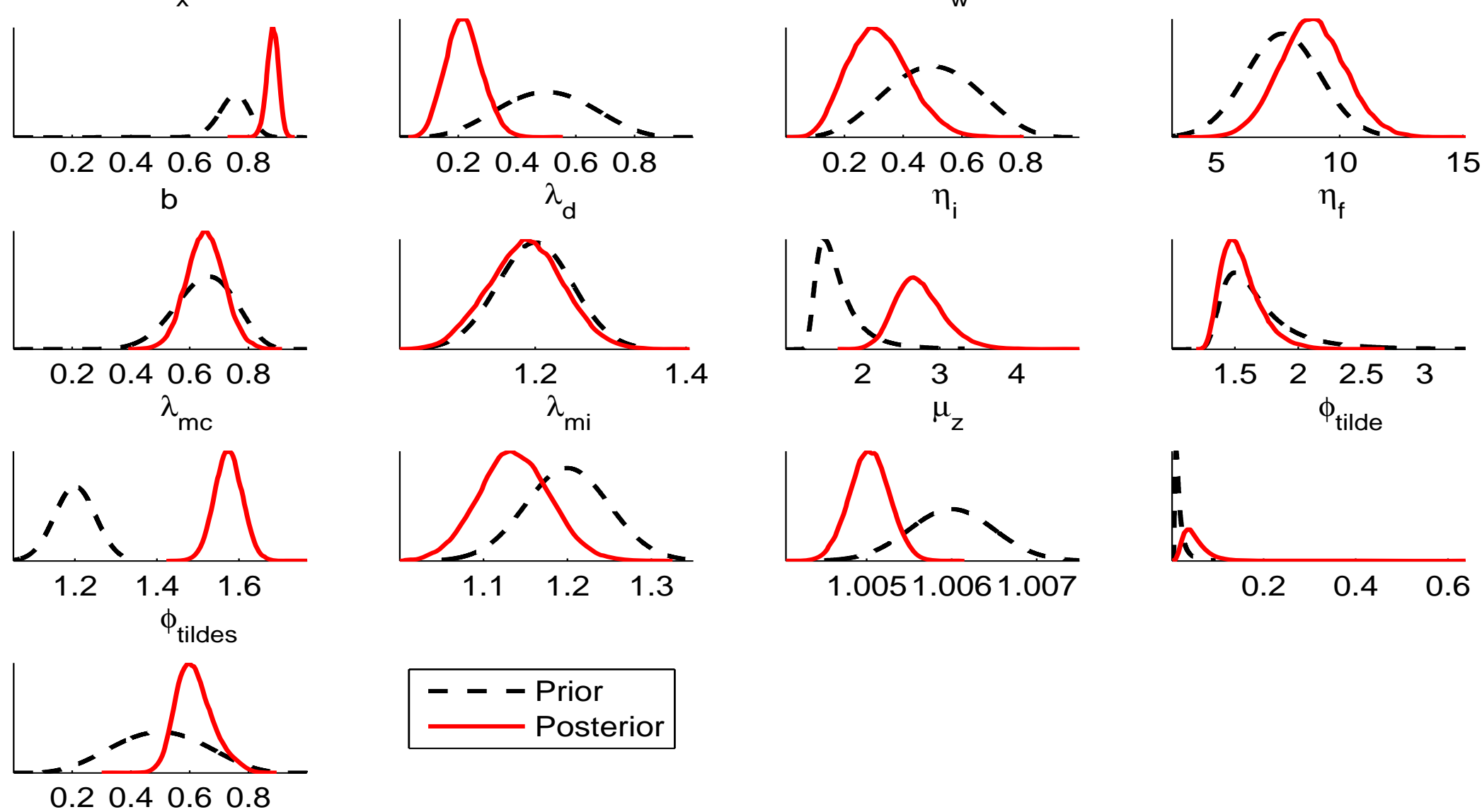

$0.20 .40 .6 \quad 0.8$ 
Figure A.1b: Prior and posterior distributions, shock parameters

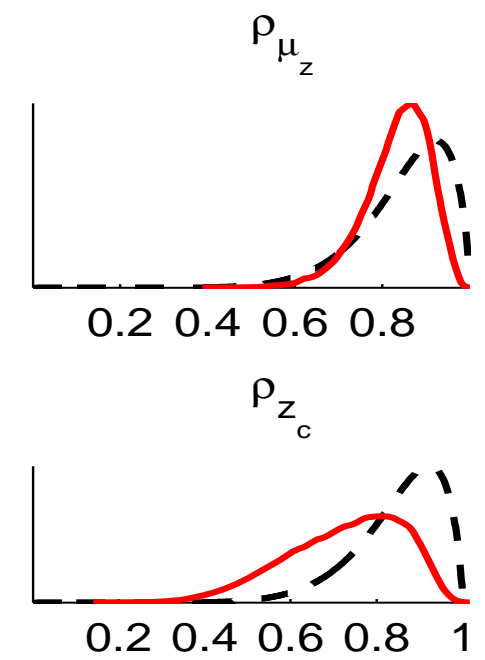

$\sigma_{\varepsilon}$
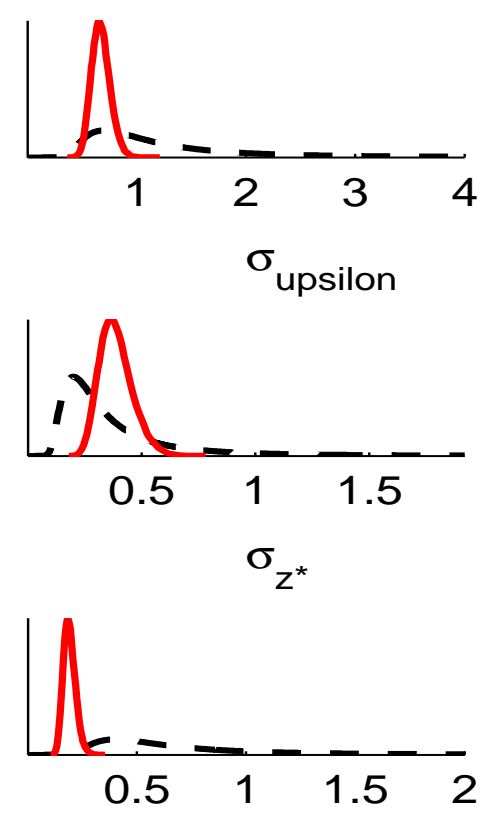

$\rho_{\varepsilon}$

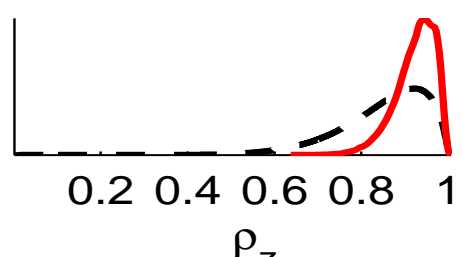

$\rho_{z_{h}}$
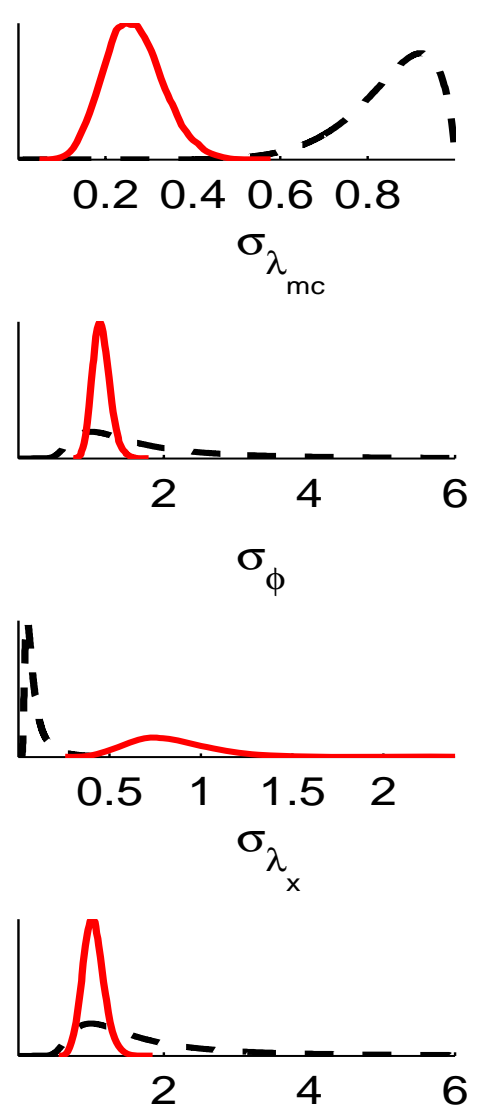

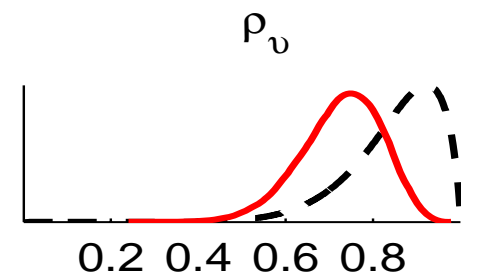

$\rho_{z^{*}}$
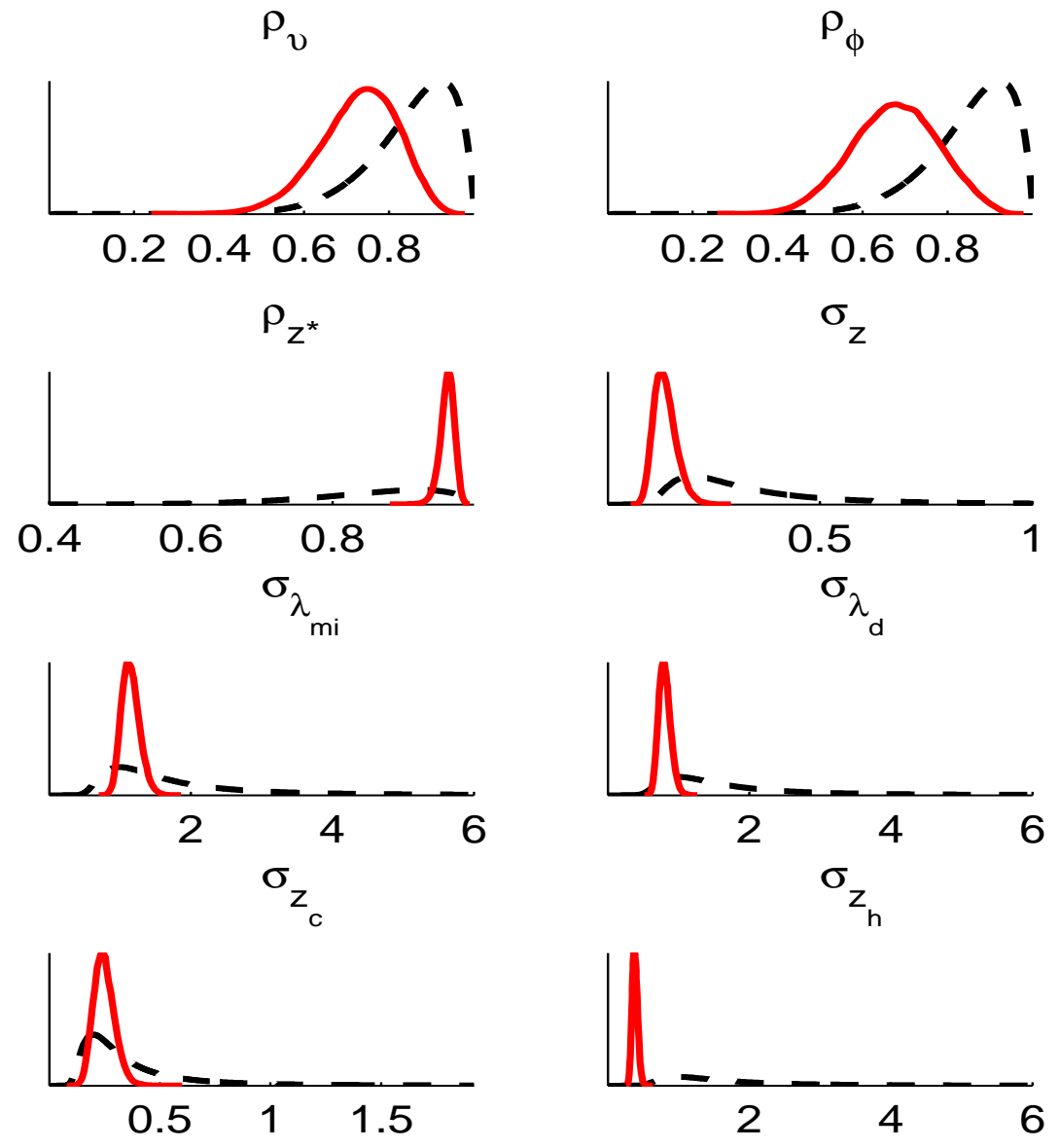

\begin{tabular}{l}
\hline-- Prior \\
\hline Posterior
\end{tabular} 
Figure A.1c: Prior and posterior distributions, policy parameters
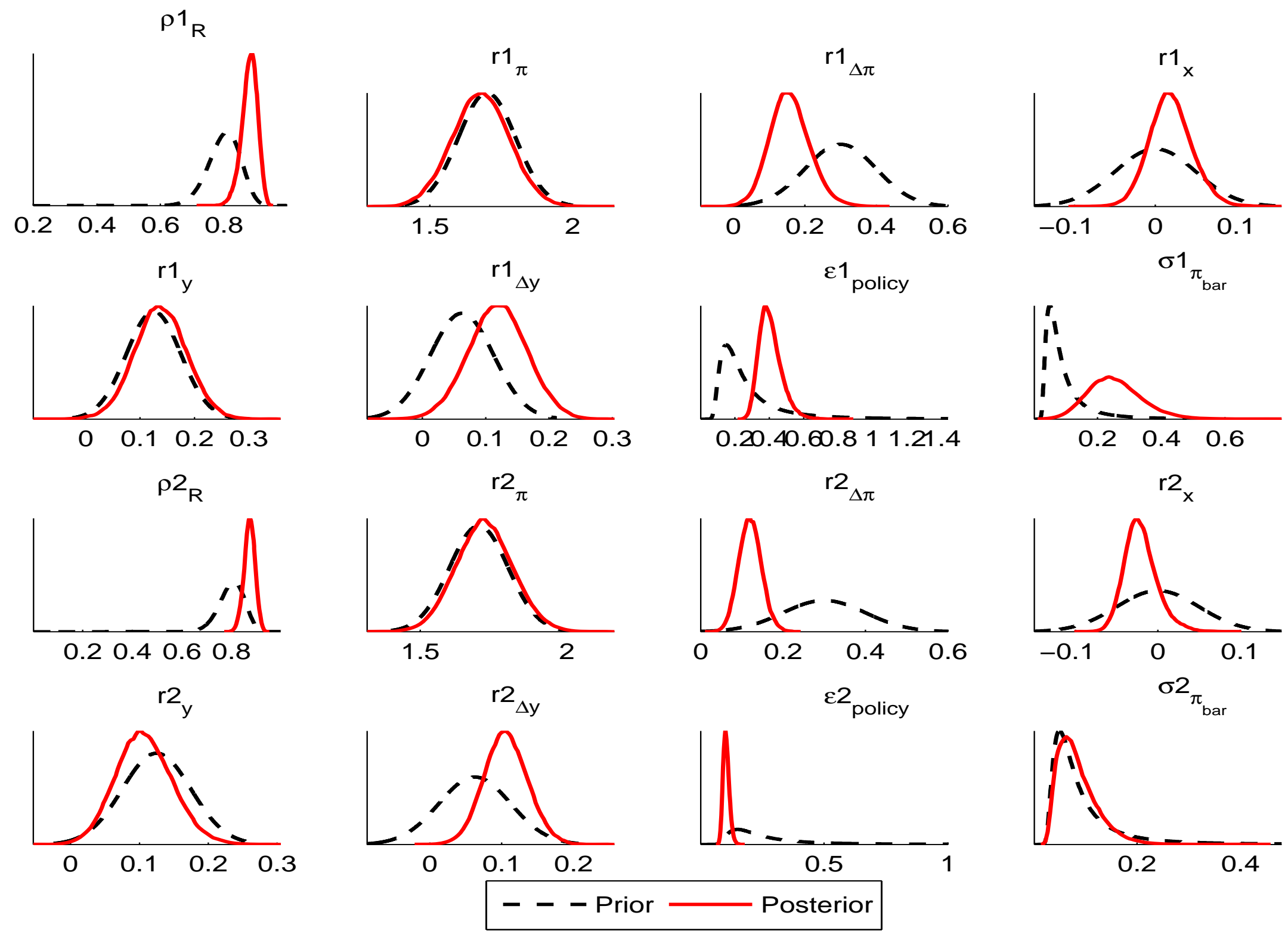
Figure A.2a: Plots of the raw Metropolis draws, friction parameters

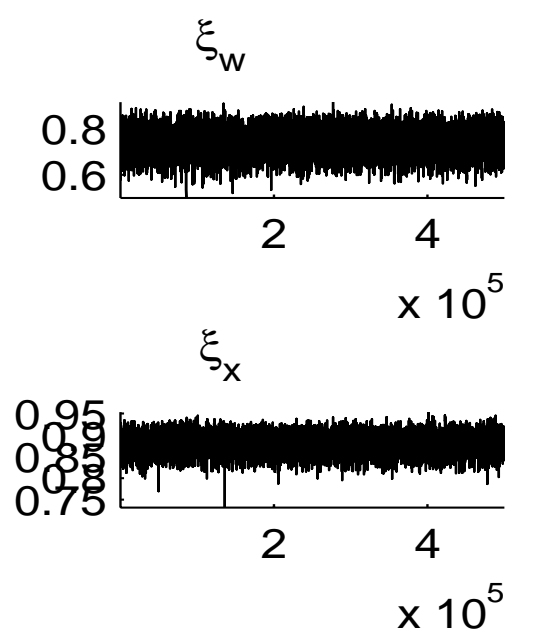

b
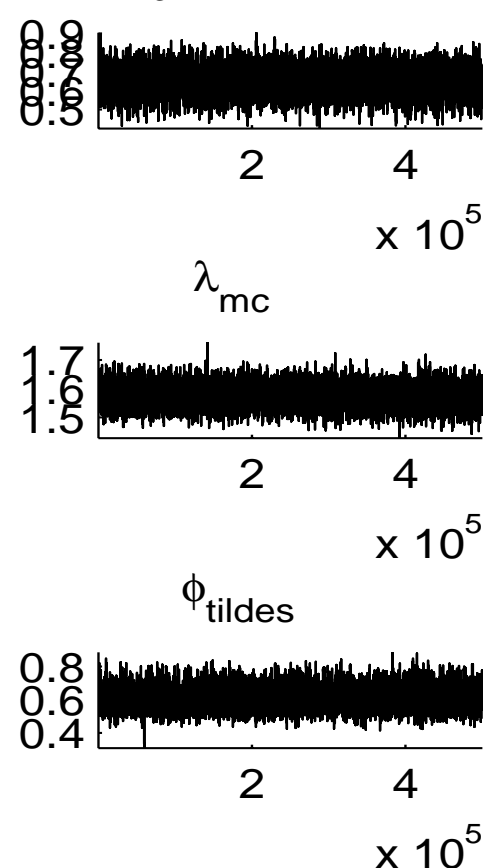

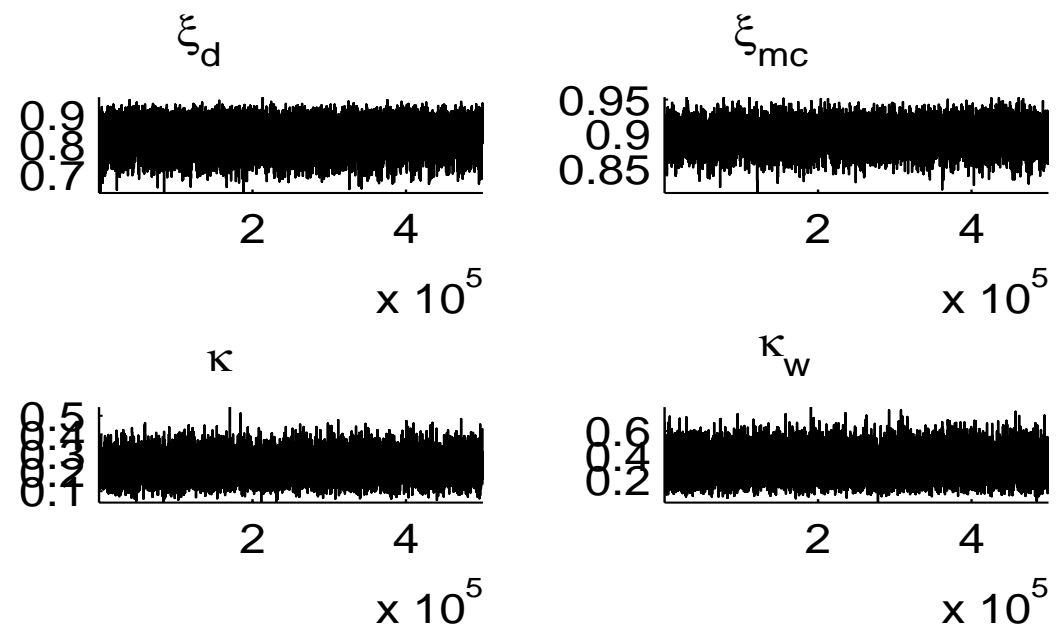

$\eta_{\mathrm{i}}$
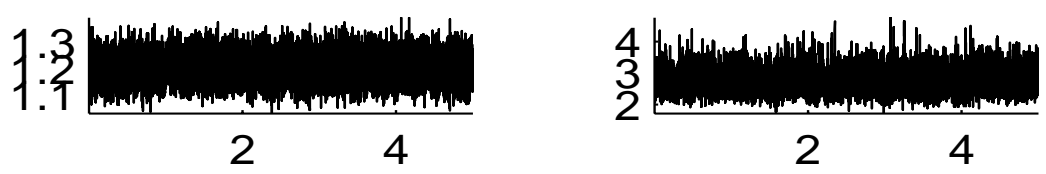

$\times 10^{5}$

$\lambda_{\mathrm{mi}}$

1.3

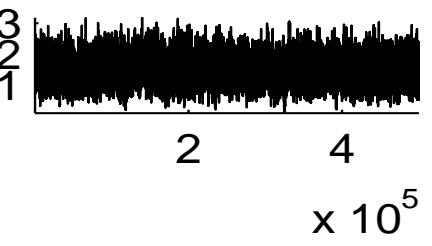

1.08955

$10^{5}$

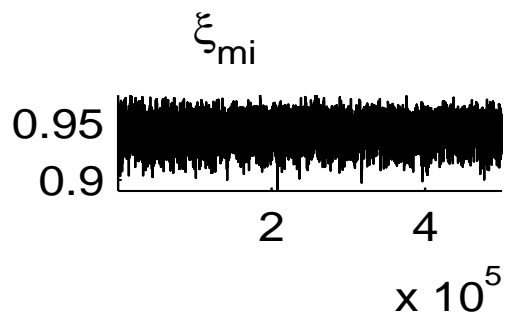

SS"

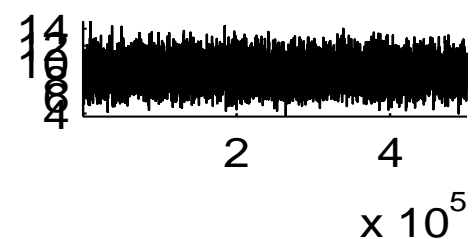

$\eta_{f}$

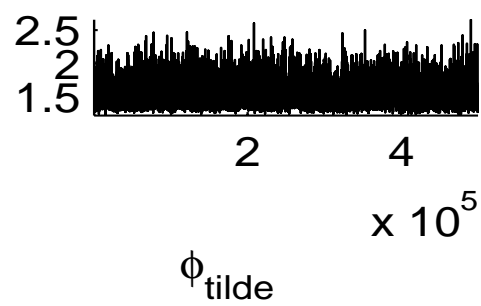

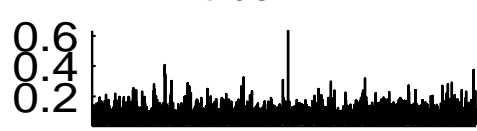

24

$\times 10^{5}$ 
Figure A.2b: Plots of the raw Metropolis draws, shock parameters

$\rho_{\mu}$

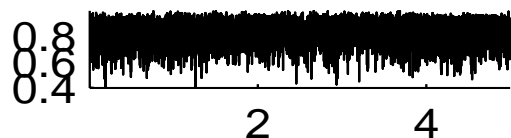
$\times 10^{5}$

$\rho_{z_{c}}$

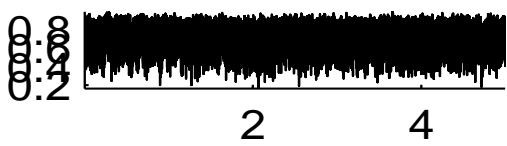

$$
\times 10^{5}
$$

$\sigma_{\varepsilon}$

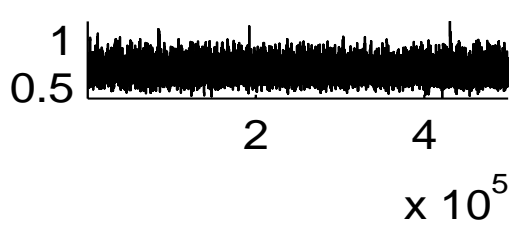

$\sigma_{\text {upsilon }}$

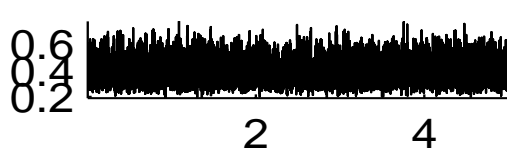

$\times 10^{5}$ $\rho_{\varepsilon}$

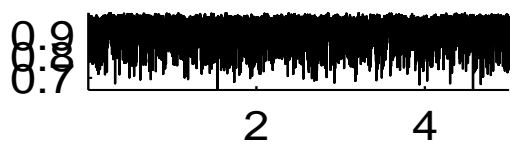

$\times 10^{5}$

$\rho_{z_{h}}$

䐺

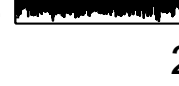

2

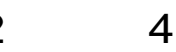

$\times 10^{5}$

$\sigma_{\lambda \mathrm{mc}}$

18
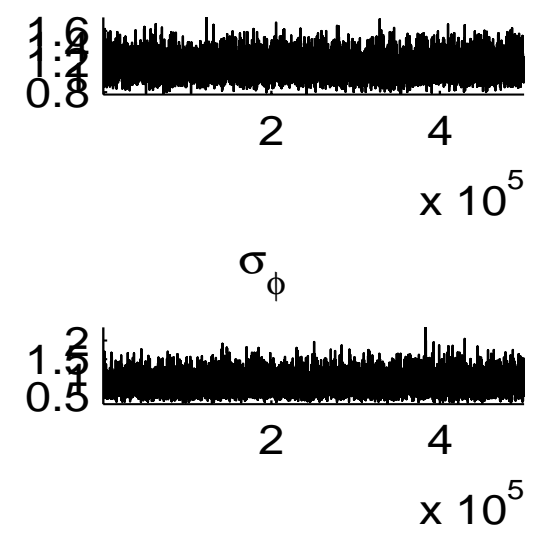

$\sigma_{\lambda}$ $\rho_{v}$

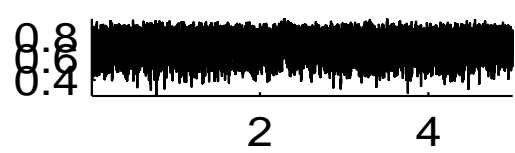

$\times 10^{5}$

$\rho_{z^{*}}$

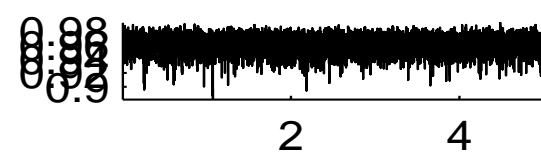

$\times 10^{5}$

$\sigma_{\lambda_{\mathrm{mi}}}$

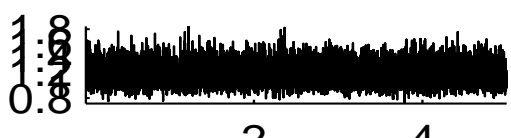

2

4

$\times 10^{5}$

$\sigma_{z_{c}}$

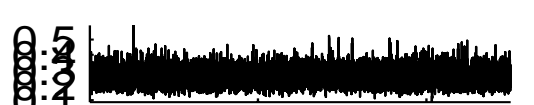

2

4

$\times 10^{5}$ $\rho_{\phi}$

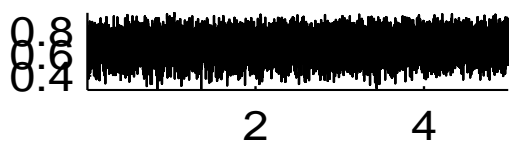

$\times 10^{5}$

$\sigma_{z}$

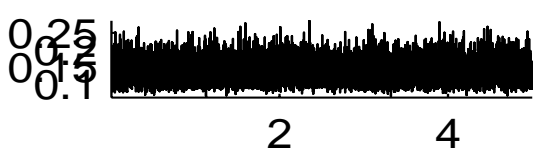

$\times 10^{5}$

$\sigma_{\lambda_{d}}$
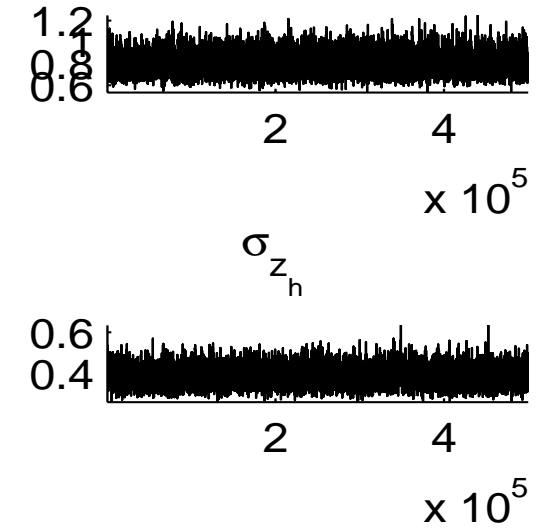

8.8

$\sigma_{z^{*}}$

1:

24

$\times 10^{5}$

24

$\times 10^{5}$ 
Figure A.2c: Plots of the raw Metropolis draws, policy parameters

$\rho 1_{R}$

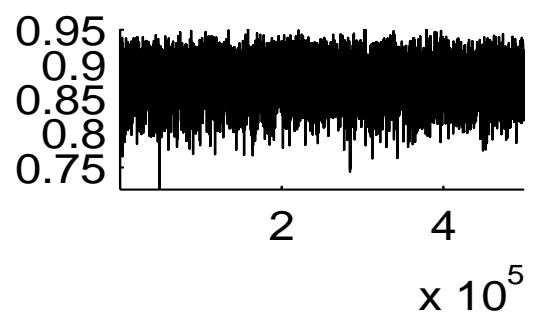

$r_{y}$

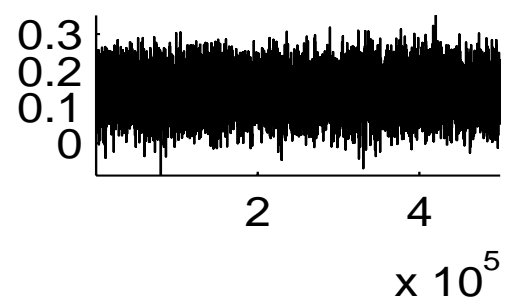

$\rho 2_{R}$

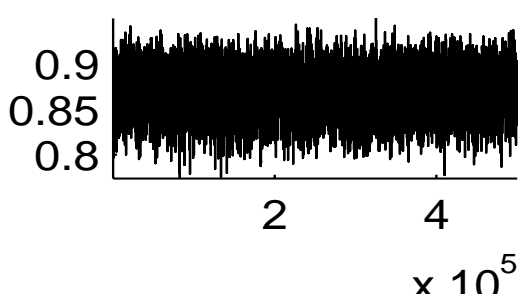

r2 $y$

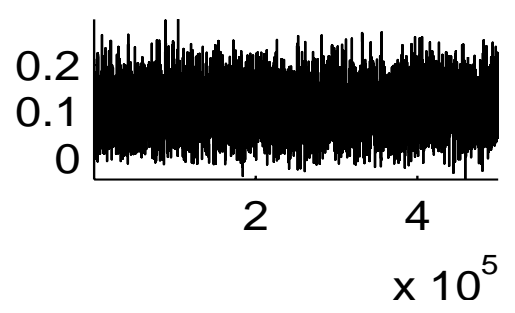

$\mathrm{r}_{\pi}$

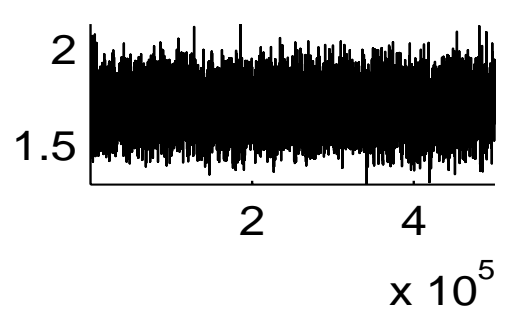

$r 1_{\Delta y}$

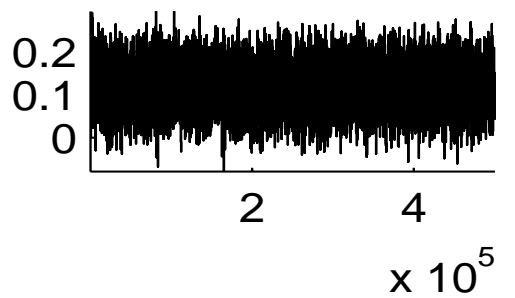

$\mathrm{r}_{\pi}$

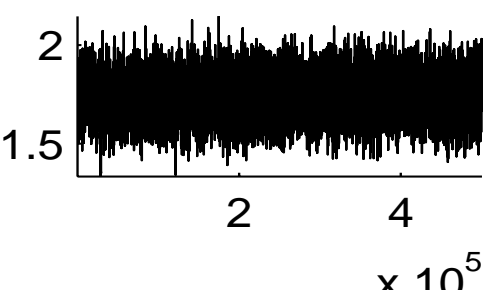

$r{ }_{\Delta y}$

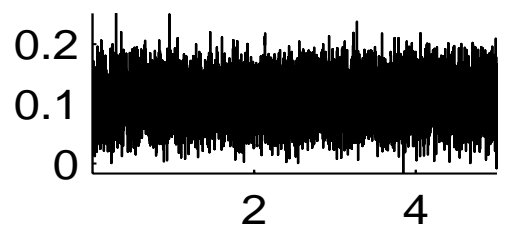

$\times 10^{5}$
$\mathrm{r}_{\Delta \pi}$

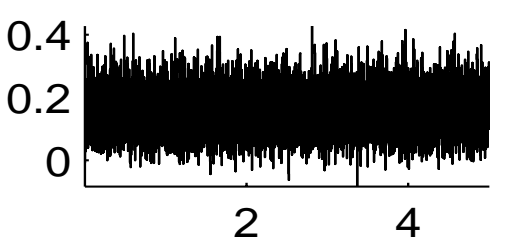

$\times 10^{5}$

$\varepsilon 1_{\text {policy }}$

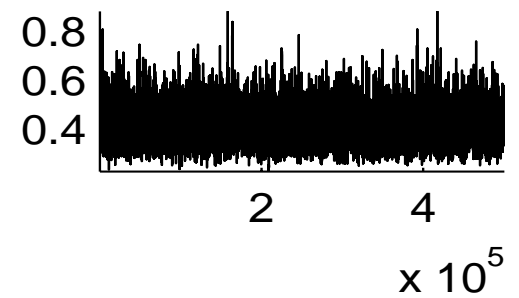

$\mathrm{r}_{\Delta \pi}$

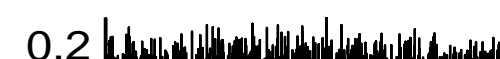
0.15 0.1 (innm

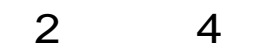

$\times 10^{5}$

$\varepsilon 2_{\text {policy }}$

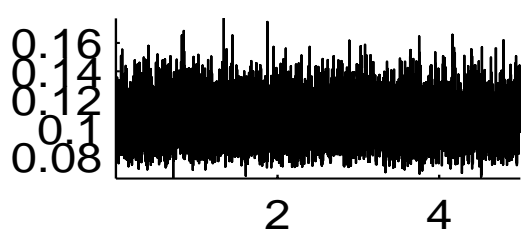

$\times 10^{5}$

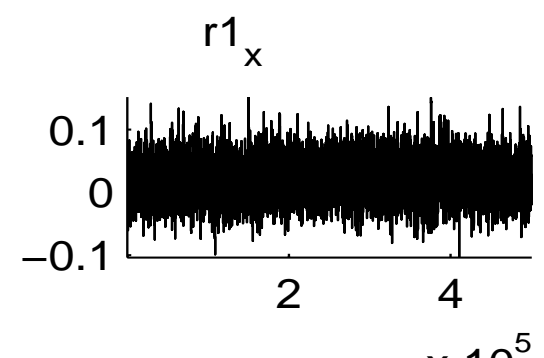

$\sigma 1_{\text {bar }}$

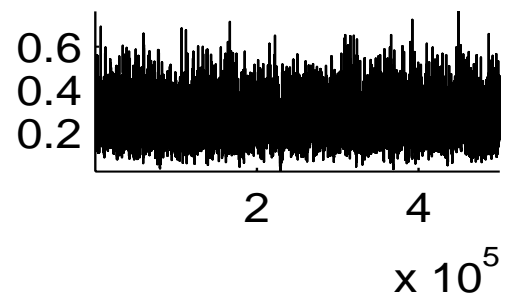

$r^{2} x$
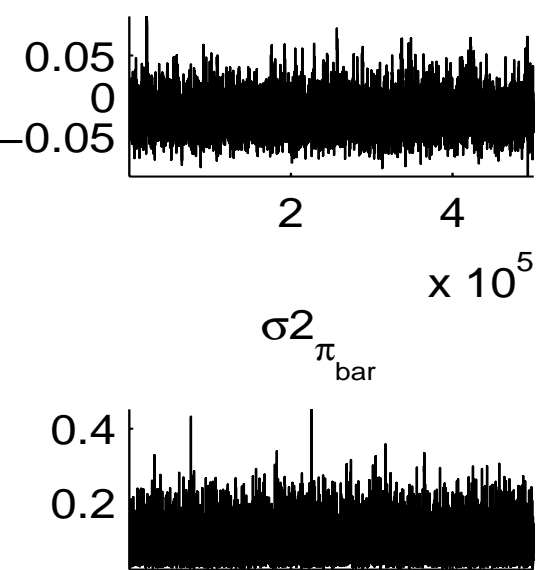

24

$\times 10^{5}$ 
Figure A.3a: CUSUM plots of the Metropolis draws, friction parameters
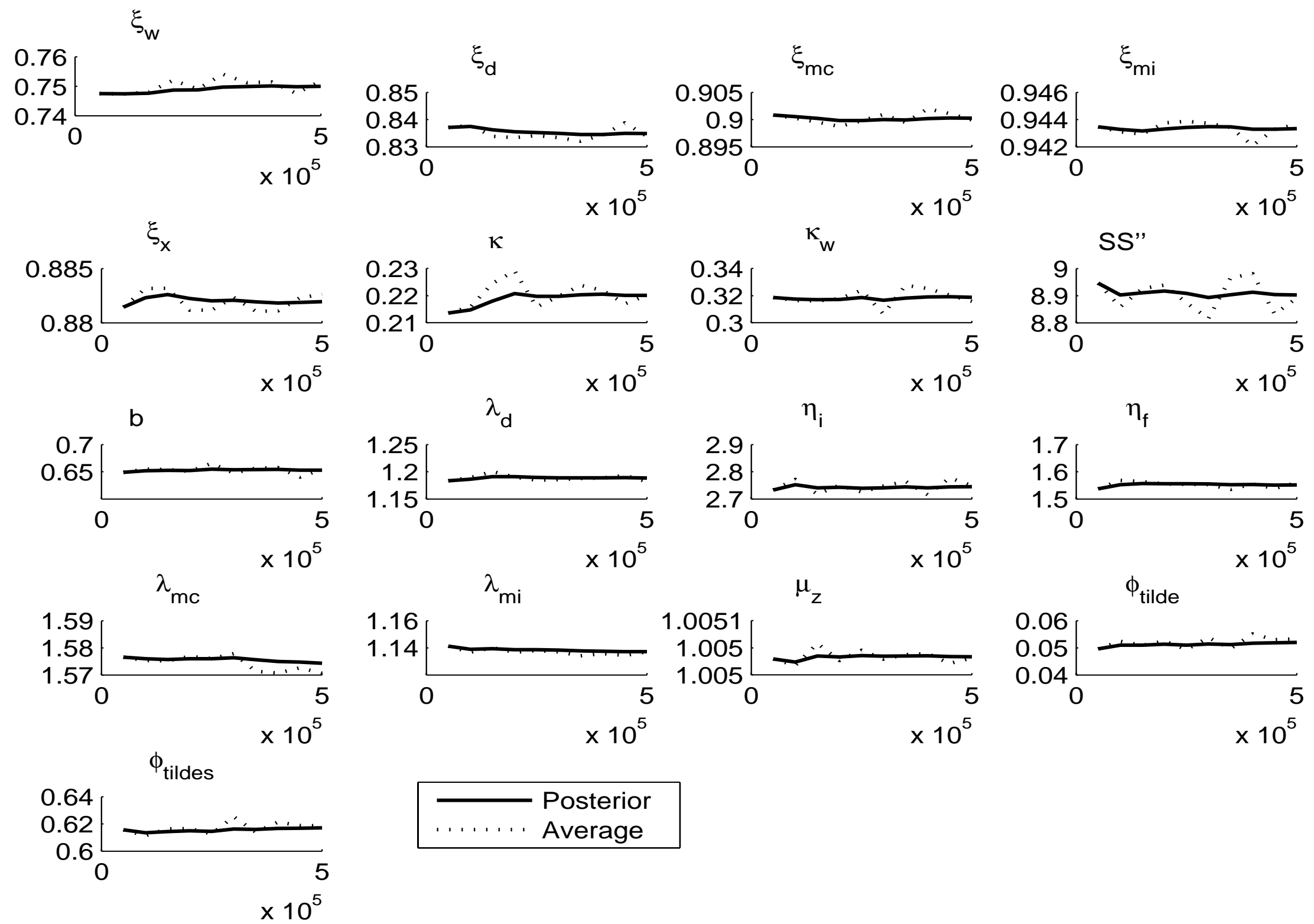
Figure A.3b: CUSUM plots of the Metropolis draws, shock parameters
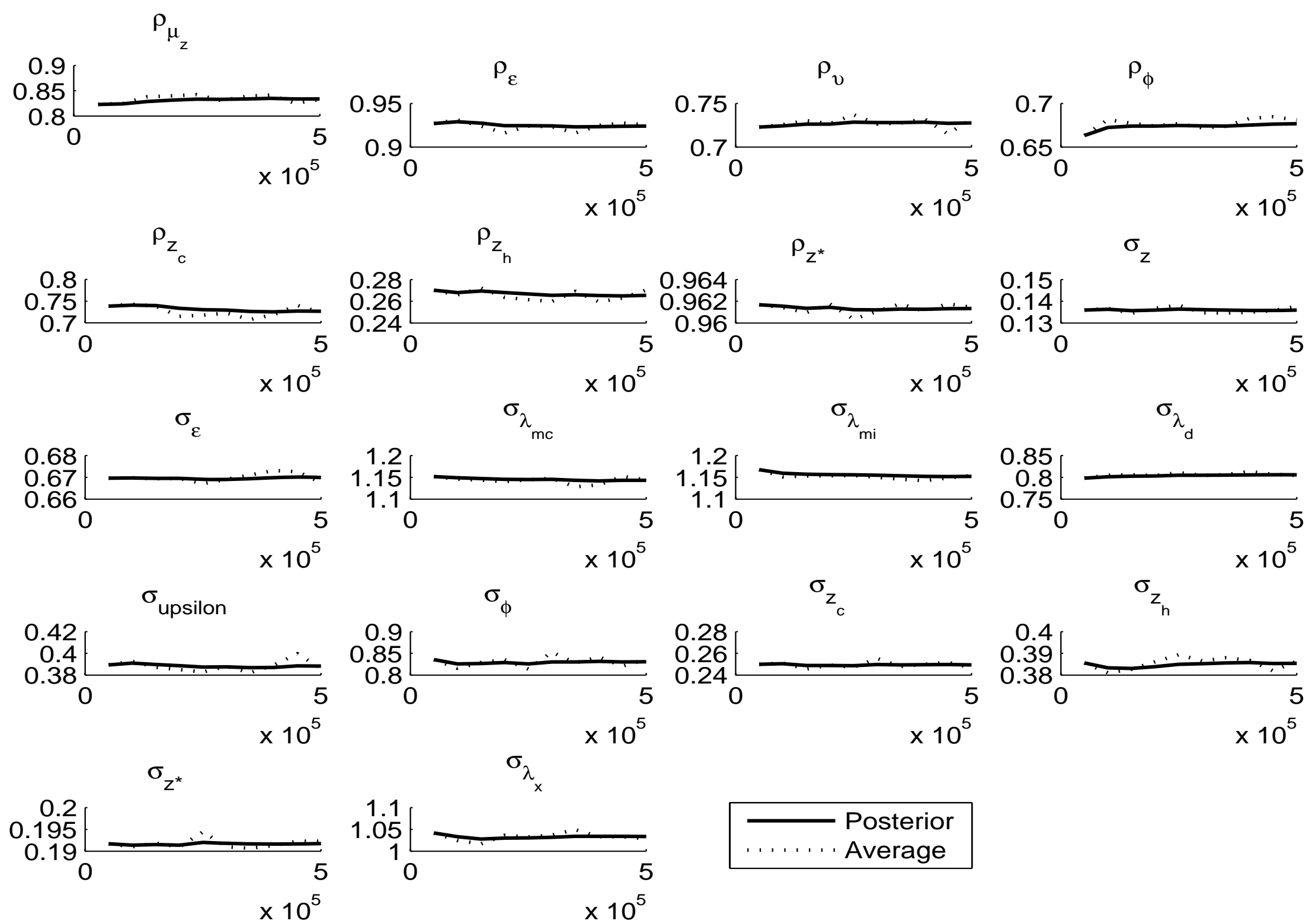
Figure A.3c: CUSUM plots of the Metropolis draws, policy parameters
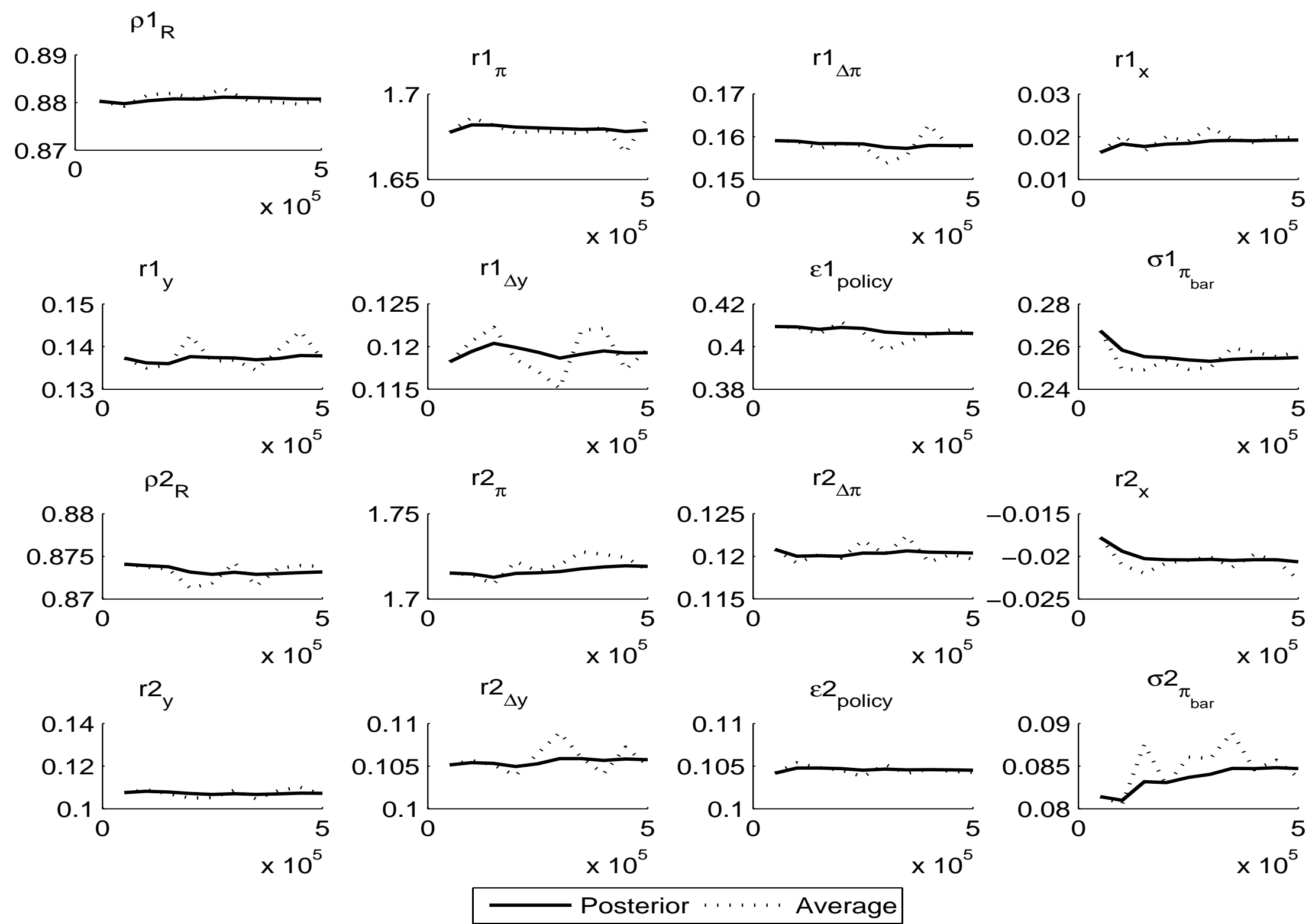
Figure A.4: Sequential marginal likelihoods

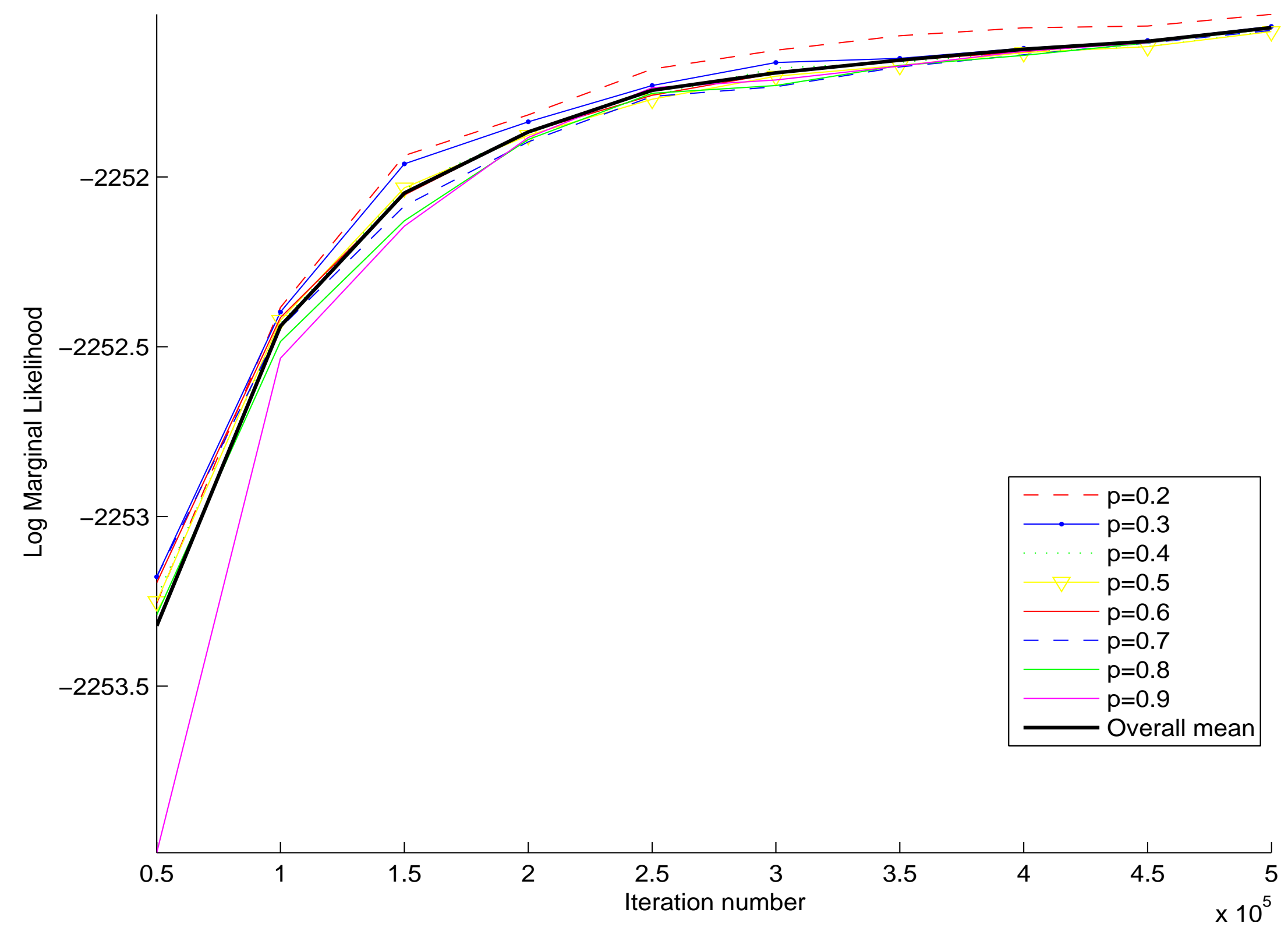


Figure A.5: Multivariate ANOVA
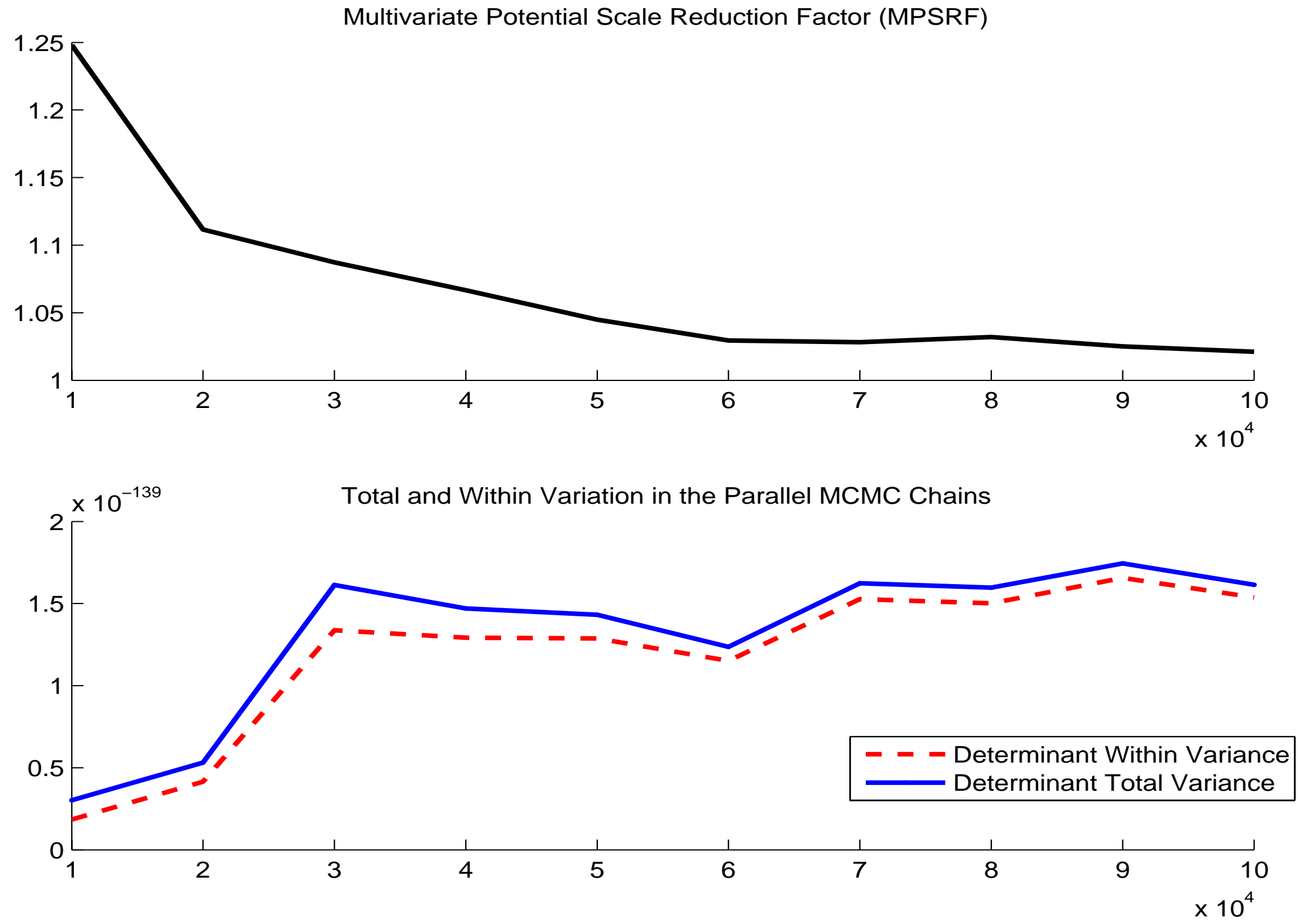

Note: The analysis is based on four Metropolis chains with different inital values and 500,000 draws each, subsampling every 5 th draw. 
Figure A.6a: Log likelihood contours in the $\left\{\widetilde{\phi}_{s}, \rho_{\phi}\right\}$-space, using all observable variables

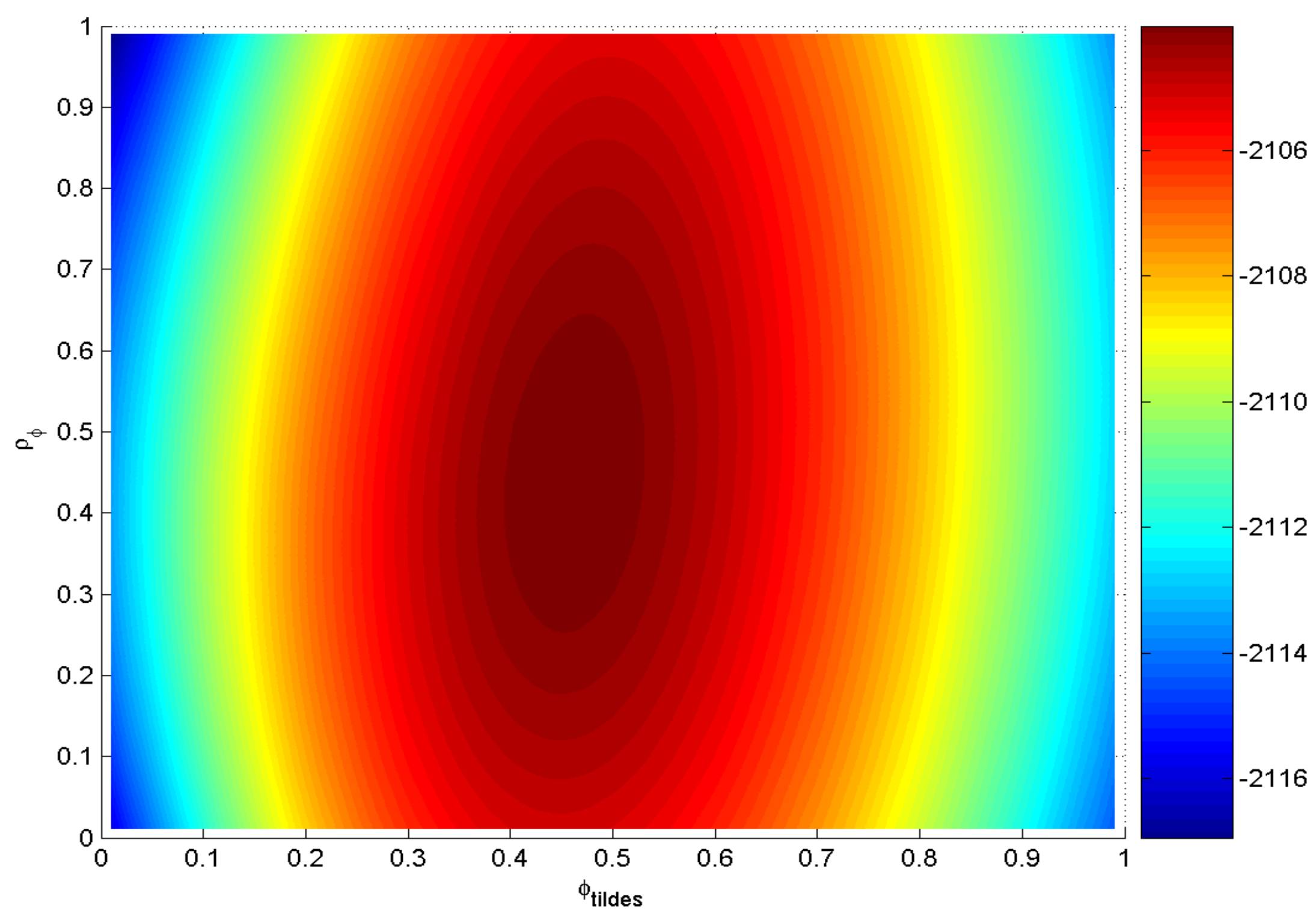


Figure A.6b: Log likelihood contours in the $\left\{\widetilde{\phi}_{s}, \rho_{\phi}\right\}$-space, only using the real exchange rate

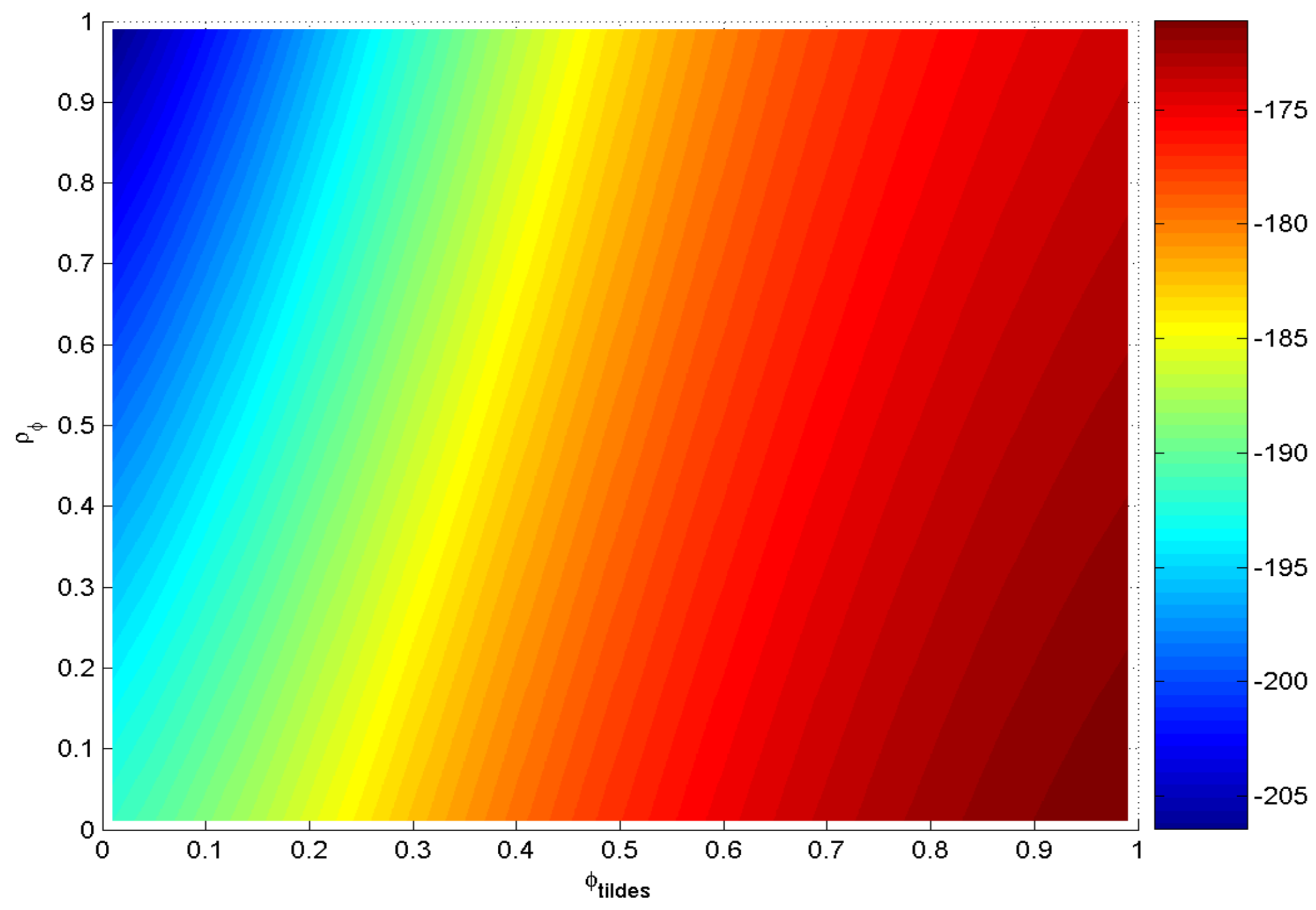


Figure A.7: Data (solid) and two-sided Kalman filtered estimates (dashed)
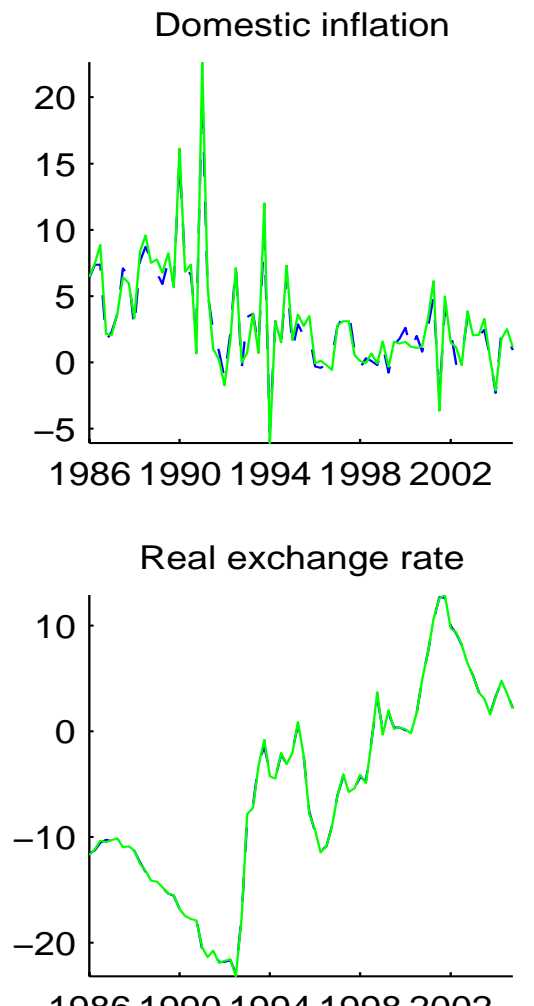

Export

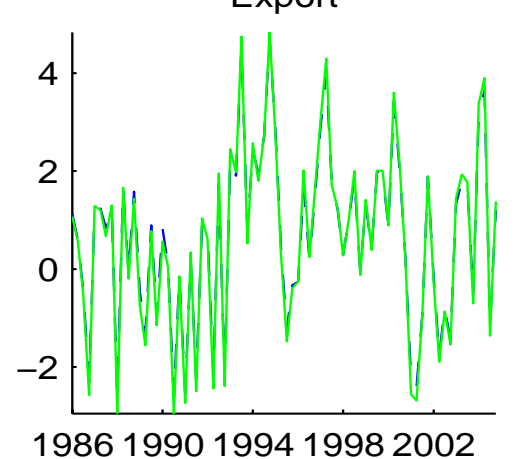

Real wage
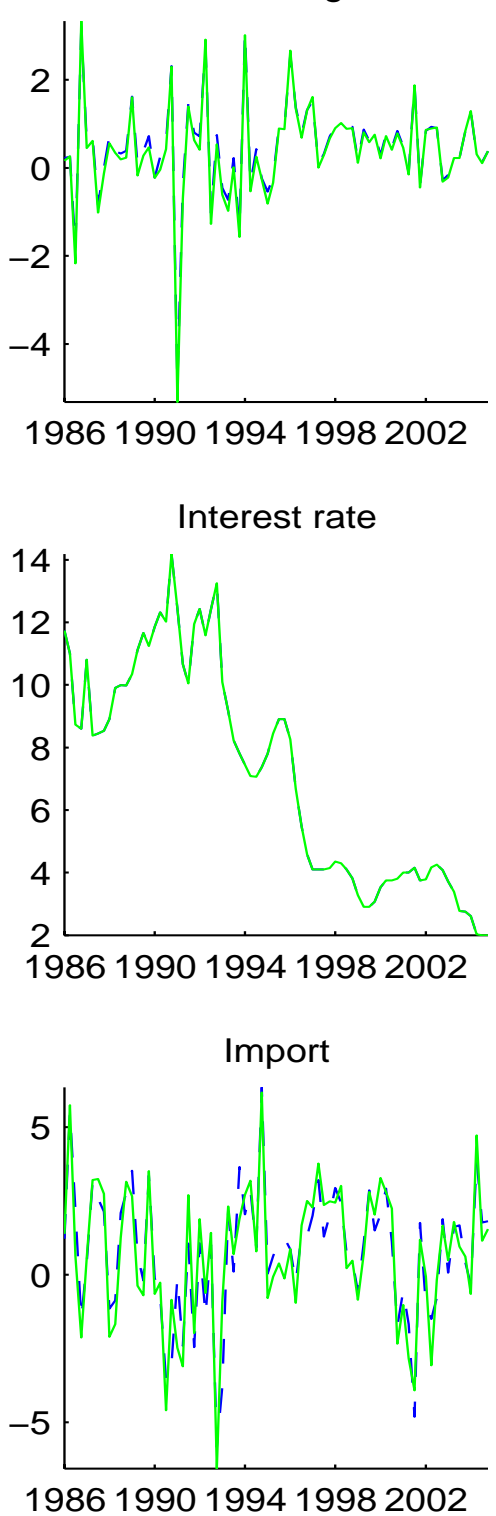

Consumption

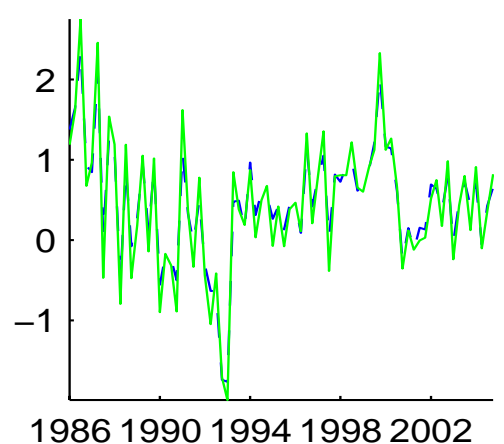

Hours worked

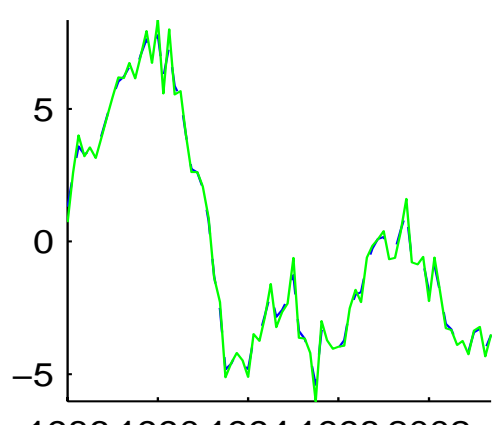

19861990199419982002

CPI inflation

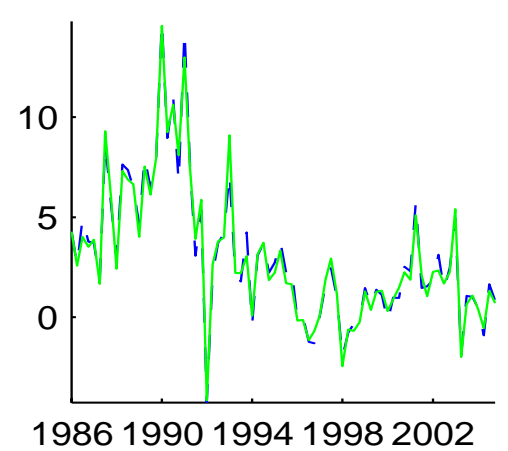

Investment

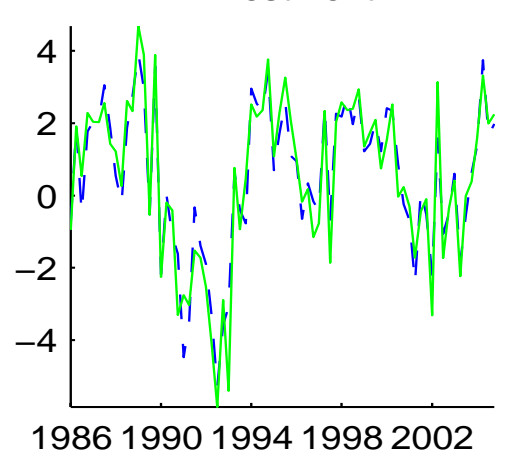

Output

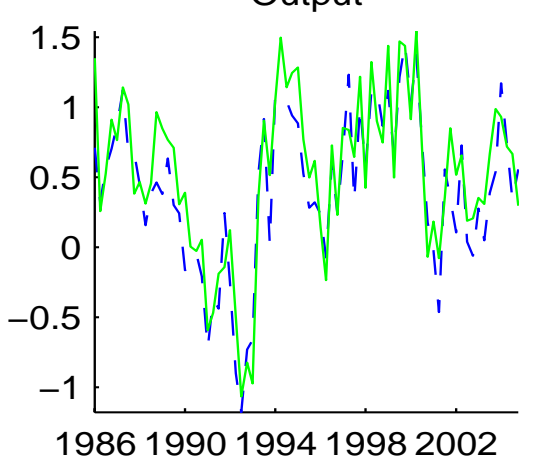
19861990199419982002 
Figure A.8: Vector autocovariance functions in the DSGE model with the modified UIP condition (solid), DSGE-VAR $\lambda=\infty$ (dotted) and DSGE-VECM $\lambda=\infty$ (dashed)

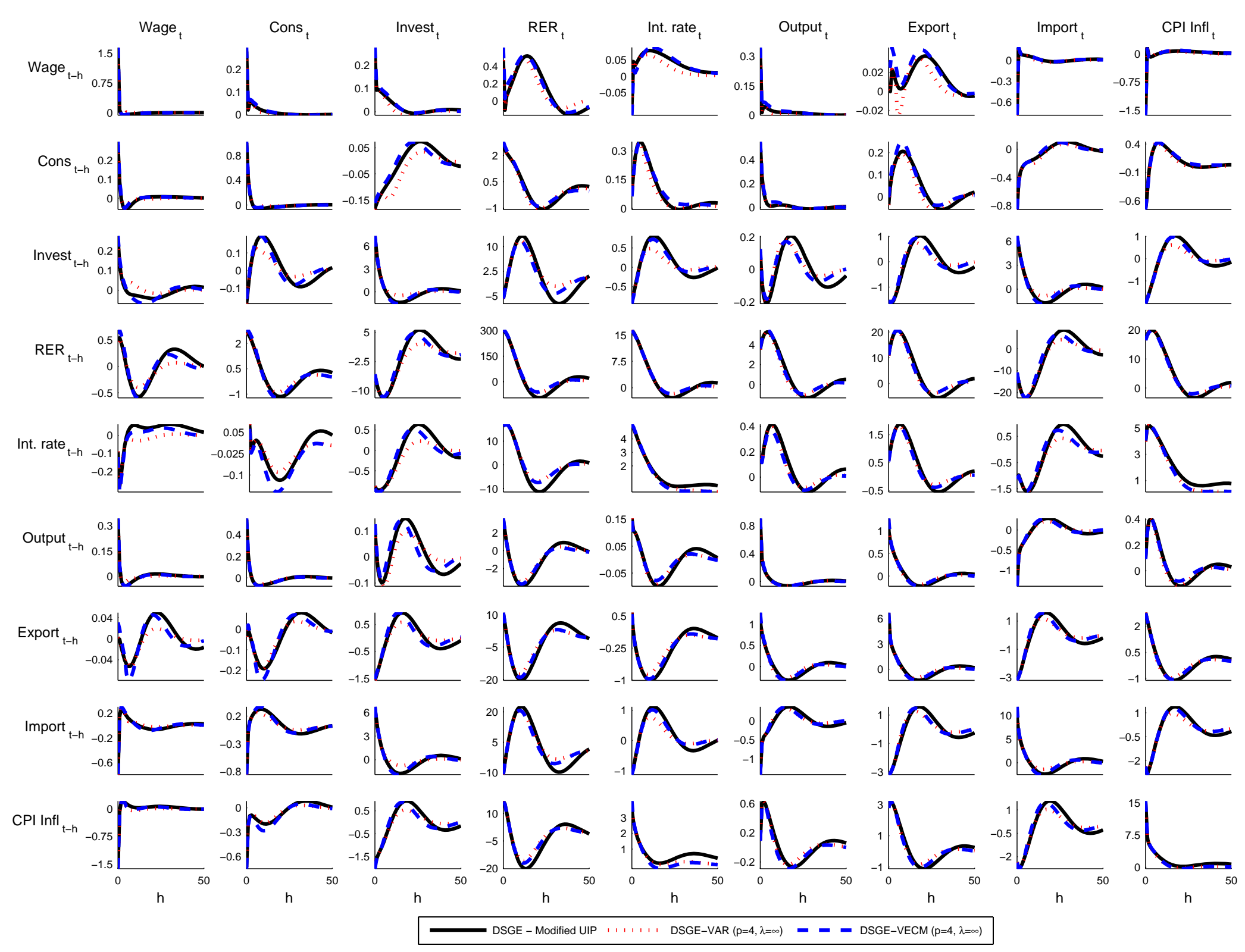


Figure A.9: Cross-correlation functions (CCF) from the DSGE-VECM $\lambda=\hat{\lambda}$ with the UIP (solid) and the modified UIP (dashed) condition. The subgraphs below the diagonal display the cross-correlation between the column variable and the lag of the row variable. The opposite order applies to the upper diagonal graphs. The CCFs are computed at the posterior mode estimates of the parameters within each model. The numbers in the bottom of the graphs are the standard deviations of the respective variable in UIP case. The corresponding standard deviations for the model with the modified UIP condition are displayed to the right of the subgraphs.
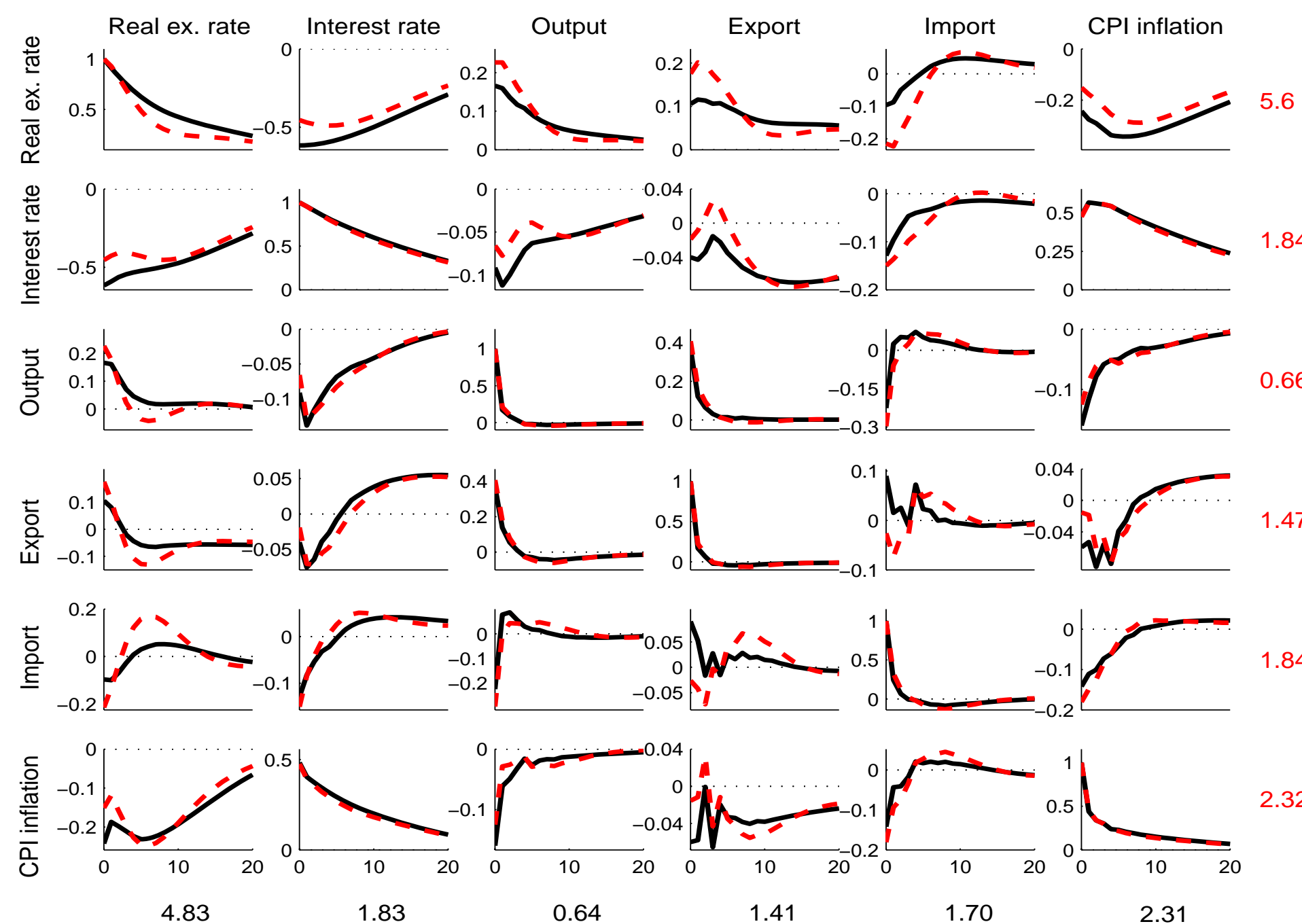


\section{Earlier Working Papers:}

For a complete list of Working Papers published by Sveriges Riksbank, see www.riksbank.se

Evaluating Implied RNDs by some New Confidence Interval Estimation Techniques

by Magnus Andersson and Magnus Lomakka....

Taylor Rules and the Predictability of Interest Rates

by Paul Söderlind, Ulf Söderström and Anders Vredin ......................................................... 2003:147

Inflation, Markups and Monetary Policy

by Magnus Jonsson and Stefan Palmqvist.....

Financial Cycles and Bankruptcies in the Nordic Countries by Jan Hansen........................................ 2003:149

Bayes Estimators of the Cointegration Space by Mattias Villani .................................................. 2003:150

Business Survey Data: Do They Help in Forecasting the Macro Economy?

by Jesper Hansson, Per Jansson and Mårten Löf

The Equilibrium Rate of Unemployment and the Real Exchange Rate:

An Unobserved Components System Approach by Hans Lindblad and Peter Sellin ........................ 2003:152

Monetary Policy Shocks and Business Cycle Fluctuations in a

Small Open Economy: Sweden 1986-2002 by Jesper Lindé

Bank Lending Policy, Credit Scoring and the Survival of Loans by Kasper Roszbach .......................... 2003:154

Internal Ratings Systems, Implied Credit Risk and the Consistency of Banks' Risk

Classification Policies by Tor Jacobson, Jesper Lindé and Kasper Roszbach .................................. 2003:155

Monetary Policy Analysis in a Small Open Economy using Bayesian Cointegrated

Structural VARs by Mattias Villani and Anders Warne

Indicator Accuracy and Monetary Policy: Is Ignorance Bliss? by Kristoffer P. Nimark ........................ 2003:157

Intersectoral Wage Linkages in Sweden by Kent Friberg .......................................................... 2003:158

Do Higher Wages Cause Inflation? by Magnus Jonsson and Stefan Palmqvist ............................. 2004:159

Why Are Long Rates Sensitive to Monetary Policy by Tore Ellingsen and Ulf Söderström .................. 2004:160

The Effects of Permanent Technology Shocks on Labor Productivity

and Hours in the RBC model by Jesper Lindé........................................................................ 2004:161

Credit Risk versus Capital Requirements under Basel II: Are SME Loans and Retail

Credit Really Different? by Tor Jacobson, Jesper Lindé and Kasper Roszbach

Exchange Rate Puzzles: A Tale of Switching Attractors

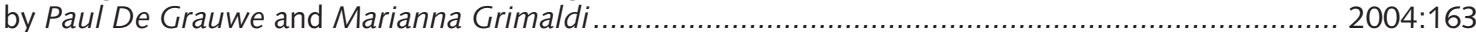

Bubbles and Crashes in a Behavioural Finance Model

by Paul De Grauwe and Marianna Grimaldi.

Multiple-Bank Lending: Diversification and Free-Riding in Monitoring

by Elena Carletti, Vittoria Cerasi and Sonja Daltung.............................................................. 2004:165

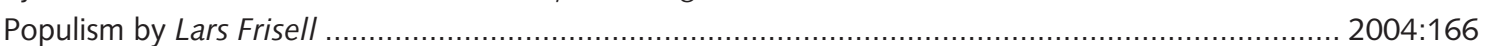

Monetary Policy in an Estimated Open-Economy Model with Imperfect Pass-Through

by Jesper Lindé, Marianne Nessén and Ulf Söderström

Is Firm Interdependence within Industries Important for Portfolio Credit Risk?

by Kenneth Carling, Lars Rönnegård and Kasper Roszbach

$2004: 168$

How Useful are Simple Rules for Monetary Policy? The Swedish Experience

by Claes Berg, Per Jansson and Anders Vredin

The Welfare Cost of Imperfect Competition and Distortionary Taxation

by Magnus Jonsson

A Bayesian Approach to Modelling Graphical Vector Autoregressions

by Jukka Corander and Mattias Villani

Do Prices Reflect Costs? A study of the price- and cost structure of retail payment

services in the Swedish banking sector 2002 by Gabriela Guibourg and Biörn Segendorf

Excess Sensitivity and Volatility of Long Interest Rates: The Role of Limited

Information in Bond Markets by Meredith Beechey.

State Dependent Pricing and Exchange Rate Pass-Through

by Martin Flodén and Fredrik Wilander.

The Multivariate Split Normal Distribution and Asymmetric Principal

Components Analysis by Mattias Villani and Rolf Larsson

Firm-Specific Capital, Nominal Rigidities and the Business Cycle

by David Altig, Lawrence Christiano, Martin Eichenbaum and Jesper Lindé

Estimation of an Adaptive Stock Market Model with Heterogeneous Agents by Henrik Amilon ........ 2005:177

Some Further Evidence on Interest-Rate Smoothing: The Role of Measurement

Errors in the Output Gap by Mikael Apel and Per Jansson...... 
Bayesian Estimation of an Open Economy DSGE Model with Incomplete Pass-Through by Malin Adolfson, Stefan Laséen, Jesper Lindé and Mattias Villani.....

Are Constant Interest Rate Forecasts Modest Interventions? Evidence from an Estimated Open Economy DSGE Model of the Euro Area by Malin Adolfson, Stefan Laséen, Jesper Lindé and Mattias Villani .... 2005:180

Inference in Vector Autoregressive Models with an Informative Prior on the Steady State by Mattias Villani.

Bank Mergers, Competition and Liquidity by Elena Carletti, Philipp Hartmann and Giancarlo Spagnolo. 2005:182

Testing Near-Rationality using Detailed Survey Data

by Michael F. Bryan and Stefan Palmqvist....

Exploring Interactions between Real Activity and the Financial Stance

by Tor Jacobson, Jesper Lindé and Kasper Roszbach. 2005:184

Two-Sided Network Effects, Bank Interchange Fees, and the Allocation of Fixed Costs by Mats A. Bergman

Trade Deficits in the Baltic States: How Long Will the Party Last?

by Rudolfs Bems and Kristian Jönsson.... 2005:186

Real Exchange Rate and Consumption Fluctuations follwing Trade Liberalization by Kristian Jönsson

Modern Forecasting Models in Action: Improving Macroeconomic Analyses at Central Banks by Malin Adolfson, Michael K. Andersson, Jesper Lindé, Mattias Villani and Anders Vredin .......... 2005:188 Bayesian Inference of General Linear Restrictions on the Cointegration Space by Mattias Villani ..... 2005:189 Forecasting Performance of an Open Economy Dynamic Stochastic General Equilibrium Model by Malin Adolfson, Stefan Laséen, Jesper Lindé and Mattias Villani..

Forecast Combination and Model Averaging using Predictive Measures

by Jana Eklund and Sune Karlsson .....

Swedish Intervention and the Krona Float, 1993-2002

by Owen F. Humpage and Javiera Ragnartz

A Simultaneous Model of the Swedish Krona, the US Dollar and the Euro

by Hans Lindblad and Peter Sellin....

Testing Theories of Job Creation: Does Supply Create Its Own Demand?

by Mikael Carlsson, Stefan Eriksson and Nils Gottfries 2006:194

Down or Out: Assessing The Welfare Costs of Household Investment Mistakes

by Laurent E. Calvet, John Y. Campbell and Paolo Sodini

Efficient Bayesian Inference for Multiple Change-Point and Mixture Innovation Models

by Paolo Giordani and Robert Kohn .... 2006:196

Derivation and Estimation of a New Keynesian Phillips Curve in a Small Open Economy by Karolina Holmberg....

Technology Shocks and the Labour-Input Response: Evidence from Firm-Level Data

by Mikael Carlsson and Jon Smedsaas 2006:198

Monetary Policy and Staggered Wage Bargaining when Prices are Sticky

by Mikael Carlsson and Andreas Westermark.....

The Swedish External Position and the Krona by Philip R. Lane 2006:200

Price Setting Transactions and the Role of Denominating Currency in FX Markets

by Richard Friberg and Fredrik Wilander 2007:201

The geography of asset holdings: Evidence from Sweden

by Nicolas Coeurdacier and Philippe Martin 
